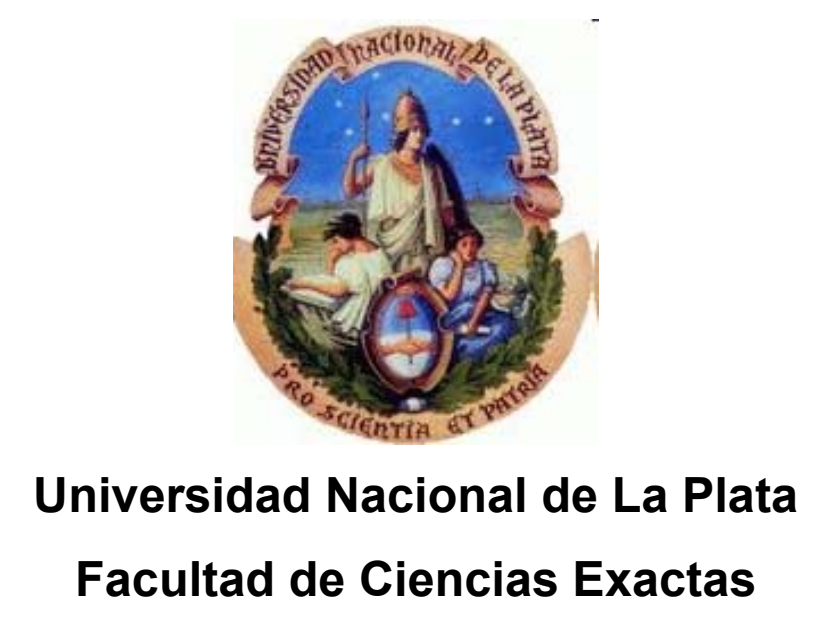

\title{
"Efecto de la intensidad de la radiación UV-C sobre la calidad sensorial, microbiológica y nutricional de frutos"
}

\author{
Trabajo de maestría \\ Autora: Ing. Sandra Patricia Cote Daza \\ Director: Dr. Ariel R. Vicente \\ Co-director: Dr. Pedro M Civello
}

\section{Lugar de realización:}

- CIDCA. Centro de Investigación y Desarrollo en Criotecnología de Alimentos. Facultad de Ciencias Exactas. Universidad Nacional de La Plata. Calle 47 y 116. La Plata (1900), Buenos Aires, Argentina. Tel/Fax: (0221) 424-9287

- Cátedra de Agroindustrias. Facultad de Ciencias Agrarias y Forestales UNLP. Calle 60 y 119. La Plata (1900), Buenos Aires, Argentina Tel: (0221) 423-6758 Int. 441.

Año 2011 
El presente trabajo de Tesis para optar al título de Magíster en Tecnología e Higiene de los Alimentos de la Facultad de Ciencias Exactas de la Universidad Nacional de La Plata, fue realizado en el Centro de Investigación y Desarrollo en Criotecnología de Alimentos (CIDCA) Facultad de Ciencias Exactas, UNLP y en la Cátedra de Agroindustrias de la Facultad de Ciencias Agrarias y Forestales, UNLP bajo la dirección del Dr. Ariel R. Vicente y Co-dirección del Dr. Pedro M Civello.

La Plata, 2011 


\section{Agradecimientos}

Quiero agradecer especialmente a mi director Ariel, quien se caracteriza por demostrar un gran cariño hacia la docencia y la academia, enseñando siempre con gran dedicación y enorme entrega, a él que me permitió formar parte de su grupo de investigación, me guió desde el inicio de este largo proceso con mucho respeto y cariño, aportando sus conocimientos, orientaciones/consejos y su gran sentido del humor, que me alentó a tener confianza en mí y mis habilidades y a realizar un trabajo independiente. También quiero agradecer a mi co-director Marcos, por permitirme realizar este trabajo en su entorno pero sobre todo por sus grandes aportes, conocimientos y apoyo.

A todas las personas que trabajan en el grupo de vegetales, a la doctora Alicia Chaves por su dedicación con el grupo, por su entrega con todos nosotros y por transmitirnos sus conocimientos invaluables, también a la doctora Analía Concellón y a Laura Lemoine, quienes estaban en momentos cruciales para el desarrollo de este trabajo. A María José Zaro, Facundo Massolo, Joaquín Hasperue, Cecilia Doporto, Cristian Ortiz, Cecilia Dini, Soledad Ibañez, ya que todos ellos estuvieron siempre atentos y dispuestos a colaborarme, además me brindaron sus conocimientos adquiridos durante su trayectoria corta o larga como investigadores, pero muy especialmente a Luis Rodoni, gracias por su apoyo incondicional, quien además compartió muchos de sus conocimientos y me brindó un respaldo muy importante y una excelente ayuda en muchas jornadas intensas de trabajo.

A mi mamá especialmente por ser incondicional en todo momento, por su gran cariño, a mi papá por enseñarme todo lo que soy, y a mis hermanas Carolina y Ángela, quienes siempre han estado acompañándome y apoyándome en todas mis decisiones, enseñándome que lo más preciado es el respeto sobre los demás, a ser coherente con lo que se piensa actuando con honestidad en todos los aspectos cotidianos. Por su apoyo moral, ético. 
A Yudy, quién me acompañó durante toda la ejecución de esta tesis y en la maestría, además me apoyó en muchas jornadas del laboratorio, de estudio, de viajes, una amiga desde hace muchos años que fue importante durante todo este aprendizaje en La Argentina.

A Natalia Quintero, Andrea Miranda, Mariana Correa, Anabel Rodríguez y Sandra Matiz, quienes con su alegría, entusiasmo y compañerismo me brindaron aportes muy importantes en mi vida y fueron un soporte en muchos momentos durante mi estadía en la ciudad de La Plata.

A Leonardo Sechi, Dra. Alicia Bevilaqua por todas sus enseñanzas y el apoyo durante los momentos más importantes y decisivos, gracias a ellos pude realizar este proyecto. También agradezco a todos los profesores que hicieron parte de esta etapa académica, quienes contribuyeron a esta formación, especialmente a la Dra. Noemí Zaritzky, Dr. Alfredo Calvelo, Dr. Guillermo Hough, Dra. Cristina Ferrero, Dra Cristina Añón, Dra. Judith Permaría y la Dra. Cecilia Puppo, Dra. Leda Giannuzzi, Dr. Segio Giner, Dra. Adriana Pinotti, Dr. Claudio Voget, Dra. Miriam Martino, Dr. Daniel Jorajuría, Dra. Mabel Tomás, Dra. Sonia Viña y nuevamente a la Dra. Alicia Chaves, Ing. Elisa Miceli, Prof. Sandra Peralta y al Dr. Ariel Vicente, fue un honor haberlos conocido y poder participar en sus cátedras.

A Elisa Miceli y Sandra Peralta personas muy especiales que a través de sus enseñanzas me entregaron lecciones de vida, por medio de sus ideas, pensamientos y de quienes aprendí muchos aspectos académicos pero muchos otros de la vida.

A los integrantes de los grupos de proteínas y microbiología que facilitaron la ejecución de mis ensayos en el laboratorio y siempre estuvieron dispuestos a ayudarme en el momento en que lo necesité. 
También quiero agradecer a todas las personas que conocí durante este trabajo, a los investigadores y becarios del CIDCA, especialmente a mis compañeros de la maestría con quienes compartí muchos espacios y me permitieron conocer diferentes aspectos de sus vidas y a quienes les deseo una feliz culminación en este proyecto que hemos empezado y que hemos realizado con mucho esfuerzo; a los funcionarios del CIDCA que colaboraron durante toda la ejecución de la maestría, a las demás instancias de la Universidad y a todos quienes de una u otra forma colaboraron en la ejecución de esta tesis y en el desarrollo de mi formación y quienes sería muy largo nombrar en este espacio pero que tendré muy presentes siempre.

A todos ellos muchos gracias,

Sandra 


\section{ÍNDICE}

Resumen 1

Abstract 3

I. INTRODUCCIÓN

I.1. Frutilla: producción, composición y generalidades de 6 manejo poscosecha.

I.2. Tomate: producción, composición y generalidades de 13 manejo poscosecha.

I.3. Tratamientos con radiación ultravioleta: su uso en alimentos. 17

$\begin{array}{ll}\text { I.3.1. Características de la radiación ultravioleta. } & 18\end{array}$

I.3.2. Efecto de la radiación UV sobre los seres vivos. 19

I.4. Ventajas y limitaciones de la aplicación de radiación UV a 24 nivel industrial.

$\begin{array}{ll}\text { II. OBJETIVOS } & 28\end{array}$

III. MATERIALES Y MÉTODOS 30

III.1. Efecto de tratamientos UV-C de diferente intensidad sobre 31 la calidad y deterioro poscosecha de frutilla.

III.2. Efecto de tratamientos UV-C de diferente intensidad sobre 32 la calidad y deterioro poscosecha de tomate.

III.3. Determinaciones de parámetros de calidad. 33

III.3.1. Ataque de hongos. 33

III.3.2. Pérdida de peso. 33

III.3.3. Color superficial y pigmentos. 33

III.3.4. Firmeza. 34

III.3.5. Sólidos solubles y acidez. 35

III.3.6. Capacidad antioxidante. $\quad 35$

III.3.7. Actividad respiratoria. 36

III.3.8. Recuentos de bacterias mesófilas y hongos. 36

III.3.9. Análisis sensorial. $\quad 37$

III.4. Análisis estadístico. 38 
IV.1. Efecto de tratamientos UV-C de diferente intensidad sobre 40 la calidad y deterioro poscosecha de frutilla.

IV.1.1. Ataque de hongos.

IV.1.2. Pérdida de peso.

IV.1.3. Color superficial y antocianinas.

IV.1.4. Firmeza.

IV.1.5. Sólidos solubles, acidez y capacidad antioxidante.

IV.1.6. Actividad respiratoria.

IV.1.7. Recuentos de bacterias mesófilas y hongos.

IV.1.8. Análisis sensorial.

IV.2. Efecto de tratamientos UV-C de diferente intensidad sobre 58 la calidad y deterioro poscosecha de tomate.

IV.2.1. Ataque de hongos.

IV.2.2. Pérdida de peso.

IV.2.3. Color superficial y licopeno.

IV.2.4. Firmeza.

IV.2.5. Sólidos solubles, acidez y capacidad antioxidante.

IV.2.6. Actividad respiratoria.

IV.2.7. Recuentos de bacterias mesófilas y hongos.

IV.2.8. Análisis sensorial. 


\section{INDICE DE TABLAS}

Pág.

Tabla I.1: Producción de frutilla a nivel mundial (miles de toneladas).

Tabla I.2: Producción de tomate a nivel mundial (miles de toneladas).

13

Tabla I.3: Diferentes regiones del espectro UV indicando sus respectivas 18 longitudes de onda. 


\section{ÍNDICE DE FIGURAS}

Pág

Figura I.1: Morfología de plantas de frutilla y aspectos de su producción. A. 8 Corona. B. Hojas. C. Flores. D. Detalle de frutos. E. Frutillas madurando en planta. F. Cultivo. G. Frutos luego de la cosecha.

Figura l.2: Estados de maduración de frutilla.

Figura I.3: Principales tipos de tomate comercializados en nuestro país. A. Redondo. B. Cherry. C. Perita. D. Larga vida. E. Platense.

Figura III.1: Planilla de evaluación sensorial presentada al panel de consumidores no entrenados.

Figura IV.1: Apariencia de frutillas control y tratadas con una dosis de $4 \mathrm{~kJ} \mathrm{~m}^{-2}$ de radiación UV-C, bajo dos intensidades diferentes (3 ó $33 W^{-2}$ ) y almacenadas a $10^{\circ} \mathrm{C}$ por 3 ó $5 \mathrm{~d}$.

Figura IV.2: Ataque de hongos en frutillas control y tratadas con una dosis de 4 $\mathrm{kJ} \mathrm{m}^{-2}$ de radiación UV-C, bajo dos intensidades diferentes (3 ó $33 \mathrm{~W} \mathrm{~m}^{-2}$ ) y almacenadas a $10^{\circ} \mathrm{C}$ por 3 ó $5 \mathrm{~d}$. Las letras distintas indican diferencias significativas en un test de Fisher con un nivel de significancia de $P \leq 0,05$.

Figura IV.3: Pérdida de peso en frutillas control y tratadas con una dosis de $4 \quad 45$ $\mathrm{kJ} \mathrm{m}^{-2}$ de radiación UV-C, bajo dos intensidades diferentes (3 ó $33 \mathrm{~W} \mathrm{~m}^{-2}$ ) y almacenadas a $10^{\circ} \mathrm{C}$ por 3 ó $5 \mathrm{~d}$. Las letras distintas indican diferencias significativas en un test de Fisher con un nivel de significancia de $P \leq 0,05$.

Figura IV.4: Luminosidad $\left(L^{*}\right)$ en frutillas control y tratadas con una dosis de 4 $\mathrm{kJ} \mathrm{m}^{-2}$ de radiación UV-C, bajo dos intensidades diferentes (3 ó $33 \mathrm{~W} \mathrm{~m}^{-2}$ ) y almacenadas a $10^{\circ} \mathrm{C}$ por 3 ó $5 \mathrm{~d}$. Las letras distintas indican diferencias significativas en un test de Fisher con un nivel de significancia de $P \leq 0,05$. 
Pág.

Figura IV.5: Tono de color superficial (hue) en frutillas control y tratadas con una dosis de $4 \mathrm{~kJ} \mathrm{~m}^{-2}$ de radiación UV-C, bajo dos intensidades diferentes (3 ó $33 \mathrm{~W} \mathrm{~m}^{-2}$ ) y almacenadas a $10^{\circ} \mathrm{C}$ por 3 ó $5 \mathrm{~d}$. Las letras distintas indican diferencias significativas en un test de Fisher con un nivel de significancia de $P$ $\leq 0,05$.

Figura IV.6: Saturación del color superficial (croma) en frutillas control y 48 tratadas con una dosis de $4 \mathrm{~kJ} \mathrm{~m}^{-2}$ de radiación UV-C, bajo dos intensidades diferentes (3 ó $33 \mathrm{~W} \mathrm{~m}^{-2}$ ) y almacenadas a $10{ }^{\circ} \mathrm{C}$ por 3 ó $5 \mathrm{~d}$. Las letras distintas indican diferencias significativas en un test de Fisher con un nivel de significancia de $P \leq 0,05$.

Figura IV.7: Antocianinas en frutillas control y tratadas con una dosis de $4 \mathrm{~kJ} \quad 48$ $m^{-2}$ de radiación UV-C, bajo dos intensidades diferentes (3 ó $33 \mathrm{~W} \mathrm{~m}^{-2}$ ) y almacenadas a $10{ }^{\circ} \mathrm{C}$ por 3 ó $5 \mathrm{~d}$. Las letras distintas indican diferencias significativas en un test de Fisher con un nivel de significancia de $P \leq 0,05$.

Figura IV.8: Firmeza en frutillas control y tratadas con una dosis de $4 \mathrm{~kJ} \mathrm{~m}^{-2}$ de 50 radiación UV-C, bajo dos intensidades diferentes (3 ó $33 \mathrm{~W} \mathrm{~m}^{-2}$ ) y almacenadas a $10^{\circ} \mathrm{C}$ por 3 ó $5 \mathrm{~d}$. Las letras distintas indican diferencias significativas en un test de Fisher con un nivel de significancia de $P \leq 0,05$.

Figura IV.9: Sólidos solubles en frutillas control y tratadas con una dosis de 451 $\mathrm{kJ} \mathrm{m}^{-2}$ de radiación UV-C, bajo dos intensidades diferentes (3 ó $33 \mathrm{~W} \mathrm{~m}^{-2}$ ) y almacenadas a $10{ }^{\circ} \mathrm{C}$ por 3 ó $5 \mathrm{~d}$. Las letras distintas indican diferencias significativas en un test de Fisher con un nivel de significancia de $P \leq 0,05$.

Figura IV.10: Acidez en frutillas control y tratadas con una dosis de $4 \mathrm{~kJ} \mathrm{~m}^{-2}$ de radiación UV-C, bajo dos intensidades diferentes (3 ó $33 \mathrm{~W} \mathrm{~m}^{-2}$ ) y almacenadas a $10{ }^{\circ} \mathrm{C}$ por 3 ó $5 \mathrm{~d}$. Las letras distintas indican diferencias significativas en un test de Fisher con un nivel de significancia de $P \leq 0,05$. 
Pág.

Figura IV.11: Capacidad antioxidante en frutillas control y tratadas con una

dosis de $4 \mathrm{~kJ} \mathrm{~m}^{-2}$ de radiación UV-C, bajo dos intensidades diferentes (3 ó 33 $W \mathrm{~m}^{-2}$ ) y almacenadas a $10^{\circ} \mathrm{C}$ por 3 ó $5 \mathrm{~d}$. Las letras distintas indican diferencias significativas en un test de Fisher con un nivel de significancia de $P$ $\triangle 0,05$.

Figura IV.12: Actividad respiratoria en frutillas control y tratadas con una dosis de $4 \mathrm{~kJ} \mathrm{~m}^{-2}$ de radiación UV-C, bajo dos intensidades diferentes (3 ó $33 \mathrm{~W} \mathrm{~m}^{-2}$ ) y almacenadas a $10^{\circ} \mathrm{C}$ por 3 ó $5 \mathrm{~d}$. Las letras distintas indican diferencias significativas en un test de Fisher con un nivel de significancia de $P \leq 0,05$.

Figura IV.13: Recuento de bacterias mesófilas (log UFC $g^{-1}$ ) en frutillas control y tratadas con una dosis de $4 \mathrm{~kJ} \mathrm{~m}^{-2}$ de radiación UV-C, bajo dos intensidades diferentes (3 ó $33 \mathrm{~W} \mathrm{~m}^{-2}$ ) y almacenadas por 3 o $5 \mathrm{~d}$. Las letras distintas indican diferencias significativas en un test de Fisher con un nivel de significancia de $P$ $\triangle 0,05$.

Figura IV.14: Recuento de hongos ( $\log U F C g^{-1}$ ) en frutillas control y tratadas con una dosis de $4 \mathrm{~kJ} \mathrm{~m}^{-2}$ de radiación UV-C, bajo dos intensidades diferentes (3 ó $33 \mathrm{~W} \mathrm{~m}^{-2}$ ) y almacenadas por 3 o $5 \mathrm{~d}$. Las letras distintas indican diferencias significativas en un test de Fisher con un nivel de significancia de $P$ $\triangle 0,05$.

Figura IV.15: Importancia de diferentes atributos en la aceptación de frutillas identificada por el panel de consumidores no entrenados $(n=38)$.

Figura IV.16: Test de ordenamiento por preferencia de frutillas control y 57 tratadas con una dosis de $4 \mathrm{~kJ} \mathrm{~m}^{-2}$ de radiación UV-C, bajo dos intensidades diferentes (3 ó $33 \mathrm{~W} \mathrm{~m}^{-2}$ ) y almacenadas a $10{ }^{\circ} \mathrm{C}$ por $3 \mathrm{~d}$, evaluadas por el panel de consumidores no entrenados $(n=38)$. 
Pág.

Figura IV.17: Apariencia de tomates control y tratados con una dosis de $4 \mathrm{~kJ}$ 58 $\mathrm{m}^{-2}$ de radiación UV-C, bajo dos intensidades diferentes (3 ó $33 \mathrm{~W} \mathrm{~m}^{-2}$ ) y almacenadas a $20^{\circ} \mathrm{C}$. por $9 \mathrm{~d}$.

Figura IV.18: Ataque de hongos en tomates control y tratados con una dosis de 59 $4 \mathrm{~kJ} \mathrm{~m}^{-2}$ de radiación UV-C, bajo dos intensidades diferentes (3 ó $33 \mathrm{~W} \mathrm{~m}^{-2}$ ) y almacenados a $20{ }^{\circ} \mathrm{C}$. por 4 ó $9 \mathrm{~d}$. Las letras distintas indican diferencias significativas en un test de Fisher con un nivel de significancia de $P \leq 0,05$.

Figura IV.19: Pérdida de peso en tomates control y tratados con una dosis de 4 60 $\mathrm{kJ} \mathrm{m}^{-2}$ de radiación UV-C, bajo dos intensidades diferentes (3 ó $33 \mathrm{~W} \mathrm{~m}^{-2}$ ) y almacenados a $20{ }^{\circ} \mathrm{C}$ por 4 ó $9 \mathrm{~d}$. Las letras distintas indican diferencias significativas en un test de Fisher con un nivel de significancia de $P \leq 0,05$.

Figura IV.20: Luminosidad ( $\left.L^{*}\right)$ en tomates control y tratados con una dosis de $4 \mathrm{~kJ} \mathrm{~m}^{-2}$ de radiación UV-C, bajo dos intensidades diferentes (3 ó $33 \mathrm{~W} \mathrm{~m}^{-2}$ ) y almacenados a $20{ }^{\circ} \mathrm{C}$ por 4 ó $9 \mathrm{~d}$. Las letras distintas indican diferencias significativas en un test de Fisher con un nivel de significancia de $P \leq 0,05$.

Figura IV.21: Tono de color superficial (hue) en tomates control y tratados con 62 una dosis de $4 \mathrm{~kJ} \mathrm{~m}^{-2}$ de radiación UV-C, bajo dos intensidades diferentes (3 ó $33 \mathrm{~W} \mathrm{~m}^{-2}$ ) y almacenados a $20^{\circ} \mathrm{C}$ por 4 ó $9 \mathrm{~d}$. Las letras distintas indican diferencias significativas en un test de Fisher con un nivel de significancia de $P$ $₫ 0,05$.

Figura IV.22: Saturación del color superficial (croma) en tomates control y tratados con una dosis de $4 \mathrm{~kJ} \mathrm{~m}^{-2}$ de radiación UV-C, bajo dos intensidades diferentes ( 3 ó $33 \mathrm{~W} \mathrm{~m}^{-2}$ ) y almacenados a $20{ }^{\circ} \mathrm{C}$ por 4 ó $9 \mathrm{~d}$. Las letras distintas indican diferencias significativas en un test de Fisher con un nivel de significancia de $P \leq 0,05$. 
Pág.

Figura IV.23: Licopeno en tomates control y tratados con una dosis de $4 \mathrm{~kJ} \mathrm{~m}^{-2}$

de radiación UV-C, bajo dos intensidades diferentes (3 ó $33 \mathrm{~W} \mathrm{~m}^{-2}$ ) y almacenados a $20{ }^{\circ} \mathrm{C}$ por 4 ó $9 \mathrm{~d}$. Las letras distintas indican diferencias significativas en un test de Fisher con un nivel de significancia de $P \leq 0,05$.

Figura IV.24: Firmeza en tomates control y tratados con una dosis de $4 \mathrm{~kJ} \mathrm{~m}^{-2}$ de radiación UV-C, bajo dos intensidades diferentes (3 ó $33 \mathrm{~W} \mathrm{~m}^{-2}$ ) y almacenados a $20{ }^{\circ} \mathrm{C}$ por 4 ó $9 \mathrm{~d}$. Las letras distintas indican diferencias significativas en un test de Fisher con un nivel de significancia de $P \leq 0,05$.

Figura IV.25: Sólidos solubles en tomates control y tratados con una dosis de 4 $\mathrm{kJ} \mathrm{m}^{-2}$ de radiación UV-C, bajo dos intensidades diferentes (3 ó $33 \mathrm{~W} \mathrm{~m}^{-2}$ ) y almacenados a $20{ }^{\circ} \mathrm{C}$ por 4 ó $9 \mathrm{~d}$. Las letras distintas indican diferencias significativas en un test de Fisher con un nivel de significancia de $P \leq 0,05$.

Figura IV.26: Acidez en tomates control y tratados con una dosis de $4 \mathrm{~kJ} \mathrm{~m}^{-2}$ de radiación UV-C, bajo dos intensidades diferentes (3 ó $33 \mathrm{~W} \mathrm{~m}^{-2}$ ) y almacenados a $20{ }^{\circ} \mathrm{C}$ por 4 ó $9 \mathrm{~d}$. Las letras distintas indican diferencias significativas en un test de Fisher con un nivel de significancia de $P \leq 0,05$.

Figura IV.27: Capacidad antioxidante en tomates control y tratados con una 66 dosis de $4 \mathrm{~kJ} \mathrm{~m}^{-2}$ de radiación UV-C, bajo dos intensidades diferentes (3 ó 33 $W \mathrm{~m}^{-2}$ ) y almacenados a $20{ }^{\circ} \mathrm{C}$ por 4 ó $9 \mathrm{~d}$. Las letras distintas indican diferencias significativas en un test de Fisher con un nivel de significancia de $P$ $\leq 0,05$.

Figura IV.28: Actividad respiratoria en tomates control y tratados con una dosis de $4 \mathrm{~kJ} \mathrm{~m}^{-2}$ de radiación UV-C, bajo dos intensidades diferentes (3 ó $33 \mathrm{~W} \mathrm{~m}^{-2}$ ) y almacenados a $20^{\circ} \mathrm{C}$ por 4 ó $9 \mathrm{~d}$. Las letras distintas indican diferencias significativas en un test de Fisher con un nivel de significancia de $P \leq 0,05$. 
Pág.

Figura IV.29: Recuento de bacterias mesófilas (log UFC $g^{-1}$ ) en tomates control y tratados con una dosis de $4 \mathrm{~kJ} \mathrm{~m}^{-2}$ de radiación UV-C, bajo dos intensidades diferentes (3 ó $33 \mathrm{~W} \mathrm{~m}^{-2}$ ). Las letras distintas indican diferencias significativas en un test de Fisher con un nivel de significancia de $P \leq 0,05$.

Figura IV.30: Recuento de hongos ( $\log U F C g^{-1}$ ) en tomates control y tratados 69 con una dosis de $4 \mathrm{~kJ} \mathrm{~m}^{-2}$ de radiación UV-C, bajo dos intensidades diferentes (3 ó $33 \mathrm{~W} \mathrm{~m}^{-2}$ ). Las letras distintas indican diferencias significativas en un test de Fisher con un nivel de significancia de $P \leq 0,05$.

Figura IV.31: Importancia de diferentes atributos en la aceptación de tomates identificada por el panel de consumidores no entrenados ( $n=35)$.

Figura IV.32: Test de ordenamiento por de tomates control y tratados con una dosis de $4 \mathrm{~kJ} \mathrm{~m}^{-2}$ de radiación UV-C, bajo dos intensidades diferentes (3 ó 33 $W \mathrm{~m}^{-2}$ ) y almacenados a $20^{\circ} \mathrm{C}$ por $4 \mathrm{~d}$, evaluados por el panel de consumidores no entrenados $(n=35)$. 


\section{$\underline{\text { Resumen }}$}

La radiación UV-C se ha utilizado en diferentes áreas de la industria de alimentos por su efecto germicida. Más allá de esto, se conoce que en el caso particular de su uso en productos con actividad metabólica como las frutas y hortalizas frescas, los tratamientos UV-C pueden provocar otros cambios beneficiosos tales como reducir la velocidad de maduración y retrasar el inicio de la senescencia. La mayor parte de los estudios realizados hasta la fecha se han focalizado en seleccionar una dosis apropiada para los diferentes productos, pero llamativamente muy poca atención se ha puesto en la determinación del efecto de la intensidad o fluencia de radiación (energía radiante por unidad de área y por unidad de tiempo) para una dosis de radiación dada. En este estudio se decidió evaluar el efecto de la intensidad de radiación sobre la eficacia de tratamientos UV-C en frutos frescos. Se analizaron los dos frutos que han sido comúnmente considerados como sistemas modelo: frutilla, un fruto no climatérico con una elevada tasa metabólica y que acumula antocianinas como pigmentos mayoritarios; y tomate, un producto climatérico con una actividad metabólica moderada en el cual el color está determinado por los carotenoides. Se cosecharon frutillas cv Camarosa (estado de madurez $75 \%$ de color superficial rojo) y tomates $c v$ Elpida (grado de madurez pintón) y se trataron con una dosis de $4 \mathrm{~kJ} \mathrm{~m}^{-2}$ de radiación UV-C bajo dos niveles de intensidad diferentes, 3 ó $33 \mathrm{~W} \mathrm{~m}^{-2}$, que demandaron 22 y 2 min de exposición a las lámparas UV-C, respectivamente. Posteriormente los frutos se colocaron en bandejas plásticas, se cubrieron con PVC perforado para evitar la acumulación de $\mathrm{CO}_{2}$ y se almacenaron a $10^{\circ} \mathrm{C}$ en el caso de frutilla y a $20^{\circ} \mathrm{C}$ en el caso de tomate. Para cada tipo de fruto, un grupo no tratado con radiación UV-C, pero envasado y almacenado como se mencionó anteriormente, se utilizó como control. Inmediatamente luego de los tratamientos y durante el almacenamiento se determinó la incidencia de hongos, la pérdida de peso, el color superficial (luminosidad, ángulo hue y croma), el contenido de antocianinas o licopeno en frutilla y tomate, respectivamente, la firmeza, la acidez, el contenido de sólidos solubles, la capacidad antioxidante y la tasa respiratoria. Así mismo, se realizaron recuentos de bacterias mesófilas, hongos y un análisis sensorial mediante un test de ordenamiento por preferencia. Independientemente de la intensidad utilizada, los tratamientos UV-C fueron de utilidad para reducir la deshidratación, el ataque de patógenos y el deterioro en ambos frutos, aunque los efectos fueron más marcados en frutilla. Para una misma dosis final, el incremento de la intensidad de la radiación UV-C provocó un mayor control de hongos tanto en frutilla como en tomate. Los tratamientos con una intensidad de $33 \mathrm{~W} \mathrm{~m}^{-2}$ también resultaron en una menor pérdida de peso al final del almacenamiento. En frutilla, luego de $5 \mathrm{~d}$ a $10^{\circ} \mathrm{C}$, la incidencia de hongos fue de $68 \%$ en los controles, $53 \%$ en los frutos tratados con la menor intensidad y sólo $12 \%$ en aquellos sometidos a una mayor fluencia. Por su parte en tomate, el porcentaje de frutos atacados al final del período de almacenamiento fue 23, 8 y $6 \%$ en los controles y en los frutos tratados con $3033 \mathrm{~W} \mathrm{~m}^{-2}$ de radiación, respectivamente. La exposición a la radiación UV-C logró además retrasar claramente la maduración en frutilla, evidenciada por una menor tasa de ablandamiento y por el retraso del desarrollo de color rojo y menor acumulación de antocianinas. Los efectos fueron también nuevamente más marcados en los tratamientos realizados a la mayor intensidad. En tomate, la influencia de los tratamientos UV-C en el retraso de la maduración fue menor que en frutilla, y similar para ambas intensidades de radiación ensayadas. Por otra parte, ni las frutillas ni los tomates tratados mostraron, a ninguna de las dos fluencias analizadas, diferencias significativas respecto a los controles en acidez o contenido de sólidos solubles o capacidad antioxidante. La tasa respiratoria 
de los frutos de tomate se incrementó durante el almacenamiento, no hallándose diferencias significativas entre frutos control y tratados. En frutilla, luego de $5 \mathrm{~d}$ a $10^{\circ} \mathrm{C}$ los frutos control presentaron una mayor tasa respiratoria que los tratados para ambas intensidades ensayadas probablemente como consecuencia de una mayor disrupción de tejidos. El análisis sensorial en ambos frutos mostró una clara preferencia de los evaluadores por los frutos tratados con UV-C y dentro de estos a los expuestos a la mayor intensidad de radiación. Finalmente los recuentos de hongos y bacterias mostraron reducciones moderadas inmediatamente luego de los tratamientos. En frutilla, al final del almacenamiento estas diferencias se hicieron más importantes, presentando los frutos tratados con la mayor intensidad un menor número de UFC que los frutos control o tratados con la menor fluencia. En tomate, al final del almacenamiento las diferencias de los recuentos de hongos y bacterias entre frutos controles y tratados fueron moderadas. Los resultados sugieren que el efecto de los tratamientos UV en el control de enfermedades, estaría asociado con una reducción de la susceptibilidad de los frutos más que con la acción germicida de la radiación. A pesar de que se requieren nuevos estudios para determinar los efectos de los tratamientos UV de alta intensidad para complementar la refrigeración, este trabajo muestra que más allá de la dosis total, la intensidad de radiación es un factor muy importante en la determinación de su eficacia. El incremento de la fluencia de 3 a $33 \mathrm{~W}$ $\mathrm{m}^{-2}$ en frutilla aumenta marcadamente los beneficios obtenidos con una dosis total de radiación de $4 \mathrm{~kJ} \mathrm{~m}^{-2}$. En tomate, las mejoras sobre la calidad de la fruta como consecuencia del aumento de la intensidad de radiación UV-C no son tan evidentes, aunque se observa un mayor control de enfermedades al igual que en frutilla. Dado que no se observaron síntomas de fitotoxicidad en ninguna de las intensidades evaluadas, el uso de las más elevadas podría resultar de interés desde el punto de vista tecnológico dado que permitiría incrementar los beneficios obtenidos, reducir los tiempos de proceso y por lo tanto aumentar las posibilidades de aplicación a nivel industrial.

PALABRAS CLAVE: tomate, frutilla, poscosecha, calidad, irradiación, UV-C. 


\section{Abstract}

UV-C radiation has been used in different areas of food industry due to its germicidal properties. Besides that, in the case of products with metabolic activity such as fresh fruits and vegetables these treatments can result in other beneficial modifications such as reducing the ripening rate and delaying senescence. Most studies performed to date have focused on selecting an appropriate UV-C dose for each commodity, but very little attention has been focused on determining the influence of radiation intensity or fluency (radiant energy per unit area an per unit time) for a given dose. In this study, we evaluated the effect of radiation intensity on the efficacy of UV-C treatments of fresh fruits. We analyzed two fruits that have been usually used as model systems: strawberry, a non climacteric fruit with very high ripening rate and that accumulates anthocyanins as major pigments, and tomato, a climacteric commodity with moderate metabolic activity, in which colour is determined by carotenoids. Strawberries cv. Camarosa were harvested with $75 \%$ of surface colour red, and tomatoes cv. Elpida were harvested at the breaker ripening stage. Both types of fruits were treated with a dose of $4 \mathrm{~kJ} \mathrm{~m}^{-2}$ of UV-C radiation, under two different intensities (3 or $33 \mathrm{~W} \mathrm{~m}^{-2}$ ). After that, fruits were put in plastic trays and covered with perforated PVC in order to avoid $\mathrm{CO}_{2}$ accumulation and were stored at 10 or $20^{\circ} \mathrm{C}$ in the case of strawberry or tomato, respectively. For each type of fruit a group was left untreated, packed and stored as previously described and used as a control. Immediately after the treatments and during storage we determined decay, weight loss, surface colour (lightness, hue angle and chroma), anthocyanin content or lycopene in strawberry and tomato, respectively, firmness, acidity, soluble solids, antioxidant capacity and respiration rate. We also evaluated the number of CFU (Colony Forming Units) for mesophylic bacteria and molds and performed a consumer preference test. UV-C treatments, independently of the intensity of radiation used, were useful to reduce dehydration, decay and deterioration in both fruits, but the effects were more marked in strawberry. The increase in radiation intensity resulted in better control of postharvest rots in both tomato and strawberry. The treatments with an intensity of $33 \mathrm{~W} \mathrm{~m}^{-2}$ reduced weight loss at the end of the storage period. In strawberry after $5 \mathrm{~d}$ at $10^{\circ} \mathrm{C}$, decay was $68 \%$ in the controls, $53 \%$ in the fruit treated with the lowest intensity of UV$\mathrm{C}$ radiation and only $12 \%$ in the fruit treated with the highest fluency. In tomato, the percentage of decayed fruit at the end of the storage period was 23,8 and $6 \%$ in control or fruit treated with $3 \circ 33 \mathrm{~W} \mathrm{~m}^{-2}$ of UV-C radiation, respectively. Exposure to UV-C also clearly delayed strawberry fruit ripening as detected by lower softening and anthocyanin accumulation and less red colour development. The effects were more drastic with the highest UV-C intensity. In tomato, the influence of the UV-C treatments on ripening was lower than in strawberry and was similar for both radiation intensities evaluated. Neither the strawberries nor the tomatoes showed at any of the radiation intensities significant differences with the controls in acidity, soluble solids or antioxidants. Respiration rate of tomato fruit increased during storage and no differences between control and treated fruit were observed. In strawberry after $5 \mathrm{~d}$ at $10{ }^{\circ} \mathrm{C}$, control fruit showed higher respiration rate than UV-C treated fruit at both radiation intensities assayed. Sensory analysis in both tomato and strawberry performed by an untrained panel indicated a clear preference for treated fruits and between them to those exposed to the highest intensity. Finally, counts for bacteria and mold showed moderate reductions immediately after the UV-C treatments. In strawberry, at the end of the storage period the differences were clearer showing fruit treated with the highest intensity lower CFUs than control and low intensity-treated fruit. 
In tomato, even at the end of storage there were subtle differences in bacterial and fungal counts. These results suggest that the effect of UV treatments in the control of postharvest rots may be associated with a reduction in fruit susceptibility rather than with the germicide effect of UV radiation. Though further studies would be useful to determine the benefits of high intensity UV-C treatments in combination with low temperature storage, the present work shows that besides the global dose, the radiation intensity is a key factor determining the efficacy of UV-C treatments on fruits. The increase in fluency from 3 to $33 \mathrm{~W} \mathrm{~m}^{-2}$ in strawberry markedly improves the benefits obtained. In tomato, the beneficial effects in fruit quality in response to increasing UV-C intensity were not so evident though better control of postharvest rots was found as well. Given that no phytotoxicity was detected at any condition evaluated, increasing UV-C intensity could be of interest from a technological perspective since it may both improve the outcome on fruit quality maintenance, reduce processing time, increasing the suitability of the technique for industrial applications.

KEYWORDS: tomato, strawberry, postharvest, quality, irradiation, UV-C 


\section{INTRODUCCIÓN}




\section{l.1. Frutilla: producción, composición y generalidades de}

\section{manejo poscosecha.}

La frutilla (Fragaria sp.) es una planta dicotiledónea perteneciente a la familia de las Rosáceas. Es un fruto múltiple denominado botánicamente "eterio" cuyo receptáculo es la parte comestible. Las Rosáceas están caracterizadas por la presencia de numerosas especies de importancia desde el punto de vista económico incluyendo frutales tales como la manzana, pera, membrillo, durazno, ciruela, cereza, almendra, zarzamora, frambuesa y algunas plantas ornamentales como los rosales, entre otros (Folta y Davis, 2006). El género Fragaria es muy diverso con alrededor de veinte especies dispersas alrededor del mundo, cada cual con una variedad de niveles de ploidia (Dotto, 2008). La frutilla cultivada comercialmente (Fragaria x ananassa Duch.) es un híbrido octaploide de frutilla de Virginia o Scarlet (F. virginiana Duch.) y la variedad sudamericana (F. chiloensis L.), (Debnath y Teixeira, 2007). En la actualidad, los principales países productores son Estados Unidos, Alemania, Italia, Turquía, Egipto y algunas naciones del este europeo (FAOSTAT, 2011). La producción mundial se ubica en los 4 millones de toneladas (Tabla I.1).

Tabla l.1: Producción de frutilla a nivel mundial (miles de toneladas). Fuente: FAOSTAT, 2011.

\begin{tabular}{|c|c|}
\hline Año & Producción \\
\hline 2006 & 3.973 \\
\hline 2007 & 3.992 \\
\hline 2008 & 4.077 \\
\hline 2009 & 4.132 \\
\hline 2010 & 4.290 \\
\hline
\end{tabular}


La producción de frutilla en Argentina, se extiende a lo largo del año y se concentra en las provincias de Santa Fe, Buenos Aires y Tucumán. La superficie total sembrada creció un 50\% en el período 1997 a 2007, debido al aumento de la utilización de riego por goteo, incorporación de nuevos cultivares y mejoras en el manejo del cultivo. La mayor superficie sembrada se encuentra en las provincias de Tucumán y Santa Fe (Coronda), donde se realiza el cultivo a campo y en túneles bajo cubierta. Se establecen 3 zonas de producción: Norte (abarca las regiones de Tucumán, Coronda, y Corrientes con producción en invierno y primavera), centro (se localiza en La Plata, Gran Buenos Aires y Mar del Plata con producción primaveroestival) y sur (contempla a las provincias patagónicas).

A continuación se describe brevemente la producción en las diferentes provincias y los períodos de cosecha.

- En la provincia de Santa Fe la producción es a campo, de fines de Agosto a fines de Diciembre y bajo protección, de mediados de Junio hasta fin de año. En Tucumán, la producción en piedemonte comienza a fines de Marzo y se extiende hasta fines de Noviembre, y en los valles de altura desde inicio de Septiembre hasta fines de Marzo.

- En la provincia de Buenos Aires hay una producción a campo en la primera semana de Febrero, luego desde mediados de Marzo a mediados de Mayo y finalmente desde mediados de Septiembre a fines de Diciembre. En Mar del Plata, la cosecha se presenta desde mediados de Noviembre hasta principios del mes de Mayo.

- En Neuquén y Río Negro desde comienzos de Diciembre hasta fines de Febrero. 
La planta de frutilla es perenne, de bajo crecimiento y presenta raíces de aspecto fibroso, una corona próxima a la superficie del suelo (Figura I.1A), tallos cortos y lignificados y hojas trifoliadas (Figura I.1B). Las flores de las variedades cultivadas son hermafroditas y se encuentran constituidas por 5 sépalos, 5 pétalos, numerosos estambres dispuestos en tres verticilos (Figura I.1C) y también múltiples pistilos ubicados en forma de espiral (Branzanti, 1989). Los frutos son carnosos, compuestos y monotalámicos. Se los considera falsos frutos dado que la mayor parte de la fracción comestible proviene del desarrollo del receptáculo, siendo los aquenios los verdaderos frutos desde el punto de vista botánico, constituidos por la semilla y sus coberturas (Figura I.1D), que se ubican en la superficie del receptáculo expandido (Dotto, 2008).

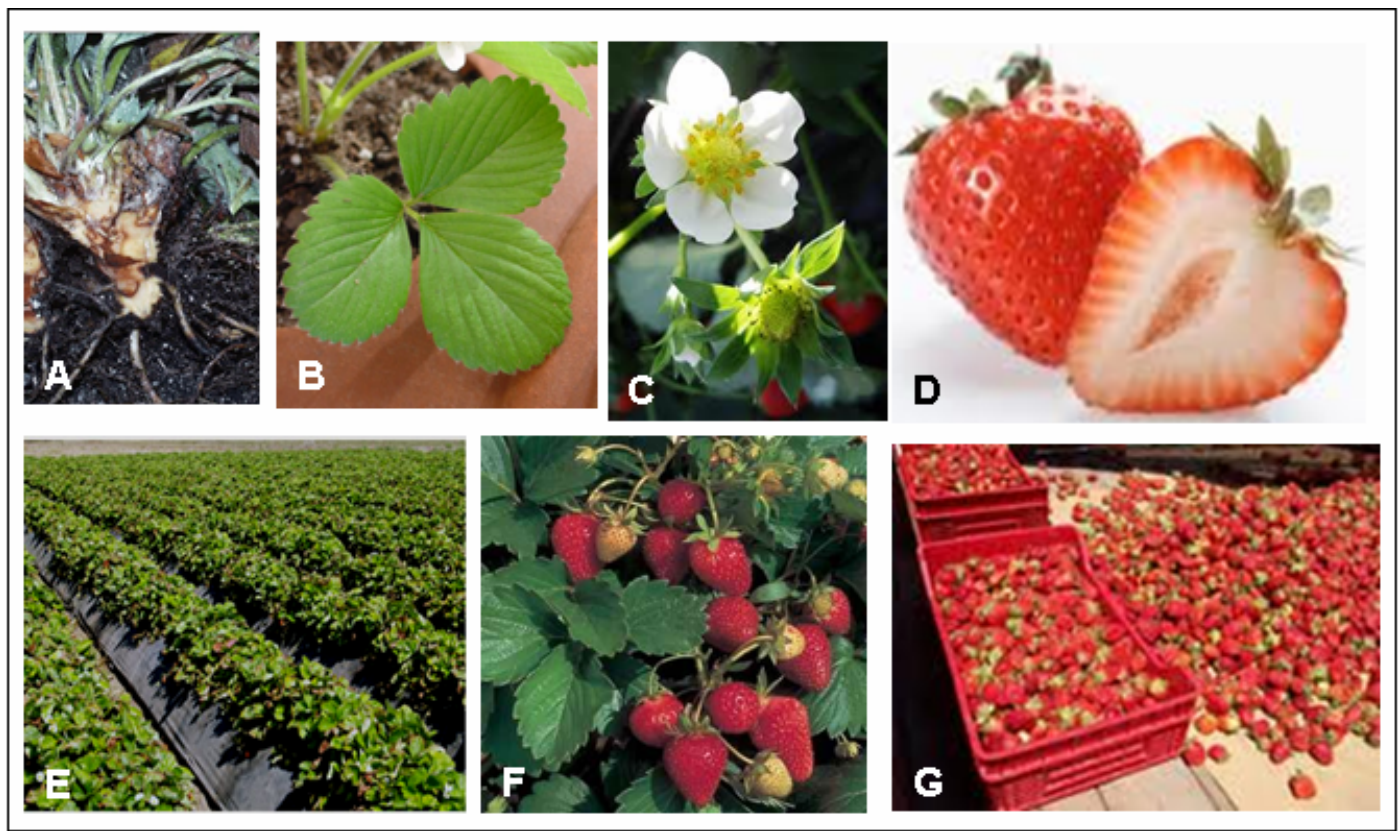

Figura l.1: Morfología de plantas de frutilla y aspectos de su producción. A. Corona. B. Hojas. C. Flores. D. Detalle de frutos. E. Cultivo. F. Frutillas madurando en planta. G. Frutos luego de la cosecha. 
Las plantas se ubican en el cultivo a una distancia aproximada de $30 \mathrm{~cm}$ en lomos que se cubren con una película plástica ("mulching") para minimizar el contacto con el suelo y con ello las podredumbres, controlar malezas y reducir la pérdida de agua (Figura I.1E). Los frutos deben cosecharse una vez completada la maduración, para evitar disminución en el sabor ya que los azúcares simples que se acumulan provienen principalmente de la planta madre (Figura I.1F y G).

La frutilla es valorada por su atractiva apariencia, por su equilibrio entre acidez y dulzor y por su aroma característico; de hecho el nombre del género Fragaria proviene del término latín Fragans que significa fragancia (Branzanti, 1989). El componente más abundante del fruto es el agua con 93-94\%, de allí que resulte muy importante durante el manejo de la fruta mantener la temperatura cercana a $0{ }^{\circ} \mathrm{C}$ y la humedad relativa elevada para prevenir la deshidratación. Aproximadamente el 75\% de los sólidos solubles están representados por los azúcares, componentes de importancia en la determinación del sabor y dentro de los que se destacan la glucosa y la fructosa (90\% del total) y una fracción pequeña de sacarosa. El ácido predominante de la frutilla es el cítrico y se ubica en niveles de 0,3-0,9\%. El color de los frutos maduros está dado por la presencia de antocianinas, que son pigmentos fenólicos solubles en agua (Walle, 2004). Las antocianinas son flavonoides con uno o más sustituyentes hidroxilo, cuyo número y posición determina las diferencias estructurales de las formas más comúnmente halladas en la naturaleza (Birt et al., 2001). En frutilla, la antocianina más abundante es el pelargonidin-3-glucósido que constituye un 45\% del total de los compuestos fenólicos en los frutos maduros (Puupponen-Pimiä et al., 2005). Los frutos son además una buena fuente de fibra (1-1,5\%), poseen un bajo contenido de carbohidratos metabolizables (4-7\%), calorías (25 Kcal cada $100 \mathrm{~g}$ ) y bajos niveles de sodio (10 $\mathrm{mg} \mathrm{kg}^{-1}$ ), lo que hace que sean recomendados en dietas saludables. Asimismo, son una excelente fuente de antioxidantes que resultan 
beneficiosos para la prevención de algunas enfermedades vinculadas con el deterioro celular ocasionado por radicales libres (Wang et al., 1996; Kresty et al., 2001; Chung et al., 2002). Dentro de los mismos se destacan los compuestos fenólicos como grupo mayoritario y el ácido ascórbico en concentraciones similares a las presentes en los cítricos (50-70 mg $\left.100 \mathrm{~g}^{-1}\right)$.

Por su fisiología, la frutilla se clasifica dentro de los frutos no climatéricos, debido a que la maduración se inicia y progresa sin que se produzca un pico en la producción de etileno ni un aumento en la respiración (Giovannoni, 2001). Por otra parte, si bien se conoce que el etileno puede tener efecto sobre la expresión de algunos genes vinculados con el ablandamiento (Villarreal et al., 2008), el desarrollo de color y provoca una mayor susceptibilidad al ataque de hongos (Ku et al., 1999, Mitcham et al., 2002), es claro que el rol de esta hormona es considerablemente menos central que el que posee en la regulación del proceso de maduración de frutos climatéricos (Giovannoni, 2001).

Comercialmente, el momento de cosecha se determina en base al desarrollo de color superficial (Figura I.2) (Kader, 2002a).

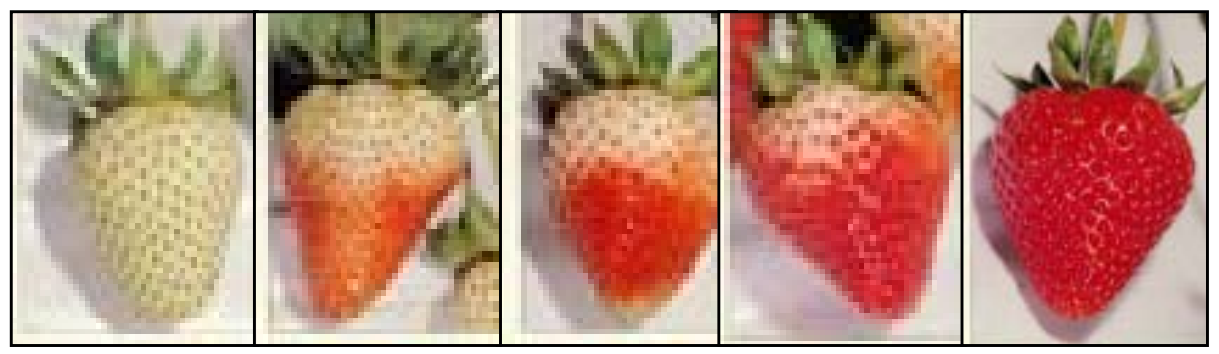

Figura 1.2: Estados de maduración de frutilla.

Por tratarse de frutos que reciben fotoasimilados hasta el final de su desarrollo, y que no acumulan almidón, la cosecha debe realizarse cerca de la madurez plena 
(más de 75\% de color rojo) (Kader, 2002b) y su adelanto se traduce en una reducción del contenido de azúcares. Desde el punto de vista de la calidad, las principales características consideradas son el color y brillo, el tamaño, la forma, la ausencia de defectos, la firmeza y el sabor (asociado con los niveles de sólidos solubles, la acidez y los niveles de compuestos aromáticos volátiles dentro de los que se destaca el furaneol). Se recomienda para la cosecha un mínimo de $7 \%$ de sólidos solubles y/o un máximo de 0,8\% de acidez titulable (DeEll et al., 2006).

Desde el punto de vista de su comportamiento durante el almacenamiento, la frutilla tiene una tasa relativamente alta de respiración $\left(50-100 \mathrm{~mL} \mathrm{CO}_{2} \mathrm{~kg}^{-1} \mathrm{~h}^{-1}\right.$ a 20 $\left.{ }^{\circ} \mathrm{C}\right)$ y por lo tanto es un fruto muy perecedero. Produce muy poco etileno $\left(<0,1 \mu \mathrm{L} \mathrm{kg}{ }^{-1}\right.$ $\mathrm{h}^{-1}$ a $\left.20^{\circ} \mathrm{C}\right)$ y, como se mencionó anteriormente, su sensibilidad a dicha hormona es baja (DeEll, 2011). La vida útil poscosecha de la frutilla destinada al consumo directo es muy breve, debido principalmente al marcado ablandamiento que sufre durante su maduración y a la elevada incidencia de hongos luego de varios días de almacenamiento.

La frutilla debe ser recolectada y manipulada con mucho cuidado. Es recomendable realizar la cosecha temprano en el día mientras que las temperaturas son bajas, pero evitando la presencia de rocío en la superficie del fruto ya que favorecería el desarrollo de Botrytis cinerea y Rhizopus stolonifer, principales patógenos de poscosecha. Las estrategias más comunes para el control de enfermedades consisten en prevenir el daño mecánico y la contaminación cruzada (eliminando las bayas dañadas o con infecciones) y refrigerar rápidamente la fruta una vez cosechada ya que no se encuentran aprobados fungicidas para su uso en poscosecha. El enfriamiento de las bayas elimina el calor de campo y extiende su vida útil (Demchak et al., 2011). Las condiciones recomendadas de almacenamiento son: 0 ${ }^{\circ} \mathrm{C}$ y $90-95 \%$ de humedad relativa. Las atmósferas modificadas $\left(15 \% \mathrm{CO}_{2}\right.$ y $\left.5 \% \mathrm{O}_{2}\right)$ 
logran muy buenos resultados pero su uso suele ser justificado sólo en envíos a mercados distantes (Mitchell et al., 1996). Otras estrategias evaluadas han sido la irradiación, los tratamientos cortos con calor, la aplicación de productos químicos (sales de calcio, 1-metilciclopropeno), aplicación de inductores de respuesta de defensa de la planta, tratamientos con compuestos naturales antimicrobianos, entre otros. Los métodos físicos, tales como tratamientos con calor y la irradiación UV-C, son estrategias de interés para retrasar el deterioro de los frutos. El control biológico y otros tratamientos capaces de activar respuestas defensivas naturales de los frutos también han mostrado resultados alentadores, aunque sólo se han utilizado a nivel de laboratorio (Peng y Sutton, 1991; Wisniewski y Wilson, 1992; Helbig, 2002; Karabulut et al., 2004). Los rápidos avances en la ingeniería genética podrían abrir otro campo de la investigación con posibilidades de reducir la susceptibilidad del fruto a las podredumbres o incrementar su calidad. Dado que ninguna de las metodologías ha logrado dar una respuesta definitiva, la búsqueda de nuevas estrategias para minimizar las pérdidas de calidad y cantidad de frutilla durante la poscosecha se torna necesaria. En particular, la optimización de metodologías que ya han mostrado buenos resultados a pequeña escala pero que no han logrado difusión comercial aún constituye un interesante desafío. 


\subsection{Tomate: producción, composición y generalidades de}

\section{manejo poscosecha.}

El tomate pertenece a la familia de las Solanáceas (Cantwell y Kasmire, 2007). El centro del origen de la especie Solanum lycopersicum es la región andina que hoy comparten Colombia, Ecuador, Perú, Bolivia y Chile (Rick, 1990). A la llegada de los españoles a América, el tomate formaba parte de los pequeños huertos de hortalizas del área mesoamericana (Nuez, 1995). De hecho, el tomate había alcanzado una fase avanzada de domesticación antes de su llegada a Europa y Asia. No obstante, el tomate cultivado tuvo su origen en el Nuevo Mundo (Rick, 1990). Luego de la conquista, los españoles y portugueses difundieron el tomate por el mundo a través de sus colonias ultramarinas, llevando el fruto hasta países asiáticos, africanos y de oriente medio.

En la actualidad, los principales países productores son China, Estados Unidos, India, Turquía y Egipto (FAOSTAT, 2011). La producción mundial se ubica en los 153 millones de toneladas (Tabla I.2).

Tabla 1.2: Producción de tomate a nivel mundial (miles de toneladas). Fuente: FAOSTAT, 2011.

\begin{tabular}{|c|c|}
\hline Año & Producción \\
\hline 2006 & 127.929 \\
\hline 2007 & 130.226 \\
\hline 2008 & 137.291 \\
\hline 2009 & 142.153 \\
\hline 2010 & 152.956 \\
\hline
\end{tabular}


En Argentina, las zonas de mayor producción de tomate bajo cubierta son las provincias de Corrientes (concentrándose en la costa del río Paraná: departamentos de Lavalle, Goya y Bella Vista) y Buenos Aires (cinturón verde que rodea a la ciudad autónoma de Buenos Aires, La Plata y cinturón verde de Mar del Plata) (Corvo, 2002). Por otra parte, la producción de tomate a campo se realiza en ocho provincias, donde se destacan las provincias de Mendoza, Salta, Jujuy y Río Negro, con una menor participación de San Juan, Buenos Aires, Catamarca y Santiago del Estero.

Si bien se lo cultiva comúnmente en forma anual, el tomate es una planta perenne. El tallo es inicialmente herbáceo, frágil, redondo y erecto; luego se torna semi-leñoso. Las hojas son compuestas, alternas, imparipinadas, con los folíolos dentados o lisos y con pelos glandulares. Las inflorescencias son racimos o cimas de flores con cinco pétalos amarillos, cinco sépalos largos, lanceolados, y cinco estambres en columna que rodean el estilo. El cáliz es persistente. El fruto es una baya bi- o plurilocular de color rojo o amarillo (Vigliola, 1991).

Actualmente, desde el punto de vista morfológico, en el mercado se comercializan los siguientes tipos de tomates (Figura I.3)

Redondo: el diámetro transversal es igual o mayor que el eje longitudinal. Está dividido en cuatro categorías, en las que el diámetro fluctúa entre los 65 a 100 milímetros. Satisface el mercado para consumo fresco.

Perita: el eje longitudinal es mayor que el transversal. Posee mayor contenido de sólidos solubles. La industria se provee de este tipo de tomate y también satisface el consumo fresco.

Cherry: corresponde a la especie S. lycopersicum var cerasiforme. Son frutos pequeños, con un diámetro inferior a los $40 \mathrm{~mm}$. Es comercializado para su consumo fresco (Corvo, 2002). 
Larga vida: incluye a aquellas variedades genéticamente mejoradas de tomate que presentan un mejor comportamiento poscosecha. Esto se logró por cruzamientos a fin de incorporar formas mutadas de los genes Nor y Rin que retrasan la maduración. Las variedades de tomate larga vida disponibles en el mercado no son transgénicas. Este tipo de tomate se encuentra bastante difundido a nivel de la distribución en las cadenas de supermercados.

Platense: el tradicional tomate de la zona, variedad botánica caracterizada por sabor intenso, forma irregular, achatada, acostillada o fuertemente lobulada. El tomate Platense es apreciado por su sabor y aroma aunque posee mayores problemas desde el punto de vista de la conservación poscosecha y menores rendimientos y un mayor porcentaje de descarte que otras variedades comerciales (Rodoni, 2008).

A

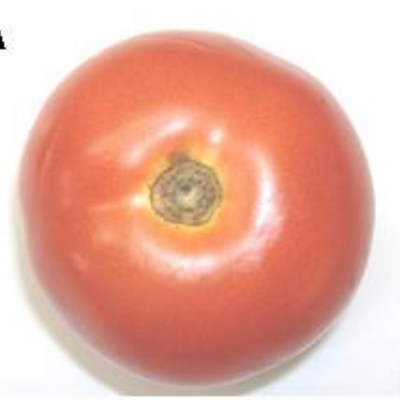

D

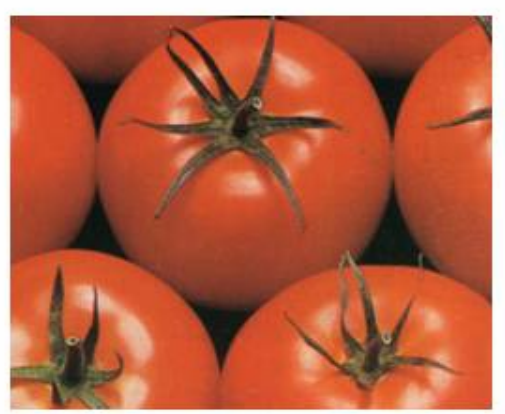

B

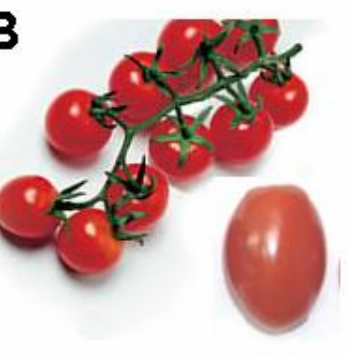

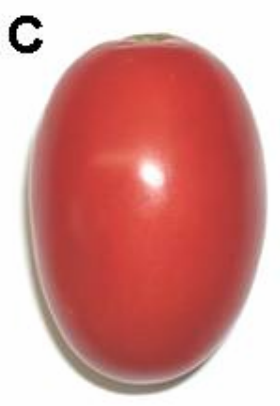

E

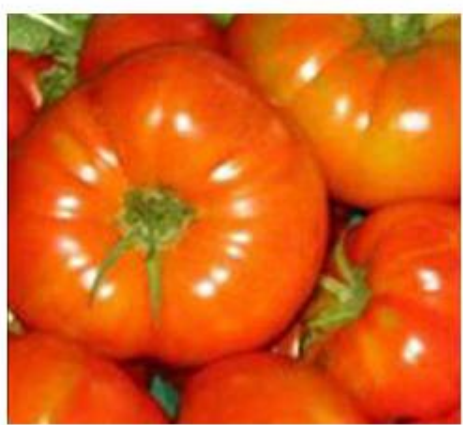

Figura l.3: Principales tipos de tomate comercializados en nuestro país. A. Redondo. B. Cherry. C. Perita. D. Larga vida. E. Platense. (Rodoni, 2008). 
Con respecto a su composición, el tomate tiene un contenido de agua de 94\%, fibra 1,2\%, lípidos 0,2\% y azúcares totales 2,62\% (divididos aproximadamente en partes iguales de glucosa y fructosa). Como aporte vitamínico, el tomate aporta 13,7 mg de vitamina C por cada $100 \mathrm{~g}$ (USDA, 2010).

El etileno es una hormona vegetal que desencadena los procesos de maduración en algunos frutos y senescencia de diversos órganos vegetales (Abeles et al., 1992). La producción de etileno en tomate presenta un pico en estados intermedios de maduración, para volver a descender en estados avanzados (Hobson y Grierson, 1993), por lo cual es clasificado como un fruto climatérico. Esta hormona posee un rol central en la regulación del proceso de maduración (Suslow y Cantwell, 2006; Rhodes, 1980; Tucker, 1993). La tasa de respiración del tomate verde maduro a $20{ }^{\circ} \mathrm{C}$ es de 14-21 mL CO $\mathrm{kg}^{-1} \mathrm{~h}^{-1}$, mientras que la del tomate rojo se encuentra en un rango de $12-22 \mathrm{~mL} \mathrm{CO}_{2} \mathrm{~kg}^{-1} \mathrm{~h}^{-1}$ (Suslow y Cantwell, 2006). Los frutos pueden cosecharse cuando han alcanzado su pleno desarrollo en la planta pero no han comenzado a madurar (estadio verde maduro). La mínima madurez para cosecha se define en términos de la estructura interna del fruto: las semillas están completamente desarrolladas y no se cortan al rebanar el fruto; el material gelatinoso está presente en al menos un lóculo y se está formando en otro (Suslow y Cantwell, 2006).

Dentro de los índices de calidad, se tiene en cuenta principalmente la uniformidad de forma y la ausencia de defectos. El tamaño es importante con respecto a las expectativas de calidad comercial, sin embargo no constituye un factor indispensable en el grado de calidad. El color debe ser uniforme (anaranjado-rojo a rojo intenso),- sin hombros verdes. La apariencia debe ser lisa, sin grietas de crecimiento, "cara de gato", sutura muy marcada, quemaduras de sol, picaduras de insectos y daño mecánico o magulladuras. El fruto debe ser firme al tacto (Suslow y Cantwell, 2006). Las temperaturas óptimas para el almacenamiento a corto plazo y 
transporte para tomate verde son de $12,5-15{ }^{\circ} \mathrm{C}$ y para tomates parcial o totalmente maduros de $10{ }^{\circ} \mathrm{C}$ a $12,5{ }^{\circ} \mathrm{C}$ con una humedad relativa de $85-90 \%$ (Abdel-Kader y ElMougy, 2007). Cabe señalar que los beneficios de la reducción de temperatura no pueden explotarse en su totalidad en tomates dado que los frutos son susceptibles al daño por frío, el cual es un desorden fisiológico que aparece en frutos almacenados por debajo de $10{ }^{\circ} \mathrm{C}$ y que provoca un pobre desarrollo de color y un aumento en la susceptibilidad a las pudriciones. El tratamiento con atmósferas modificadas y controladas en tomate no producen grandes beneficios y la búsqueda de métodos alternativos para el manejo de poscosecha resulta de gran interés.

\subsection{Tratamientos con radiación ultravioleta: su uso en}

\section{alimentos.}

La radiación ultravioleta (UV) es conocida por su efecto germicida y su aplicación en esterilización, y ha sido adoptada especialmente en áreas en las que la contaminación microbiológica tiene gran importancia (Civello et al., 2006). Asimismo, se ha utilizado por mucho tiempo en la industria alimentaria para la purificación de ambientes donde se procesan o fabrican alimentos, en la desinfección de agua y de superficies de empaque. También se ha experimentado su aplicación directa en algunos alimentos frescos y procesados. Así, se ha usado en el control de enfermedades poscosecha de frutas y hortalizas y se ha demostrado su efecto beneficioso en numerosos sistemas (Shama y Alderson, 2005; Civello et al., 2006). 


\section{l.3.1. Características de la radiación ultravioleta.}

La zona dentro del espectro electromagnético correspondiente a la radiación ultravioleta comprende longitudes de onda desde $400 \mathrm{~nm}$, extremo violeta del espectro visible, hasta los $100 \mathrm{~nm}$ y puede a su vez subdividirse en tres zonas (Tabla I.3).

Tabla 1.3: Diferentes regiones del espectro UV indicando sus respectivas longitudes de onda.

\begin{tabular}{|c|c|}
\hline Radiación & Longitud de onda \\
\hline UV-A & $315-400 \mathrm{~nm}$. \\
\hline UV-B & $280-315 \mathrm{~nm}$. \\
\hline UV-C & $100-280 \mathrm{~nm}$. \\
\hline
\end{tabular}

La región denominada UV-A corresponde a las radiaciones entre 315 y 400 nm y la zona UV-B abarca radiaciones en el rango 280-315 $\mathrm{nm}$. El espectro solar contiene gran cantidad de estas radiaciones que en condiciones normales son absorbidas parcialmente por el ozono atmosférico. Por último, la sub-región C incluye a las radiaciones con la longitud de onda de entre 100 y $280 \mathrm{~nm}$ y normalmente no llega a la superficie terrestre. La radiación UV-C es utilizada comúnmente por su acción germicida en la eliminación de bacterias, levaduras, algas y mohos. La misma, si no se toman las precauciones necesarias, puede resultar peligrosa para la piel y los ojos y ocasionar serias lesiones en los seres humanos (Valea, 1998). 


\subsubsection{Efecto de la radiación UV sobre los seres vivos.}

\section{a. Efecto germicida}

Los efectos germicidas de la radiación UV-C han sido conocidos por largo tiempo. Niels Ryberg Finsen (1860-1904) fue el pionero en usar rayos UV para el tratamiento de enfermedades. En 1901, publicó los resultados del tratamiento de Lupus vulgaris con radiación ultravioleta y dos años más tarde le fue otorgado el Premio Nobel de Medicina (Civello et al., 2006). Los seres vivos reaccionan de diferente forma a la radiación ultravioleta, algunos resisten dosis mayores que otros. Los organismos eucariotas son en general más resistentes que los procariotas. Los hongos, por ejemplo, resisten una dosis de radiación superior a la requerida para conseguir el mismo porcentaje de destrucción en bacterias (Valea, 1998). Asimismo, para un organismo dado existen marcadas diferencias; por ejemplo, las formas de resistencia como las esporas son menos sensibles a la radiación UV que los respectivos micelios. Los efectos deletéreos de la radiación UV se han vinculado con alteraciones en diferentes macromoléculas como proteínas, lípidos y ácidos nucleicos (Shama y Alderson, 2005). La exposición a la radiación UV puede dar lugar a la formación de radicales libres favoreciendo la oxidación de los lípidos de la membrana y provocando alteraciones funcionales a nivel celular. Con respecto a las proteínas, se conoce que la exposición a la radiación UV-C puede provocar modificaciones a nivel de las estructuras secundarias, terciarias y/o cuaternarias, favorecer su agregación y oxidación. Por último, el efecto de la radiación UV-C sobre los ácidos nucléicos ha sido ampliamente estudiado y es a este nivel en donde ocurren las principales modificaciones que afectan la capacidad reproductiva de los microorganismos irradiados. La eficacia en el control microbiano por acción de la radiación UV-C se 
asocia, casi en su totalidad, con su absorción por el ADN (Harm, 1980). La radiación UV-C conduce a daños graves en la estructura de esta macromolécula, motivando cambios químicos en sus bases nitrogenadas. La reacción más frecuente conduce a la formación de un anillo del tipo ciclobutano entre la timina y la citosina. Este proceso finaliza con la formación de dímeros de timina, lo que entraña una distorsión drástica en la estructura del ADN impidiendo la ulterior decodificación de su información. Otras lesiones inducidas por la radiación UV-C incluyen la formación de aductos pirimidínicos y fotohidratos, que se forman con menor frecuencia que los dímeros de pirimidina pero que también conducen a la alteración del ADN y la generación de mutaciones (Valea, 1998).

\section{b. Efectos sobre los frutos}

Si bien la radiación UV se utilizó originariamente en la desinfección de agua o de superficies, varios grupos de investigación han comenzado a evaluar la posibilidad de extender su uso para los tratamientos directos en los alimentos (Civello et al., 2006). De este modo, se han realizado investigaciones orientadas a determinar las bases fisiológicas de los efectos de la radiación UV en alimentos, así como los beneficios que puede proveer esta tecnología. En los últimos años, el tratamiento con radiación UV se propuso como un método para reducir las pérdidas poscosecha de productos fruti-hortícolas ocasionadas por el ataque de microorganismos, a la vez que para retrasar la sobre-maduración y senescencia (Shama, 2007). Los tratamientos UVC demostraron ser eficaces en el control de patógenos humanos y por lo tanto su uso podría eventualmente contribuir a asegurar la inocuidad de las frutas y hortalizas. Yaun et al., (2003) irradiaron con UV-C manzanas inoculadas con E. coli O157:H7 y lograron reducciones de 3,3 ciclos logarítmicos en los recuentos, mientras que en 
tomates inoculados con Salmonella sp. se alcanzó una reducción de 2,19 ciclos. Diversos trabajos han mostrado que los tratamientos con UV-C permiten controlar el desarrollo de microorganismos y en consecuencia permiten retrasar la incidencia y severidad de enfermedades de poscosecha. De este modo, existen reportes del control eficaz de Alternaria en manzana cv. Golden Delicious (Stevens et al., 1996) y de Botrytis cinerea en "berries" (Baka et al., 1999; Pan et al., 2004; Vicente et al., 2005). También se ha demostrado la eficacia de los tratamientos en el control de Penicillium digitatum en cítricos cv. Marsh Seedless (Stevens et al., 1996) y de Rhizopus sp en tomate y frutilla (Civello et al., 2006). Resulta de interés mencionar que el control de enfermedades en frutos tratados con radiación UV-C también se ha observado inclusive en casos en los que se realizaron inoculaciones con posterioridad a los tratamientos. Pombo et al., (2010) irradiaron frutillas con UV-C y luego inocularon los frutos con una suspensión de conidios de $B$. cinerea; los resultados mostraron la disminución del 30\% del número de frutillas infectadas luego de 5 y 9 días de almacenamiento, sugiriendo que el efecto se debería, al menos parcialmente, a la generación de una serie de respuestas defensivas en el producto. Estas podrían incluir la expresión de genes que codifiquen para enzimas con acción antifúngica y la inducción de la biosíntesis de compuestos antimicrobianos (Shama y Alderson, 2005). La acumulación de fitoalexinas, tales como escopoletina y escoparona, se ha comprobado en cítricos tratados con UV-C (D'Hallewin et al., 1999). Otras manifestaciones que podrían también contribuir a reducir la susceptibilidad al ataque de patógenos en frutos irradiados incluyen la acumulación de enzimas relacionadas, en forma directa o indirecta, con mecanismos defensivos tales como fenilalanina amonio-liasa, peroxidasa, polifenoloxidasa, quitinasa y $\beta-1,3-D$ glucanasa (Barka, 2001; El Ghaouth et al., 2003; Civello et al., 2006; Shama, 2007; Pombo et al., 2010). 
Varios estudios han permitido determinar que los tratamientos con bajas dosis de UV resultan valiosos para retrasar la senescencia y maduración de diferentes productos fruti-hortícolas. Los efectos se han descrito en hortalizas de hoja como lechuga (Allende et al., 2006), raíces como zanahoria (Mercier et al., 2000), inflorescencias como brócoli (Costa et al., 2006; Lemoine et al., 2008), arilos como granada (López et al., 2005), en frutos climatéricos como tomate (Maharaj et al., 1999), manzana y durazno (Stevens et al., 1998) y no climatéricos como pimiento (Mercier et al., 2001; Vicente, 2005), pomelo (D'hallewin et al., 2000), naranja, uva y frutilla (Baka et al, 1999, Pan et al., 2004). En algunos casos se ha informado un aumento en la producción de etileno, lo cual probablemente se asocie a la aplicación de tratamientos excesivos y con el consecuente daño de los tejidos (Civello et al., 2006).

Con relación a la influencia de los tratamientos sobre los niveles de los diferentes pigmentos presentes en frutas y hortalizas, diversos estudios demuestran que la exposición a la radiación UV-C permite reducir la degradación de clorofila, y retrasar la acumulación de antocianinas y carotenoides. Costa et al., (2006) describieron que la exposición a dosis de $14 \mathrm{~kJ} \mathrm{~m}^{-2}$ de radiación UV-C retrasó la degradación de clorofila en cabezas de brócoli. Esto mostró una correlación con la reducción de la actividad de enzimas vinculadas al catabolismo del mencionado pigmento (Lemoine et al., 2008). Con respecto a los carotenoides, en tomate y pimientos tratados se observa una menor acumulación que en los frutos control (Maharaj et al., 1999; Vicente et al., 2005). Estudios realizados en frutilla concluyeron que dosis de 0,25-1,0 kJ m² disminuyen la acumulación de antocianinas (Baka et al., 1999; Pan et al., 2004). En el caso de aplicación de tratamientos con dosis excesivas se puede favorecer la degradación de los tres grupos de pigmentos mencionados por 
daño oxidativo, así como el pardeamiento como consecuencia de la polimerización de quinonas mediada por polifenoloxidasa y/o peroxidasa (Apel y Hirt, 2004).

Otro de los cambios que ocurre durante la maduración de frutos es el ablandamiento, el cual fue retrasado en diferentes especies por la exposición a la radiación UV (Maharaj et al., 1999; Pan et al., 2004; Vicente, 2004; Perkins et al., 2008). El mantenimiento de la firmeza de los frutos tratados con UV-C se considera que se encuentra asociado con la inactivación de enzimas relacionadas con el desensamblaje de polímeros de pared celular (Stevens et al, 2004).

En algunos sistemas se ha observado como consecuencia de los tratamientos con UV-C una reducción del daño por frío (Vicente et al., 2005). En pimiento rojo la exposición por un período muy breve a la radiación UV-C permitió reducir la incidencia y severidad del picado superficial. El efecto protector de los tratamientos podría deberse a que la exposición a la radiación activa defensas antioxidantes que luego permiten mejorar la detoxificación de radicales libres durante el almacenamiento a bajas temperaturas (Andrade et al., 2011).

Algunos trabajos sugieren que la manipulación del metabolismo de los productos mediante tratamientos con UV-C podría redundar en una menor pérdida, o incluso en el incremento, de la actividad antioxidante con el consiguiente beneficio nutricional. En uva, los tratamientos poscosecha con radiación UV-C permitieron incrementar marcadamente los niveles de resveratrol (Cantos et al., 2002). Esta inducción de componentes con capacidad anti-radical ha sido descrita también en otros frutos como arándano cv "Bluecrop", donde además de reducir el ataque de patógenos, la exposición a radiación UV-C incrementó la actividad antioxidante total de los frutos (Perkins et al., 2008). 


\section{I.4. Ventajas y limitaciones de la aplicación de radiación UV a nivel industrial.}

Los tratamientos de radiación de UV-C presentan numerosas ventajas ya que son procesos relativamente cortos, se aplican en seco y requieren menos infraestructura que otros métodos, y son económicos debido a que la inversión de capital es generalmente baja al igual que el costo de mantenimiento. En general no hay restricciones legales para su aplicación y los efectos sobre la calidad de los frutos son claros, por lo que constituye una excelente alternativa para extender la vida poscosecha de frutas y vegetales. A pesar de esto, existen muy pocos casos documentados del uso de tratamiento de UV en productos fruti-hortícolas a nivel industrial. Esto podría obedecer a diferentes motivos que no se encuentran claramente establecidos pero sobre los cuales podría especularse:

\section{a) Falta de difusión}

b) Falta de exigencia de algunos mercados: Esto ha determinado que no se hayan incorporado aún tecnologías básicas como la refrigeración, limitándose el manejo poscosecha a favorecer la rápida rotación de la mercadería, aceptando las mermas de calidad y cantidad de producto como una característica inherente al sistema.

c) Aspectos técnicos específicos: Los tubos a utilizarse para el tratamiento de los frutos deben tener protección contra roturas y en general los plásticos que se utilizan a tal fin absorben la radiación UV. Si bien existen tubos germicidas recubiertos con polímeros resistentes a la rotura y transparentes a la radiación UV-C en el exterior, en 
nuestro país los mismos no se comercializan. De todos modos, esto podría revertirse fácilmente en la medida que la demanda justifique la importación de los mencionados tubos. Otros aspecto a considerar es que la radiación no es penetrante, por lo que debiera asegurarse la exposición de la totalidad de la superficie del producto a la radiación, ya sea rotándolo o colocando lámparas que incidan tanto desde arriba como desde abajo del producto a tratar.

d) Adaptación a líneas de empaque: Por último, el caso de frutos que se manejan en forma continua en líneas de empaque, la irradiación UV-C requeriría adecuar la exposición a las velocidades comúnmente utilizadas. La adaptación de tratamientos de irradiación a las condiciones de operación continua de las líneas de empaque resulta un aspecto deseable que podría incrementar sustancialmente las posibilidades de adopción a escala comercial.

La mayoría de los estudios hasta la fecha en los cuales se evalúa el uso de radiación UV-C en frutas y hortalizas se han focalizado en seleccionar una dosis de radiación apropiada para cada uno de los frutos y a partir de esto determinar su efecto sobre el comportamiento de los mismos en el almacenamiento. De hecho, comúnmente los trabajos publicados reportan solamente la dosis total de radiación. La dosis de los tratamientos se expresa en unidades de energía por unidad de área y surge del producto del tiempo de tratamiento por la intensidad o fluencia de radiación, determinada por la potencia de irradiación del equipo por unidad de área: 


$$
\boldsymbol{D}\left(k J m^{-2}\right)=\boldsymbol{I}\left(k W m^{-2}\right) \times \boldsymbol{t}(\mathrm{s})
$$

Donde:

$D=$ Dosis del tratamiento expresada por ejemplo en $\mathrm{kJ} \mathrm{m}^{-2}$

I= Intensidad fluencia de radiación expresada por ejemplo en $\mathrm{kW} \mathrm{m}^{-2}$

$\boldsymbol{t}=$ Tiempo de tratamiento expresado en segundos.

Más allá de la dosis recibida, la intensidad de la radiación puede determinar su efecto sobre los organismos. En el área de desinfección de aguas Sommer et al., (1996a, b), encontraron que la radiación UV ocasiona una mayor inactivación a intensidades más altas. Por su parte Liu y Zhang (2006) demostraron que a mayor intensidad de UV existe un control más efectivo de E. coli, Staphylococcus aureus y Candida albicans. Para la radiación UV-B, se conoce claramente que la exposición a una fluencia elevada provoca la inducción de respuestas generales de stress, daño mecánico y defensa (A-H-Mackerness et al., 2001; Brosché y Strid, 2003; Ulm y Nagy, 2005; Kilian et al., 2007), mientras que la exposición a intensidades inferiores se asocia con la expresión de genes involucrados en la protección al daño y adaptación al exceso de radiación (Ulm et al, 2004; Jenkins et al., 2001; Frohnmeyer et al., 2001; Brown y Jenkins, 2008). Del mismo modo, los efectos de inactivación de ciertas enzimas que se han descrito por acción de los tratamientos UV podrían estar afectados por la intensidad de la radiación recibida (Frohnmeyer et al., 2001; Stratmann, 2003). En función de lo antedicho resulta de interés evaluar la influencia que podría tener el aumento de la intensidad de radiación sobre la eficacia de los tratamientos UV-C en frutos. El aumento de la fluencia, en caso de ser posible, permitiría acortar el tiempo de residencia de los frutos en los túneles de tratamiento y 
con ello redundar en procesos que podrían tener una mayor factibilidad para su aplicación en la industria. De todos modos, es probable que la fluencia apropiada dependa del producto considerado y que la aplicación de niveles por encima de un umbral pudiera provocar cambios indeseables. Por lo tanto, resulta necesario conocer cuáles son los efectos del incremento de la intensidad de radiación sobre la maduración y senescencia de frutos, aspecto que se decidió estudiar en el marco del presente trabajo de tesis. 


\section{OBJETIVOS}




\section{OBJETIVO GENERAL}

- Evaluar el efecto de la intensidad de radiación sobre la eficacia de tratamientos UV-C en frutos frescos.

\section{OBJETIVOS ESPECÍFICOS}

- Analizar el efecto de tratamientos UV-C de diferente intensidad sobre la calidad organoléptica, microbiológica y nutricional de frutilla.

- Determinar el efecto de tratamientos UV-C de diferente intensidad sobre la calidad organoléptica, microbiológica y nutricional de tomate. 


\section{MATERIALES Y MÉTODOS}




\section{III.1. Efecto de tratamientos UV-C de diferente intensidad sobre la calidad y deterioro poscosecha de frutilla.}

Se cosecharon frutillas (Fragaria $\times$ ananassa cv Camarosa), en estado de madurez comercial ( $90 \%$ de color superficial rojo) y se trasladaron al laboratorio. Los frutos se colocaron en bandejas plásticas de PET (10 frutos por bandeja). Posteriormente, las bandejas se ubicaron bajo de un banco de irradiación con 11 lámparas UV-C (254 nm, TUV G30T8, 30W, Philips, Argentina) y se expusieron a una dosis de $4 \mathrm{~kJ} \mathrm{~m}^{-2}$ a diferentes intensidades de radiación (3 y $33 \mathrm{~W} \mathrm{~m}^{-2}$ ). Estas intensidades de luz UV-C se lograron con 2 lámparas encendidas durante 22 min o bien 11 lámparas durante 2 min, respectivamente. La intensidad de la radiación y la dosis se determinaron con un radiómetro (Cole-Parmer, Vernon Hills, IL, USA). Durante el tratamiento se utilizó un ventilador para la remoción del ozono generado dentro de la cámara de irradiación. Finalizado el tratamiento, las bandejas con frutos se cubrieron con un film de PVC perforado y se almacenaron a $10^{\circ} \mathrm{C}$. Los controles correspondientes, sin tratamiento UV-C, se envasaron como se mencionó anteriormente y se almacenaron directamente a $10^{\circ} \mathrm{C}$. Se prepararon 16 bandejas conteniendo 10 frutos cada una para cada tratamiento. Los frutos control o tratados con las diferentes intensidades de radiación de UV-C se muestrearon al inicio del ensayo y luego de 2 y 5 d de almacenamiento. Los frutos se analizaron inmediatamente o bien se tomaron muestras de frutos que fueron congelados en $\mathrm{N}_{2}$ líquido en mitades y se almacenaron a $-80{ }^{\circ} \mathrm{C}$ hasta su uso. Se realizaron determinaciones de ataque de hongos, pérdida de peso, firmeza, color superficial ( $L^{*}$, hue, croma), antocianinas, acidez, sólidos solubles, antioxidantes, actividad respiratoria, recuentos de hongos y bacterias mesófilas y estudios sensoriales de 
ordenamiento por preferencia con un panel de evaluadores no entrenado, según se describe en la sección III.3.

\section{III.2. Efecto de tratamientos UV-C de diferente intensidad sobre la calidad y deterioro poscosecha de tomate.}

Se cosecharon frutos de tomate (Solanum lycopersicum cv. Elpida) en estado de madurez pintón y se trasladaron al laboratorio. Los frutos se colocaron en bandejas plásticas PET (4 frutos por bandeja). Posteriormente, las bandejas se ubicaron bajo un banco de irradiación con 11 lámparas UV-C (254nm, TUV G30T8, 30 W, Phillips, Argentina) y se expusieron a una dosis de $4 \mathrm{~kJ} \mathrm{~m}^{-2}$ a diferentes intensidades de radiación (3 y $33 \mathrm{~W} \mathrm{~m}^{-2}$ con 2 y 11 lámparas encendidas, respectivamente). Tanto la dosis aplicada como la intensidad de la radiación se determinaron con un radiómetro (Cole-Parmer, Vernon Hills, IL, USA). Durante el tratamiento se utilizó un ventilador para la remoción del ozono generado. Finalizado el tratamiento, las bandejas con frutos se cubrieron con un film de PVC perforado y se almacenaron a $20^{\circ} \mathrm{C}$. Los controles correspondientes sin tratamiento UV-C se envasaron como se mencionó anteriormente y se almacenaron directamente a $20{ }^{\circ} \mathrm{C}$. Se utilizaron 16 bandejas conteniendo 4 frutos cada una para cada tratamiento. Los frutos control o tratados con las diferentes intensidades de radiación UV-C se evaluaron al inicio del ensayo y luego de 4 ó 9 d de almacenamiento. Los frutos se analizaron inmediatamente (firmeza, color superficial y pérdida de peso), se cortaron en gajos longitudinales, se congelaron y almacenaron a $-80^{\circ} \mathrm{C}$ hasta su uso. Se realizaron evaluaciones de color superficial, pérdida de peso, ataque de hongos, tasa respiratoria, acidez, antioxidantes hidrofílicos, licopeno, firmeza, sólidos solubles, recuentos de hongos y bacterias 
mesófilas y estudios sensoriales de ordenamiento por preferencia con un panel de evaluadores no entrenado según se describe en la sección III.3.

\section{III.3. Determinaciones de parámetros de calidad.}

\section{III.3.1. Ataque de hongos.}

Se evaluó en forma visual la apariencia externa de los frutos y se determinó la presencia de micelio fúngico macroscópicamente visible. Los resultados se expresaron como porcentaje de frutos atacados.

\section{III.3.2. Pérdida de peso.}

Se pesaron las bandejas conteniendo 10 frutos, en el caso de frutillas, o los frutos individuales, en el caso de tomates, al comienzo del experimento y durante el almacenamiento. Los resultados se expresaron como porcentaje de pérdida de peso.

\section{IIl.3.3. Color superficial y pigmentos.}

El color superficial se determinó con un colorímetro (Minolta, Modelo CR-400 Osaka, Japón) obteniendo los parámetros $L^{\star}$, a y b. Los resultados se expresaron a partir de los cambios en la luminosidad $\left(L^{\star}\right)$, el ángulo hue $\left(\operatorname{tg}^{-1} \mathrm{~b}^{\star} / \mathrm{a}^{\star}\right)$ y croma $\left(\mathrm{a}^{\star^{2}+}\right.$ $\left.b^{\star^{2}}\right)^{1 / 2}$. Se realizaron 60 determinaciones para cada tipo de fruto, combinación de tratamiento y tiempo de almacenamiento evaluado. 
Para la evaluación del contenido de antocianinas se procesaron en un molinillo las frutillas congeladas y aproximadamente $0,1 \mathrm{~g}$ del polvo resultante se extrajo con 5 $\mathrm{mL}$ de metanol conteniendo $\mathrm{HCl} 1 \%(\mathrm{v} / \mathrm{v})$. La muestra se agitó en un vortex, se centrifugó a $9.000 \times g$ por 10 min a $4{ }^{\circ} \mathrm{C}$ y se midió la absorbancia del sobrenadante en la fase líquida a 515 nm empleando un espectrofotómetro (Shimadzu Modelo 1240, USA). Los resultados se expresaron como micromoles de pelargonidín-3-glucósido por kilogramo de fruto fresco, utilizando $\varepsilon=36.000 \mathrm{M}^{-1} \mathrm{~cm}^{-1}$. Para cada tratamiento $\mathrm{y}$ tiempo de almacenamiento se realizaron dos moliendas independientes y para cada una de ellas las determinaciones se realizaron por triplicado.

Para la determinación de licopeno se procesaron en un molinillo los frutos de tomate congelados y aproximadamente $0,10 \mathrm{~g}$ del polvo resultante se extrajo con $5 \mathrm{~mL}$ de hexano:acetona:etanol (2:1:1). La muestra se agitó en un vortex y se adicionó $1 \mathrm{~mL}$ de agua. Se midió la absorbancia del sobrenadante de la fase liquida a $503 \mathrm{~nm}$ empleando un espectrofotómetro. Los resultados se expresaron como miligramos de licopeno por cada 100 gramos de peso fresco, utilizando $\varepsilon=172.000 \mathrm{M}^{-1} \mathrm{~cm}^{-1}$. Para cada tratamiento y tiempo de almacenamiento se realizaron dos moliendas independientes y para cada una de ellas las determinaciones se realizaron por triplicado.

\section{III.3.4. Firmeza.}

Se utilizó un equipo Texture Analyzer (TA.XT2, Stable Micro Systems Texture Technologies, Scarsdale, NY, USA), equipado con una sonda plana de $3 \mathrm{~mm}$ de diámetro y se realizaron ensayos de compresión. Cada fruto se deformó una distancia de $3,5 \mathrm{~mm}$ a una velocidad de $1,5 \mathrm{~mm} \mathrm{~s}^{-1}$ en las determinaciones de frutilla, y $10 \mathrm{~mm}$ a una velocidad de $1,0 \mathrm{~mm} \mathrm{~s}^{-1}$ en las determinaciones de tomate, registrándose la 
pendiente de la curva de fuerza en función de la distancia de avance. Los resultados se expresaron en $\mathrm{N} \mathrm{mm}^{-1}$. Se realizaron 30 determinaciones para cada tipo de fruto, combinación de tratamiento y tiempo de almacenamiento evaluado.

\section{III.3.5. Sólidos solubles y acidez.}

Se trituró el tejido vegetal congelado en un molinillo, posteriormente se filtró por gasa y se midió el contenido de sólidos solubles totales con un refractómetro digital (Atago, USA). Se realizaron dos moliendas para cada condición de tiempo y tratamiento efectuado y las muestras se midieron por duplicado. El equipo se controló con soluciones de sacarosa de concentración conocida y los resultados se expresaron como gramos de sacarosa cada $100 \mathrm{~g}$ de fruto fresco. Las determinaciones de acidez se realizaron de acuerdo al método AOAC (1980). Se procesaron los frutos, se pesaron $5 \mathrm{~g}$ y se agregaron $50 \mathrm{~mL}$ de agua destilada y se tituló con $\mathrm{NaOH} 0,1 \mathrm{~N}$ hasta $\mathrm{pH}$ 8,2. Los resultados se expresaron como mmol H $\mathrm{Hg}^{-1}$. Se realizaron 2 moliendas independientes y las determinaciones se realizaron por duplicado.

\section{III.3.6. Capacidad antioxidante.}

La capacidad para neutralizar radicales libres de los frutos se analizó de acuerdo al procedimiento descrito por Brand-Williams et al., (1995). El tejido congelado (0,8 g para frutilla y $1,2 \mathrm{~g}$ para tomate) se procesó con $5 \mathrm{~mL}$ de etanol y la mezcla se centrifugó a $9.000 \times g$ por 10 min a $4{ }^{\circ} \mathrm{C}$ y se guardó el sobrenadante para realizar las determinaciones. Alícuotas del extracto etanólico $(0,150,300,450,600 \mu \mathrm{L})$ y etanol en cantidad necesaria para $1 \mathrm{~mL}$ se adicionaron a tubos conteniendo $3 \mathrm{~mL}$ de 2,2difenil-1-picrilhidrazil (DPPH') 0,040 $\mathrm{g} \mathrm{L}^{-1}$ en metanol. Se midió la absorbancia luego de 
$90 \min$ a $515 \mathrm{~nm}$ en un espectrofotómetro. Se graficó el porcentaje de DPPH remanente contra el volumen de extracto adicionado y se determinó el volumen de extracto necesario para reducir la concentración de $\mathrm{DPPH}^{\circ}$ en un $50 \%$; se calculó la masa (mg) de fruto equivalente a dicho volumen de extracto, a la cual se definió como $\mathrm{EC}_{50}$. El poder anti-radical se expresó como $\mathrm{EC}_{50}{ }^{-1}\left(\mathrm{mg}^{-1}\right)$. Para cada fruto, tratamiento y tiempo de almacenamiento a analizar se realizaron dos extracciones independientes y de cada una se analizaron las muestras por duplicado.

\section{III.3.7. Actividad respiratoria.}

La producción de dióxido de carbono se determinó con un sensor infrarrojo para detección de dicho gas (Alnor Compu-flow, Model 8650, Alnor, USA). Aproximadamente $400 \mathrm{~g}$ de frutos de tomate $0150 \mathrm{~g}$ de frutilla se colocaron en un recipiente hermético y se midió la producción de $\mathrm{CO}_{2}$ en función del tiempo a $20{ }^{\circ} \mathrm{C}$. Los resultados se expresaron como $\mathrm{mL}$ de $\mathrm{CO}_{2} \mathrm{~kg}^{-1} \mathrm{~h}^{-1}$. Las determinaciones se realizaron por triplicado para cada fruto, tratamiento y tiempo de almacenamiento.

\section{III.3.8. Recuentos de bacterias mesófilas y hongos.}

Se tomaron $25 \mathrm{~g}$ de diferentes frutos para cada tiempo de almacenamiento a analizar y se procesaron en $250 \mathrm{~mL}$ de agua peptona $1 \%$ estéril por $15 \mathrm{~min}$. A partir de la suspensión resultante, se prepararon dos series de diluciones y $1 \mathrm{~mL}$ de las mismas se sembraron en medios de cultivo específicos para recuentos de bacterias aerobias y hongos (Petrifilm ${ }^{\mathrm{TM}} 6400$ y 6407; 3M, Argentina). Las placas para el recuento de bacterias mesófilas se incubaron a $37^{\circ} \mathrm{C}$ por $2 \mathrm{~d}$ y las correspondientes al recuento de hongos a $20^{\circ} \mathrm{C}$ por $5 \mathrm{~d}$. Para cada tratamiento y tiempo de almacenamiento a analizar 
se realizaron dos extracciones independientes y de cada una se analizaron las muestras por duplicado. Los resultados se expresaron como log UFC $g^{-1}$.

\section{III.3.9. Análisis sensorial.}

Se trataron las frutillas y los tomates como se describió en las secciones III.1 y III.2 y se realizaron ensayos de preferencia con un panel no entrenado de 35 consumidores (Hough et al., 2006), utilizando el test de ordenamiento de preferencia (Hough 2010, Ryffel et al., 2008). En el ensayo, cada panelista recibió tres muestras codificadas con números de 3 dígitos al azar junto con una planilla; en primera instancia los consumidores debían indicar su preferencia entre las muestras, ordenándolas según el grado de preferencia evaluando el aspecto visual de los frutos. En segundo lugar se indagó sobre la razón de su elección. En la Figura III.1 se muestra la planilla de evaluación presentada a los evaluadores.

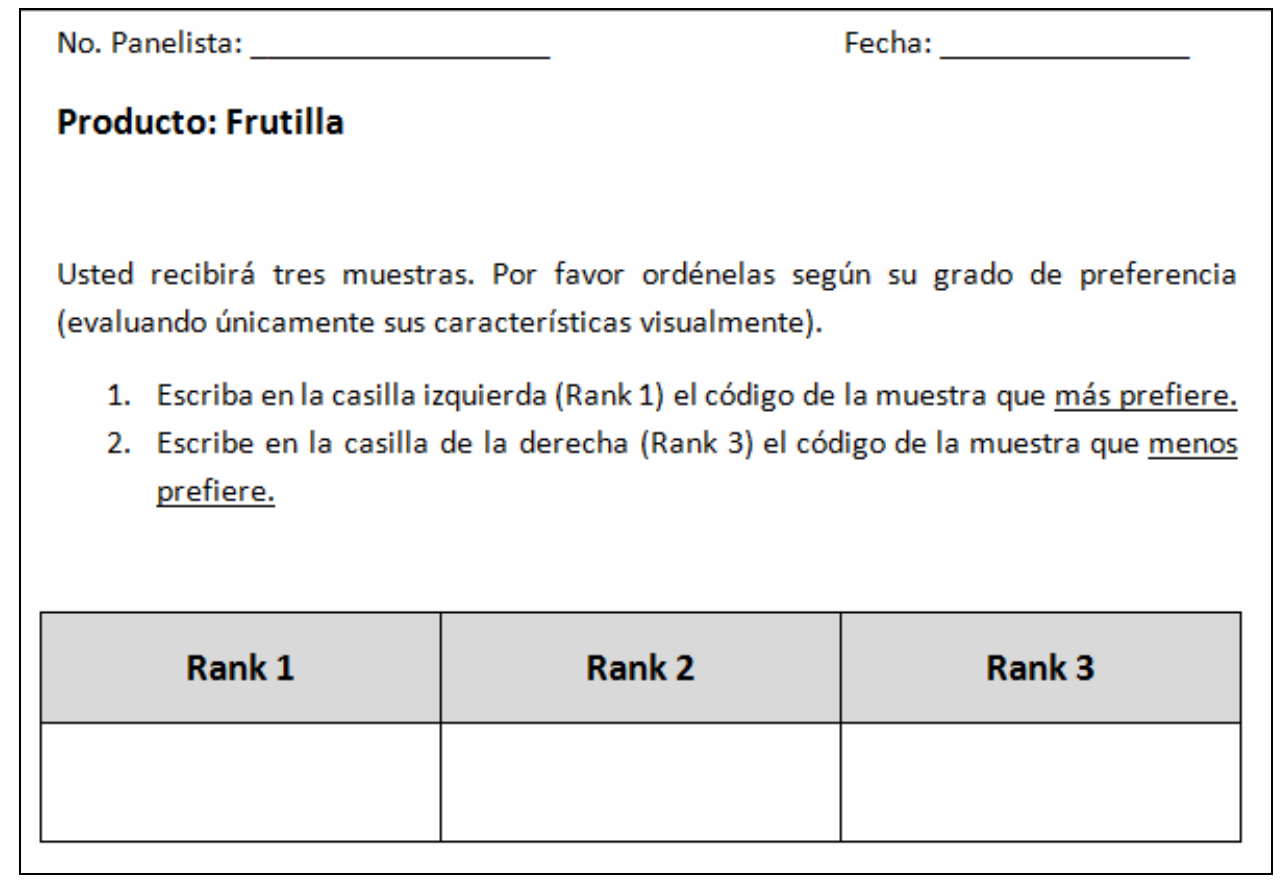

Figura Ill.1: Planilla de evaluación sensorial presentada al panel de consumidores no entrenados. 
Para el análisis de los resultados sensoriales se consideraron 3, 2 ó 1 puntos para cada grupo de frutos evaluados en la primera, segunda y tercera posición en términos de preferencia. Posteriormente se graficó el puntaje total acumulado por cada tratamiento.

\section{III.4. Análisis estadístico.}

Los experimentos se diseñaron empleando un diseño factorial, siendo los factores el tratamiento y el tiempo de almacenamiento. Los resultados obtenidos fueron evaluados mediante ANOVA y las medias se compararon mediante un test de comparaciones múltiples (Fisher) a un nivel de significancia de $\mathrm{P} \leq 0,05$ utilizando el software SYSTAT. 


\section{RESULTADOS Y DISCUSIÓN}




\section{IV.1. Efecto de tratamientos UV-C de diferente intensidad sobre la calidad y deterioro poscosecha de frutilla.}

\section{IV.1.1. Ataque de hongos.}

En los últimos años se observa una mayor preocupación por la utilización de agroquímicos en frutas y hortalizas, por lo cual las legislaciones de varios países han aumentado las exigencias hacia estos productos, al igual que los niveles permitidos de residuos. En tal sentido, se ha incrementado el interés en la búsqueda de metodologías alternativas para la desinfección que no dejen residuos en los productos.

El uso de la irradiación con bajas dosis de luz UV se ha sugerido como tratamiento poscosecha de frutos para mantener la calidad y controlar la incidencia y severidad de microorganismos alterantes (Civello et al., 2006). Baka, et al., (1999), informaron una disminución del ataque fúngico en frutillas tratadas con UV-C (dosis de 0,25 y 1,0 kJ $\mathrm{m}^{-2}$ ). Los autores sugirieron que la dosis total recibida tiene influencia sobre el grado de respuesta logrado. Por su parte, en el estudio realizado por Vicente (2004), se encontró que los tratamientos UV permiten disminuir el deterioro poscosecha en boysenberry, fruto para el cual los tratamientos húmedos de desinfección resultan inconvenientes. En arándanos se han utilizado con éxito tratamientos con radiación UV (1-4 $\mathrm{kJ} \mathrm{m}^{-2}$ ) para reducir las pérdidas poscosecha (Perkins-Veazie et al., 2008). En estos estudios, como en la mayor parte de los trabajos que analizaron el efecto de la radiación UV-C sobre la calidad de frutos, se evaluaron diferentes dosis de radiación total pero se mantuvo constante la fluencia o intensidad de radiación (radiación recibida por unidad de área y por unidad de tiempo). Dada la poca información existente se decidió realizar el presente estudio para clarificar el rol de la intensidad de 
radiación en la eficacia de los tratamientos UV-C en frutos. Para tal fin se mantuvo constante la dosis total de radiación UV-C en $4 \mathrm{~kJ} \mathrm{~m}^{-2}$, ya que había mostrado efectos beneficiosos en frutilla y tomate en estudios previos (Maharaj et al.; 1999, Pan et al., 2004), y se analizaron dos condiciones de intensidad diferentes (3 y $33 \mathrm{~W} \mathrm{~m}^{-2}$ ). En la Figura IV.1 se observa que las frutillas irradiadas para cualquiera de las intensidades estudiadas presentaron mejor apariencia que los controles luego de 5 días de almacenamiento. De todos modos, se visualiza que, tanto desde el punto de vista de la incidencia de hongos como del progreso de la maduración, existen claras diferencias dentro de los frutos tratados para las dos intensidades de radiación ensayadas. Los mejores resultados se obtuvieron en los frutos irradiados con $33 \mathrm{~W} \mathrm{~m}^{-2}$ que mostraron una menor incidencia de podredumbres y mantuvieron el brillo superficial. La evolución del tono de color fue también retrasada en los frutos tratados con una intensidad de 33 $\mathrm{W} \mathrm{m}^{-2}$. Asimismo, los frutos tratados con la mayor intensidad de radiación no presentaron exudado de jugo y mostraron un menor marchitamiento del cáliz.

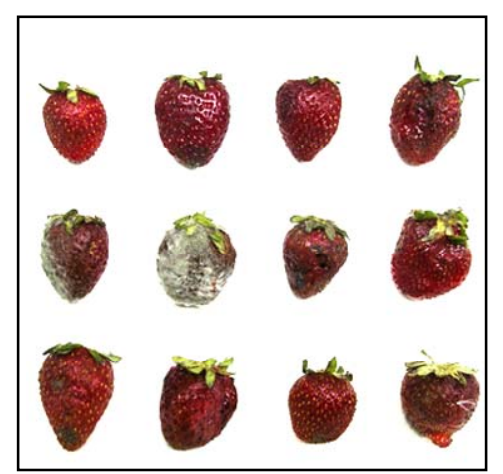

Control

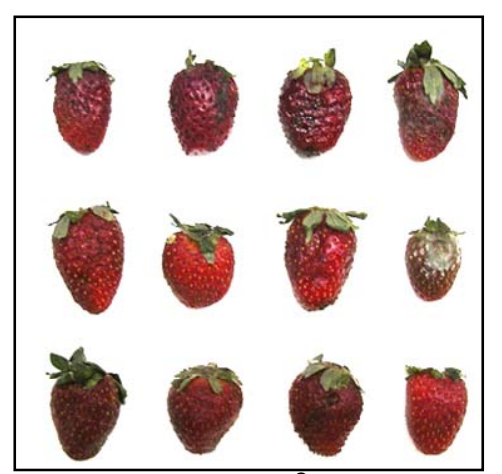

$3 \mathrm{~W} \mathrm{~m}^{-2}$

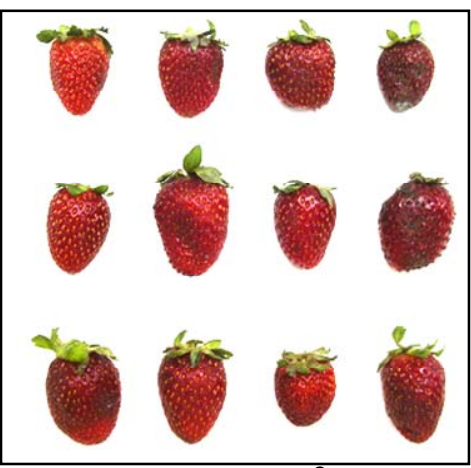

$33 \mathrm{~W} \mathrm{~m}^{-2}$

Figura IV.1: Apariencia de frutillas control y tratadas con una dosis de $4 \mathrm{~kJ} \mathrm{~m}^{-2}$ de radiación UV-C, bajo dos intensidades diferentes (3 ó $33 \mathrm{~W} \mathrm{~m}^{-2}$ ) y almacenadas a 10 ${ }^{\circ} \mathrm{C}$ por 3 o $5 \mathrm{~d}$. 
En la Figura IV.2 se observa que las frutillas control presentaron un mayor desarrollo de hongos que las tratadas durante todo el período de almacenamiento. Aquí se visualiza claramente que las diferencias de eficacia entre las dos intensidades de radiación ensayadas fueron muy marcadas. Luego de 5 d sólo un $12 \%$ de frutos irradiados con la mayor intensidad $\left(33 \mathrm{~W} \mathrm{~m}^{-2}\right.$ ) mostraron ataque fúngico, en comparación con niveles de $46 \%$ para los frutos tratados con una intensidad de $3 \mathrm{~W} \mathrm{~m}^{-}$ ${ }^{2}$ y de $68 \%$ en las frutillas no irradiadas. Stevens et al. (1996) hallaron que la aplicación de tratamientos UV-C $\left(0,75-4 \mathrm{~kJ} \mathrm{~m}^{-2}\right)$ en manzanas inoculadas con Colletotrichum gloeosporioides (microorganismo responsable de la antracnosis) disminuyó en forma significativa la tasa de infecciones, el tamaño de las lesiones desarrolladas y la esporulación del hongo. El control de enfermedades de poscosecha como consecuencia del tratamiento de frutos con radiación UV-C se ha asociado por un lado con un efecto directo de la radiación sobre los microorganismos deteriorantes y por otra parte con la activación de respuestas defensivas cuando los frutos son sometidos ante condiciones moderadas de estrés (Shama y Alderson, 2005). En frutilla, Pan et al., (2004) mostraron que los tratamientos UV-C con dosis similares a las ensayadas en el presente estudio y con una intensidad intermedia retrasan la germinación de conidios de Botrytis y Rhizopus. Marquenie et al., (2002) informaron que el logaritmo del número de conidios viables de Botrytis cinerea y Monilia fruticola disminuye en forma lineal con la dosis de UV-C aplicada. Por otra parte, se ha comprobado en diferentes sistemas la inducción de respuestas activas de defensa en productos tratados con UV (Ben-Yehoshua et al., 1992; Mercier et al., 1993a y 1993b; Cantos et al., 2002). El refuerzo de las paredes celulares por entrecruzamiento de componentes de naturaleza fenólica, lignificación y suberización en respuesta a la exposición a la radiación UV ha sido descrito por Charles et al., (2009). Pombo et al., (2010) también hallaron que el tratamiento de frutillas con radiación UV-C puede incrementar la 
transcripción de genes y la actividad de enzimas involucradas en la defensa contra patógenos en frutilla. Entre las 10 y 48 horas posteriores a la irradiación UV-C los frutos tratados mostraron un incremento en la actividad polifenoloxidasa. La activación por tratamientos UV-C de genes codificantes para $\beta-1,3$-glucanasa y quitinasa ha sido descrita también en otros frutos (El Ghaouth et al., 2003).

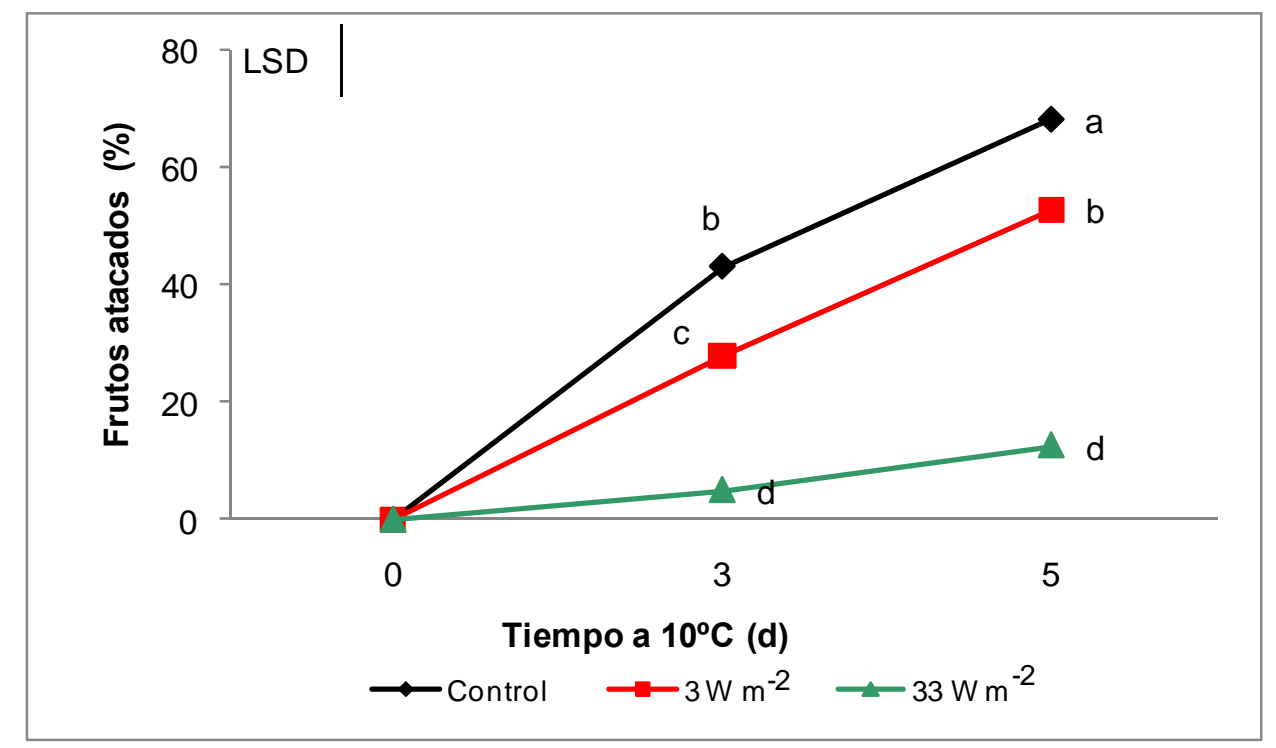

Figura IV.2: Ataque de hongos en frutillas control y tratadas con una dosis de $4 \mathrm{~kJ} \mathrm{~m}^{-2}$ de radiación UV-C bajo 2 intensidades diferentes (3 ó $33 \mathrm{~W} \mathrm{~m}^{-2}$ ) y almacenadas a 10 ${ }^{\circ} \mathrm{C}$ por 3 o $5 \mathrm{~d}$. Las letras distintas indican diferencias significativas en un test de Fisher con un nivel de significancia de $P \leq 0,05$.

Los resultados de este trabajo muestran que, más allá de la dosis, la intensidad de radiación juega un rol muy importante en la eficacia de los tratamientos UV-C en el control de hongos, uno de los principales problemas de poscosecha de frutilla. Si bien la intensidad podría estar afectando tanto a los mecanismos directos como indirectos involucrados en el control de los patógenos, es necesario realizar estudios más extensivos. Schreiner et al., (2009) sugirieron que la intensidad de radiación recibida tiene influencia en la acumulación de compuestos fenólicos, varios de los cuales 
poseen capacidad antimicrobiana. Resultaría de interés la realización de futuros estudios para caracterizar con más detalle estos efectos en la respuesta a la irradiación UV-C de diferente intensidad en frutos.

\section{IV.1.2. Pérdida de peso.}

La pérdida de peso de los frutos se incrementó durante el almacenamiento, alcanzando valores entre 7,5 y 10\% al final del mismo (Figura IV.3). Luego de 3 d a 10 ${ }^{\circ} \mathrm{C}$ se detectó la misma pérdida de peso en los grupos control y tratado con una intensidad de $3 \mathrm{~W} \mathrm{~m}^{-2}$, pero los frutos tratados con la mayor intensidad (33 $\mathrm{W} \mathrm{m}^{-2}$ ) registraron una menor pérdida de peso. La misma tendencia se mantuvo al finalizar el período de almacenamiento entre frutos control y tratados con la mayor intensidad de radiación, pero no se detectaron en este caso diferencias significativas entre las frutillas expuestas a las dos intensidades de radiación UV-C. La menor pérdida de peso de los frutos tratados podría asociarse con un menor deterioro de los mismos como consecuencia de los tratamientos y con una mayor integridad de las barreras a la deshidratación (Charles et al., 2009). 


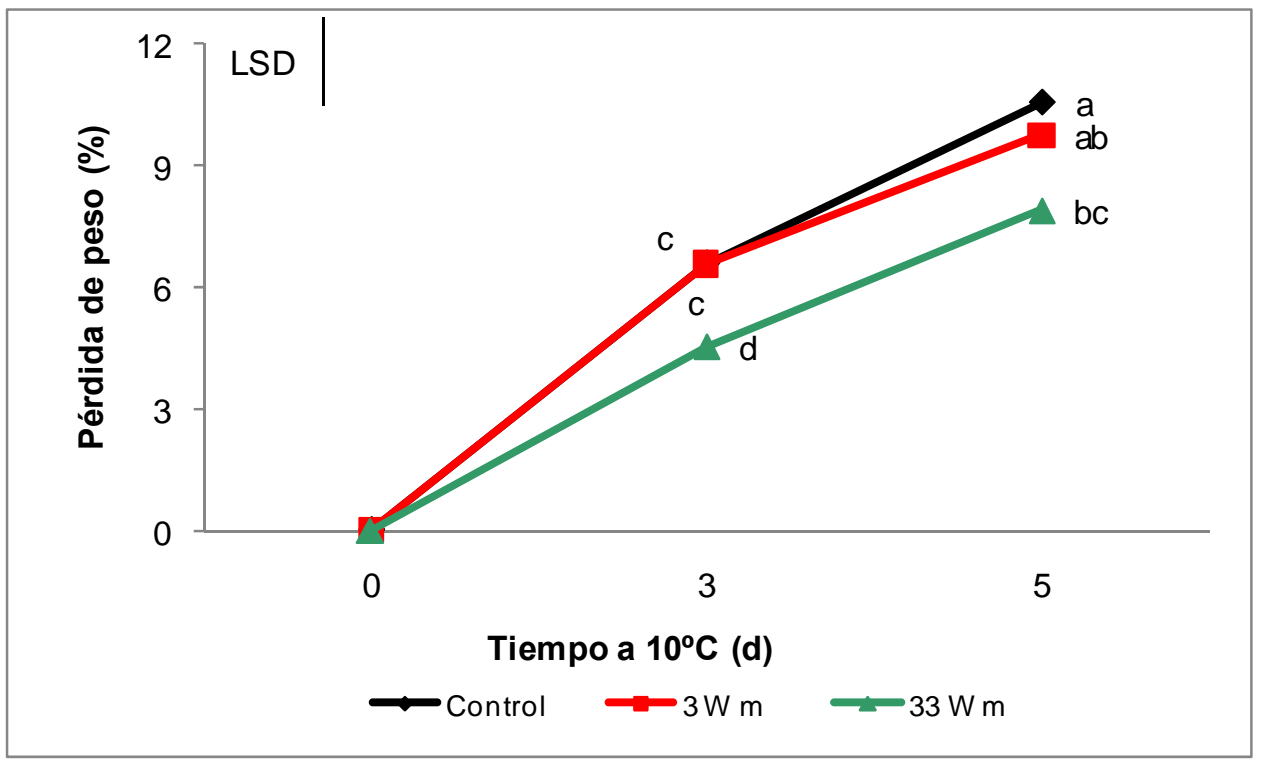

Figura IV.3: Pérdida de peso en frutillas control y tratadas con una dosis de $4 \mathrm{~kJ} \mathrm{~m}^{-2}$ de radiación UV-C, bajo dos intensidades diferentes (3 ó $33 \mathrm{~W} \mathrm{~m}^{-2}$ ) y almacenadas a $10^{\circ} \mathrm{C}$ por 3 o $5 \mathrm{~d}$. Las letras distintas indican diferencias significativas en un test de Fisher con un nivel de significancia de $P \leq 0,05$.

\section{IV.1.3. Color superficial y antocianinas.}

A fin de evaluar la alteración del color superficial de las frutillas debido al avance de la maduración o bien del deterioro superficial, se analizó la variación en la luminosidad $\left(L^{*}\right)$, el tono (hue) y la saturación del color (croma) durante el almacenamiento. La luminosidad $\left(L^{*}\right)$ de los frutos disminuyó durante el almacenamiento (Figura IV.4). Este efecto fue previamente descrito durante la maduración de frutilla (Vicente et al., 2002). Los tratamientos UV-C retrasaron la pérdida de luminosidad de los frutos siendo este efecto similar para las dos intensidades de radiación UV-C. 


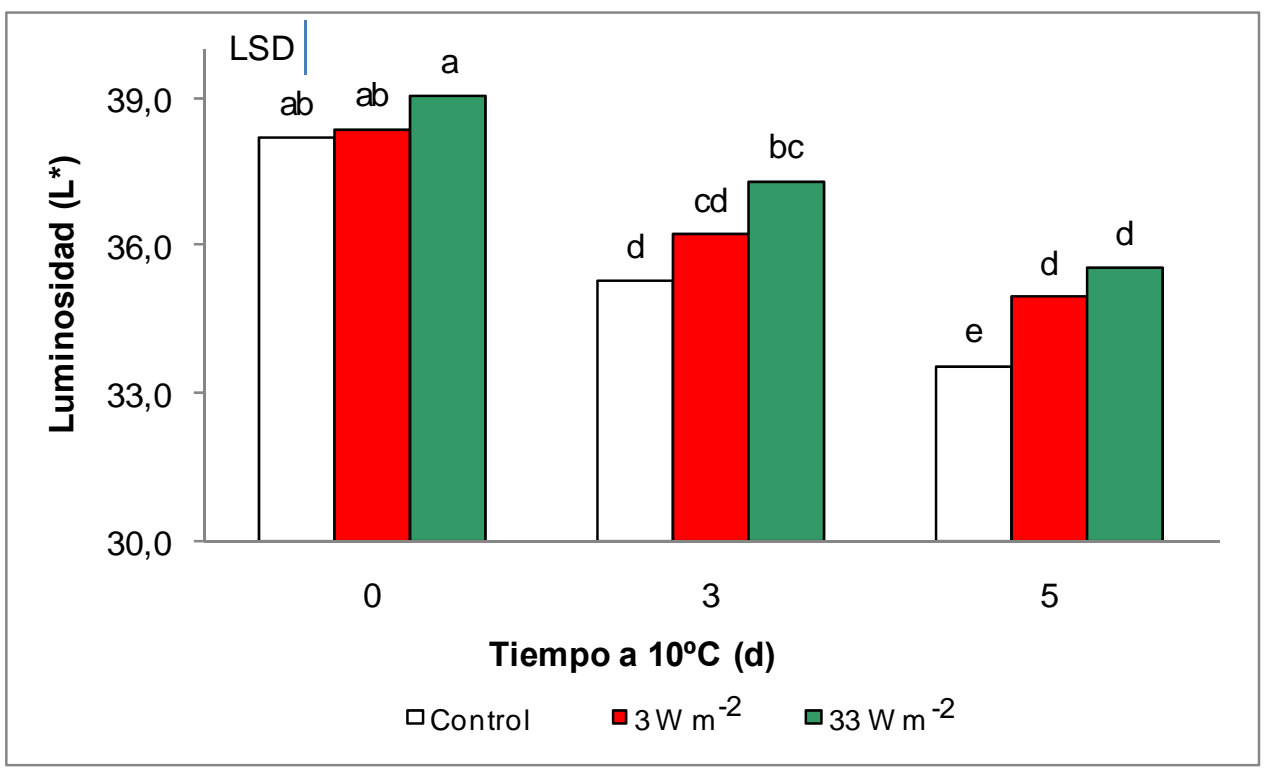

Figura IV.4: Luminosidad ( $\left.L^{*}\right)$ en frutillas control y tratadas con una dosis de $4 \mathrm{~kJ} \mathrm{~m}^{-2}$ de radiación UV-C, bajo dos intensidades diferentes (3 ó $33 \mathrm{~W} \mathrm{~m}^{-2}$ ) y almacenadas a $10{ }^{\circ} \mathrm{C}$ por 3 o $5 \mathrm{~d}$. Las letras distintas indican diferencias significativas en un test de Fisher con un nivel de significancia de $P \leq 0,05$.

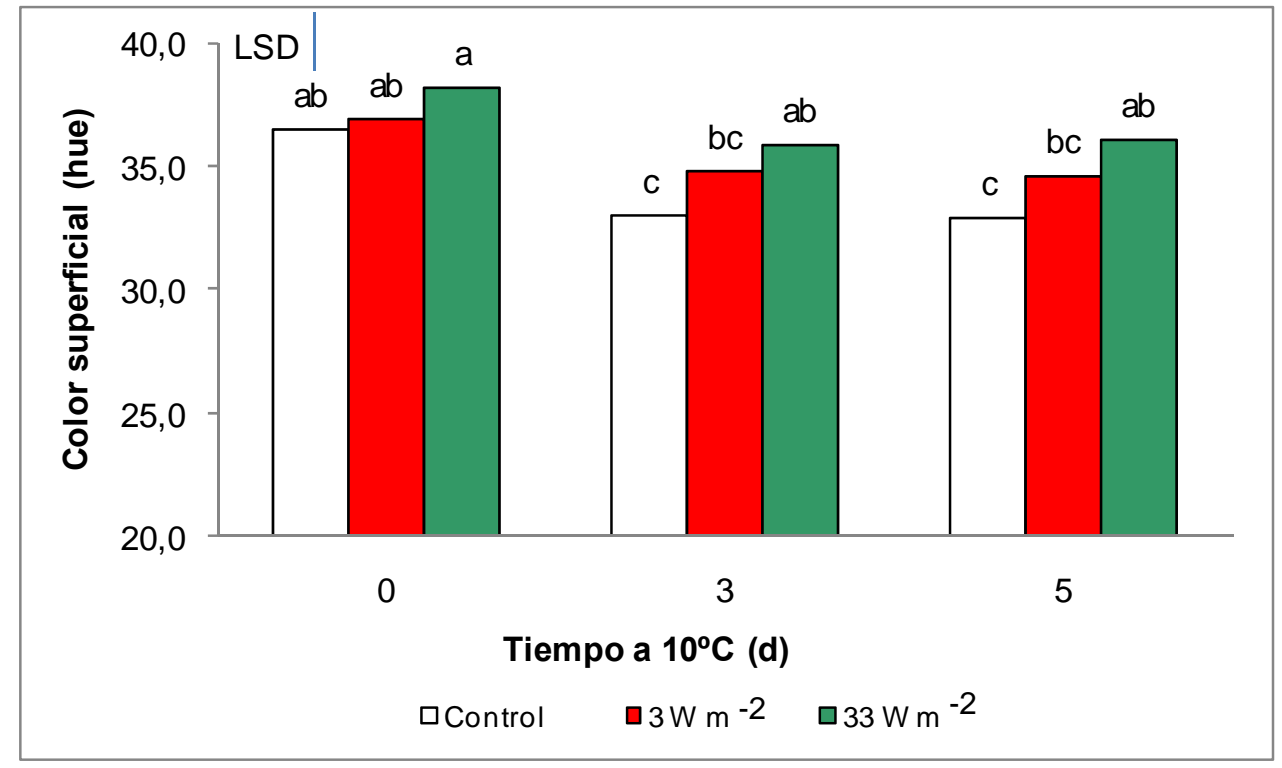

Figura IV.5: Tono de color superficial (hue) en frutillas control y tratadas con una dosis de $4 \mathrm{~kJ} \mathrm{~m}^{-2}$ de radiación UV-C, bajo dos intensidades diferentes (3 ó $33 \mathrm{~W} \mathrm{~m}^{-2}$ ) y almacenadas a $10^{\circ} \mathrm{C}$ por 3 o $5 \mathrm{~d}$. Las letras distintas indican diferencias significativas en un test de Fisher con un nivel de significancia de $P \leq 0,05$. 
Inmediatamente luego del tratamiento no se detectaron cambios en el valor de hue en los frutos tratados. Este parámetro disminuyó durante el almacenamiento, indicando un progreso del desarrollo del color superficial rojo (Figura IV.5). Luego de 3 $\mathrm{d}$ de almacenamiento los frutos irradiados con la intensidad de $33 \mathrm{~W} \mathrm{~m}^{-2}$ mostraron mayores valores de hue que los controles y tratados con la menor intensidad de UV-C. Las diferencias se mantuvieron aún luego de $5 \mathrm{~d}$ a $10^{\circ} \mathrm{C}$. El croma se redujo durante el almacenamiento en todos los frutos, pero el descenso ocurrió en forma más lenta en los frutos irradiados con la intensidad más elevada (Figura IV.6). Finalmente, la menor variación de los parámetros de color de los frutos se correlaciona con una reducción en la acumulación de pigmentos antociánicos en los frutos tratados. Luego de 3 d, el contenido de antocianinas fue menor que en los controles para ambas intensidades de radiación (Figura IV.7). Posteriormente dicho contenido aumentó más rápidamente en los frutos tratados con la intensidad de $3 \mathrm{~W} \mathrm{~m}^{-2}$, no mostrando diferencias con el control a los $5 \mathrm{~d}$ de almacenamiento. Contrariamente, las frutillas irradiadas con elevada intensidad presentaron un contenido de antocianinas $25 \%$ menor que los controles aún luego de $5 \mathrm{~d}$ de almacenamiento. En trabajos previos en frutillas irradiadas con UV-C con una dosis similar a la utilizada se encontró un retraso en la acumulación de antocianinas (Pan et al., 2004). Asimismo, algunos estudios han descrito una reducción en la actividad fenilalanina amonio-liasa (PAL) (enzima que interviene en la síntesis de antocianinas) en frutos tratados con UV-C (Nigro, et al., 2000). En este trabajo se observa claramente que la intensidad de radiación, más allá de la dosis, es un factor importante en la determinación de los niveles finales de antocianinas. 


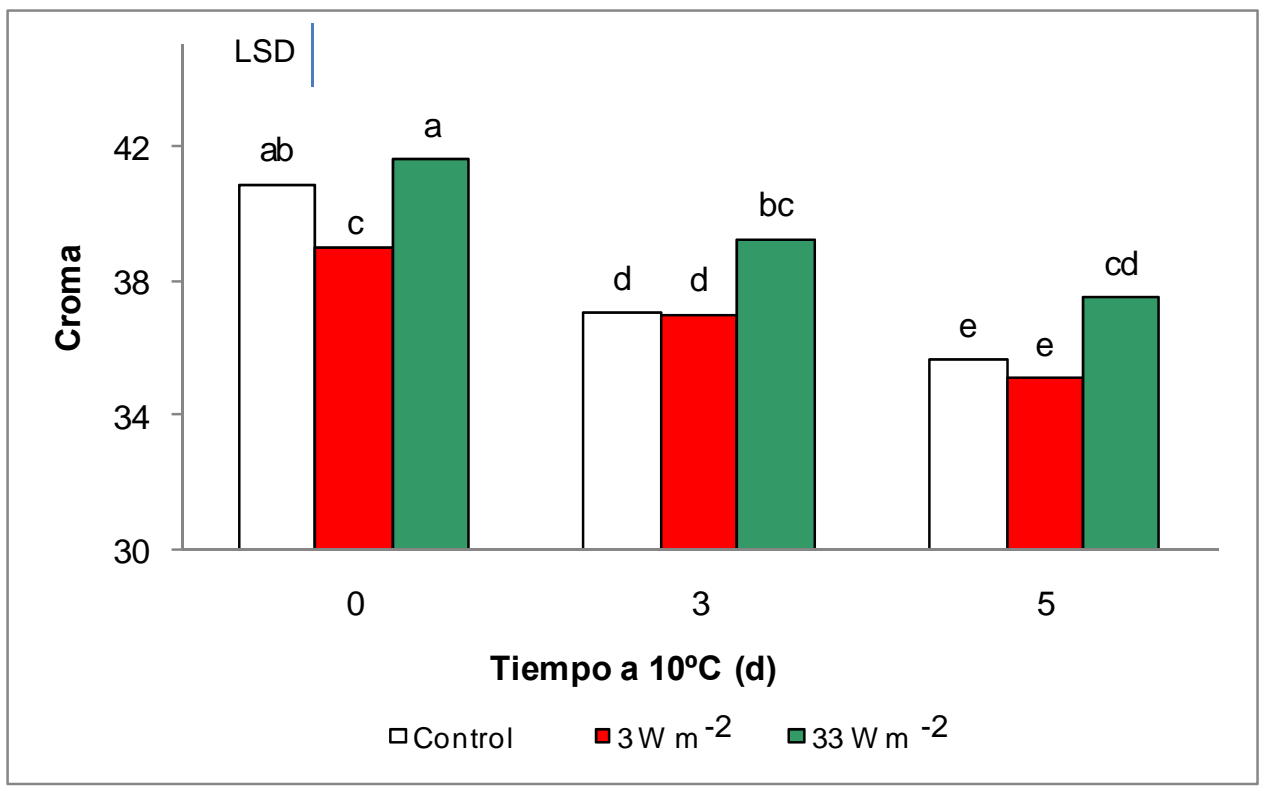

Figura IV.6: Saturación del color superficial (croma) en frutillas control y tratadas con una dosis de $4 \mathrm{~kJ} \mathrm{~m}^{-2}$ de radiación UV-C, bajo dos intensidades diferentes (3 ó $33 \mathrm{~W}$ $\mathrm{m}^{-2}$ ) y almacenadas a $10^{\circ} \mathrm{C}$ por 3 o $5 \mathrm{~d}$. Las letras distintas indican diferencias significativas en un test de Fisher con un nivel de significancia de $P \leq 0,05$.

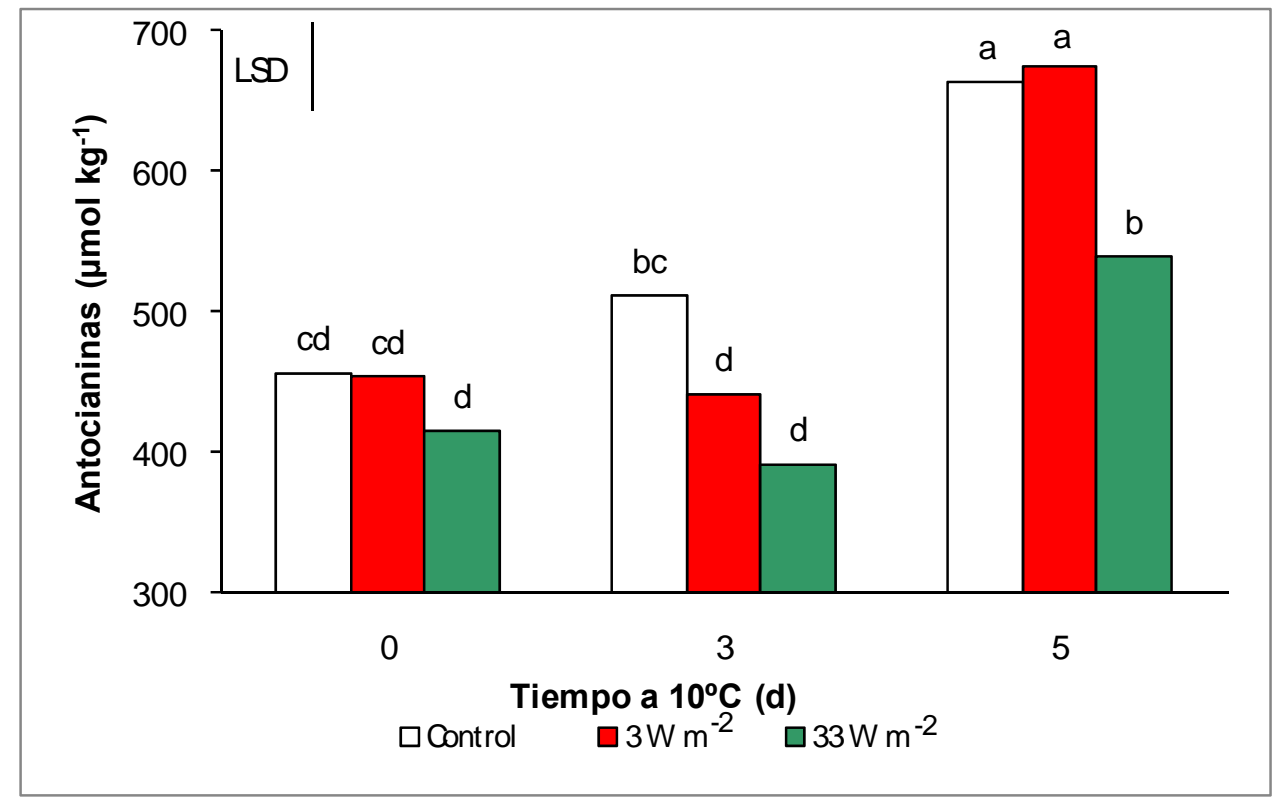

Figura IV.7: Antocianinas en frutillas control y tratadas con una dosis de $4 \mathrm{~kJ} \mathrm{~m}^{-2}$ de radiación UV-C, bajo dos intensidades diferentes (3 ó $33 \mathrm{~W} \mathrm{~m}^{-2}$ ) y almacenadas a 10 ${ }^{\circ} \mathrm{C}$ por 3 o $5 \mathrm{~d}$. Las letras distintas indican diferencias significativas en un test de Fisher con un nivel de significancia de $P \leq 0,05$. 


\section{IV.1.4. Firmeza.}

El avance de la maduración o del deterioro van acompañados, en general, de un ablandamiento progresivo. La firmeza disminuyó después un período de almacenamiento de $3 \mathrm{~d}$ a $10^{\circ} \mathrm{C}$ en los frutos control o irradiados con baja intensidad de radiación UV-C respecto al valor inicial, mientras que se mantuvo sin variaciones en los frutos tratados con $33 \mathrm{~W} \mathrm{~m}^{-2}$ (Figura IV.8). Luego de $5 \mathrm{~d}$ estos frutos se mantuvieron aún más firmes que los frutos control. Al final del almacenamiento los valores de resistencia a la penetración fueron de $0,57 \mathrm{~N} \mathrm{~mm}^{-1}$ para las frutillas control, mientras que en los frutos tratados con una intensidad de $3 \mathrm{~W} \mathrm{~m}^{-2}$ y $33 \mathrm{~W} \mathrm{~m}^{-2}$ se registraron valores de 0,65 y $0,72 \mathrm{~N} \mathrm{~mm}^{-1}$ respectivamente. La pérdida de firmeza fue retrasada en tomate (Maharaj et al., 1999), frutilla (Pan et al., 2004) y pimiento (Vicente et al., 2005) luego de la irradiación UV-C con dosis de 3,6; 4,1 y $7 \mathrm{~kJ} \mathrm{~m}^{-2}$ aunque no se informó la intensidad de radiación utilizada. El retraso del ablandamiento ha sido asociado a alteraciones en la actividad de enzimas de degradación de pared celular (Civello et al., 2006). El presente estudio muestra que la intensidad de radiación utilizada también posee una influencia significativa en el retraso del ablandamiento ocasionado por los tratamientos UV-C. Esto podría relacionarse con modificaciones en la actividad de enzimas de pared como se ha mostrado en frutos tratados con distintas dosis (Barka et al., 2000) y requeriría de mayores estudios. 


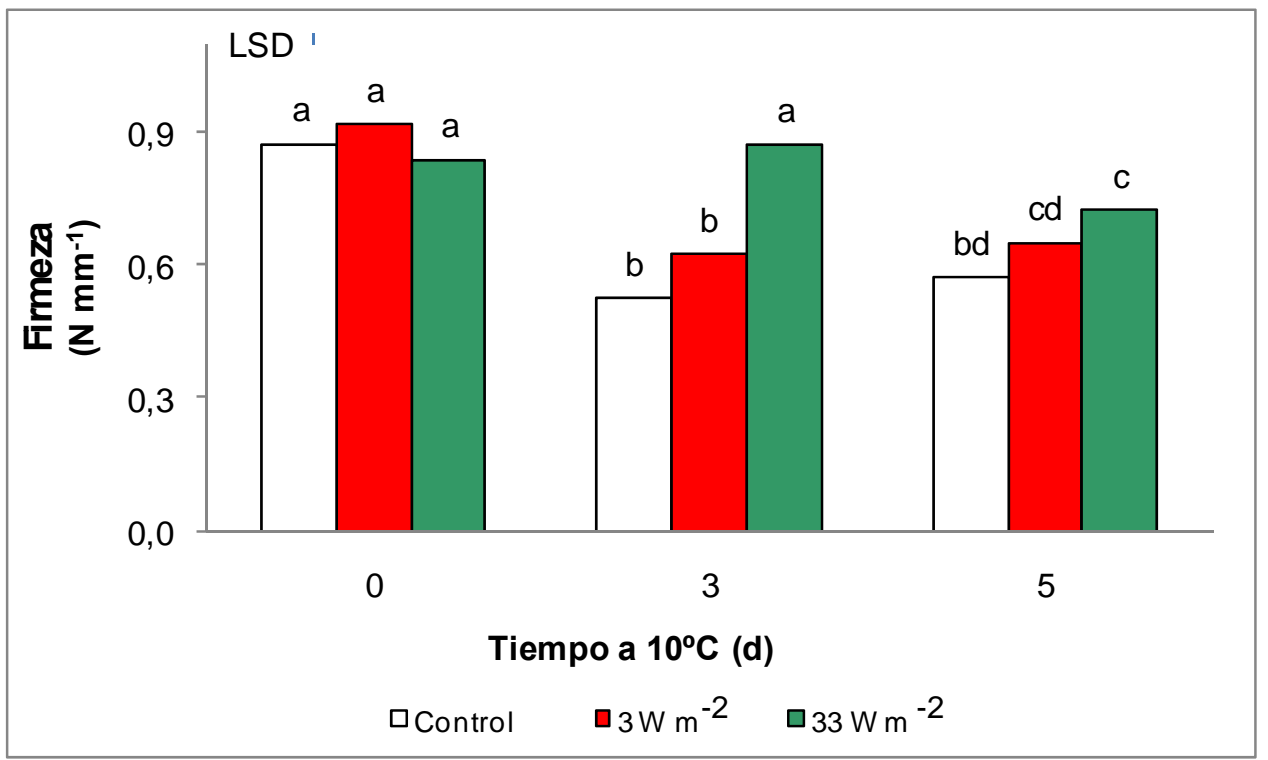

Figura IV.8: Firmeza en frutillas control y tratadas con una dosis de $4 \mathrm{~kJ} \mathrm{~m}^{-2}$ de radiación UV-C, bajo dos intensidades diferentes (3 ó $33 \mathrm{~W} \mathrm{~m}^{-2}$ ) y almacenadas a 10 ${ }^{\circ} \mathrm{C}$ por 3 o $5 \mathrm{~d}$. Las letras distintas indican diferencias significativas en un test de Fisher con un nivel de significancia de $P \leq 0,05$.

\section{IV.1.5. Sólidos solubles, acidez y capacidad antioxidante.}

El contenido de sólidos solubles se mantuvo constante durante el almacenamiento tanto para frutos control como tratados (Figura IV.9). Por su parte la acidez no mostró grandes variaciones durante los 3 primeros días a $10{ }^{\circ} \mathrm{C}$ y se incrementó probablemente como consecuencia del daño de los frutos hacia el final del almacenamiento. Este incremento fue inferior en los frutos tratados con UV-C para las dos intensidades evaluadas (Figura IV.10). 


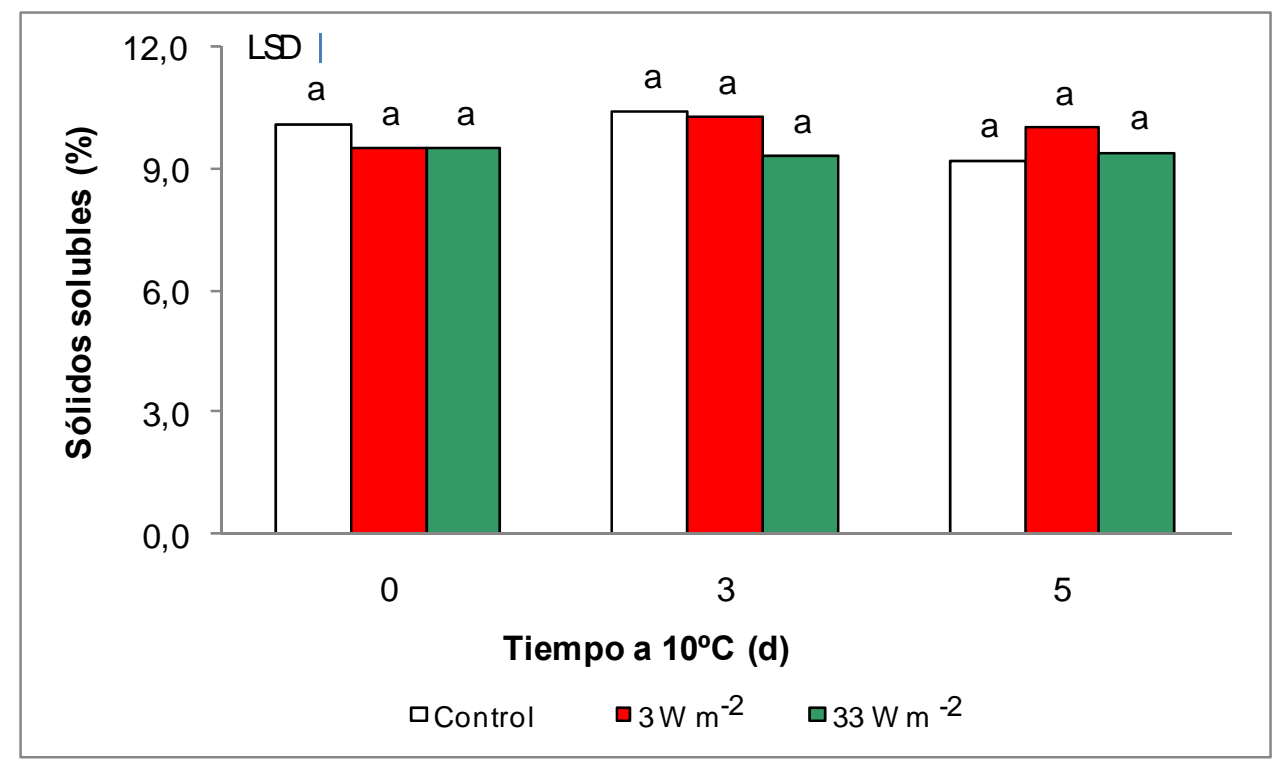

Figura IV.9: Sólidos solubles en frutillas control y tratadas con una dosis de $4 \mathrm{~kJ} \mathrm{~m}^{-2}$ de radiación UV-C bajo dos intensidades diferentes (3 ó $33 \mathrm{~W} \mathrm{~m}^{-2}$ ) y almacenadas a 10 ${ }^{\circ} \mathrm{C}$ por 3 o $5 \mathrm{~d}$. Las letras distintas indican diferencias significativas en un test de Fisher con un nivel de significancia de $P \leq 0,05$.

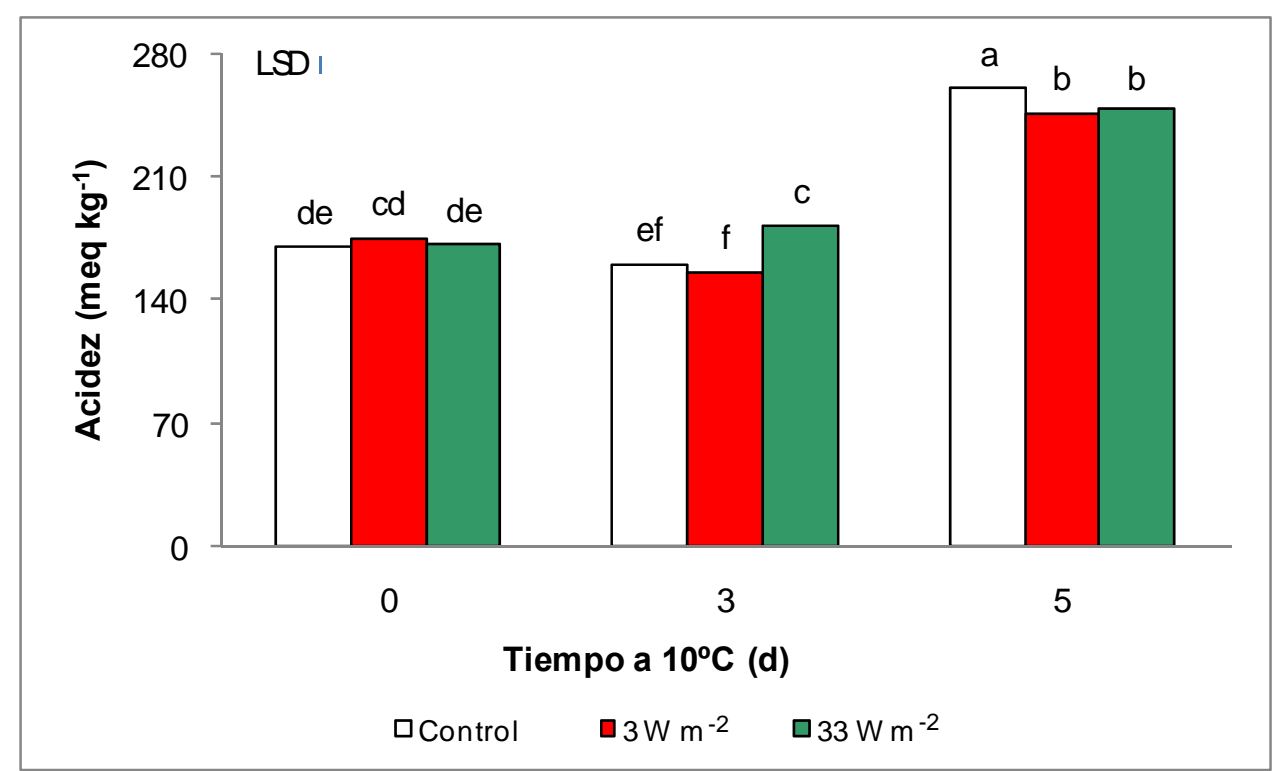

Figura IV.10: Acidez en frutillas control y tratadas con una dosis de $4 \mathrm{~kJ} \mathrm{~m}^{-2}$ de radiación UV-C, bajo dos intensidades diferentes (3 ó $33 \mathrm{~W} \mathrm{~m}^{-2}$ ) y almacenadas a 10 ${ }^{\circ} \mathrm{C}$ por 3 o $5 \mathrm{~d}$. Las letras distintas indican diferencias significativas en un test de Fisher con un nivel de significancia de $P \leq 0,05$. 
Finalmente, la capacidad antioxidante de naturaleza hidrofílica no mostró cambios significativos entre tratamientos o durante el almacenamiento (Figura IV.11). Esto es coincidente con estudios previos que mostraron que estos componentes en frutilla fueron poco afectados por tratamientos con UV-C (Pan et al., 2004; Vicente 2004). En síntesis, los resultados sugieren que los tratamientos UV-C no alteran en forma negativa a los atributos asociados con el sabor y valor nutricional.

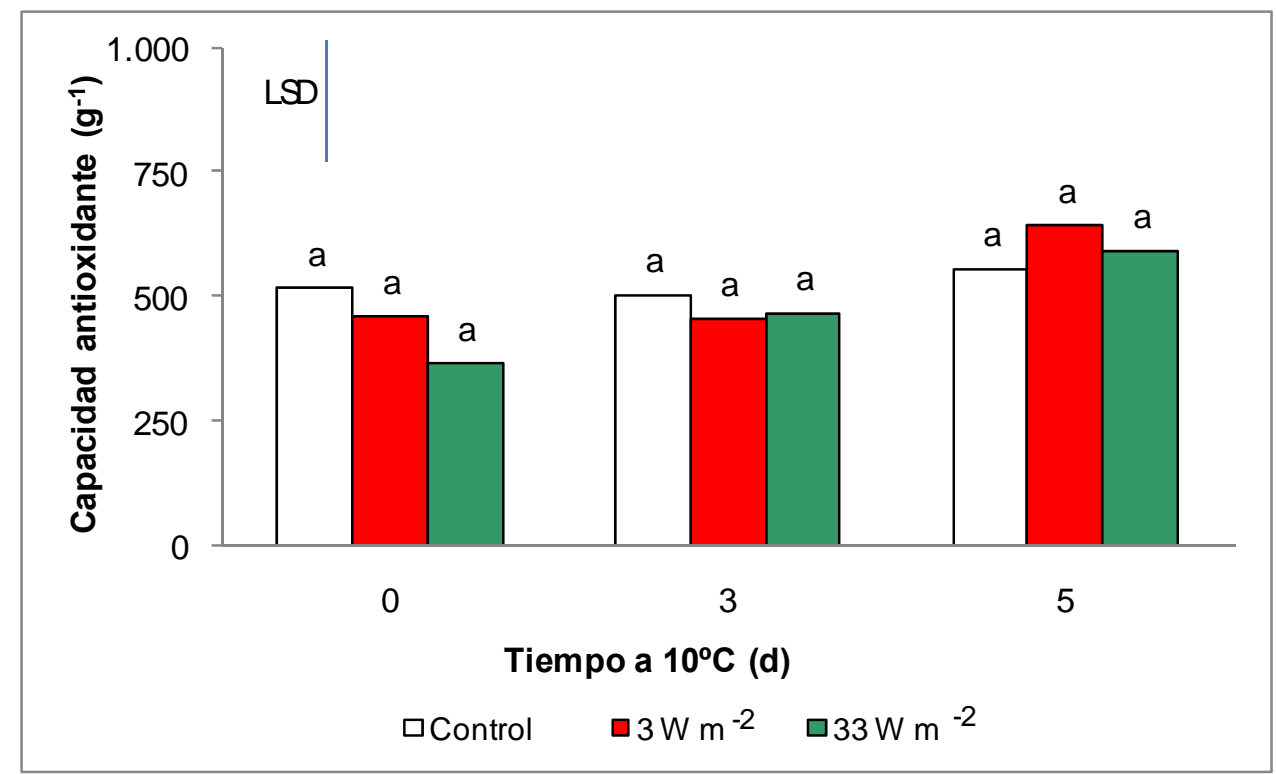

Figura IV.11: Capacidad antioxidante en frutillas control y tratadas con una dosis de 4

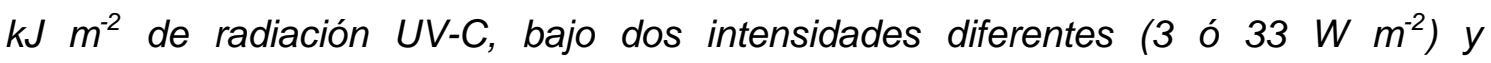
almacenadas a $10^{\circ} \mathrm{C}$ por 3 o $5 \mathrm{~d}$. Las letras distintas indican diferencias significativas en un test de Fisher con un nivel de significancia de $P \leq 0,05$.

\section{IV.1.6. Actividad respiratoria.}

La actividad respiratoria aumentó durante el almacenamiento tanto en frutos control como tratados. El aumento observado en la tasa respiratoria podría interpretarse como una consecuencia del daño que exacerba el metabolismo (Kader, 2002). Los frutos tratados presentaron una menor actividad respiratoria que los 
controles en el día 5, siendo los valores similares para las dos intensidades de radiación evaluadas (Figura IV.12).

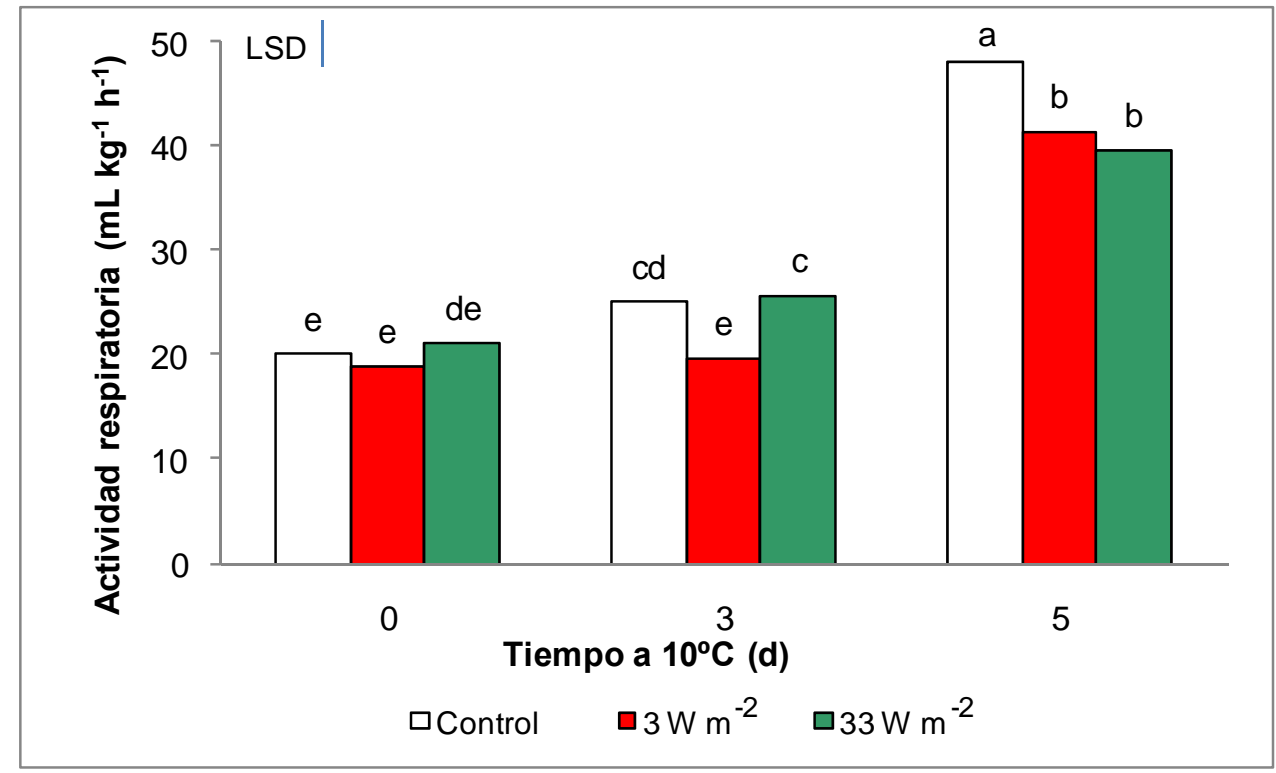

Figura IV.12: Actividad respiratoria en frutillas control y tratadas con una dosis de $4 \mathrm{~kJ}$ $\mathrm{m}^{-2}$ de radiación UV-C bajo dos intensidades diferentes (3 ó $33 \mathrm{~W} \mathrm{~m}^{-2}$ ) y almacenadas a $10^{\circ} \mathrm{C}$ por 3 ó $5 \mathrm{~d}$. Las letras distintas indican diferencias significativas en un test de Fisher con un nivel de significancia de $P \leq 0,05$.

Estos resultados coinciden con los informados por Baka et al., (1999), quienes describieron que frutilla tratadas con UV presentaban una reducción en la velocidad de respiración cuando eran almacenadas.

\section{IV.1.7. Recuentos de bacterias mesófilas y hongos.}

Si bien el efecto germicida de la radiación UV-C es conocido, este depende de la dosis utilizada y de el tipo de microorganismo considerado (Civello et al., 2006). A fin de evaluar este aspecto y analizar los cambios en la dinámica poblacional de hongos y bacterias mesófilas totales, se realizaron recuentos en los frutos control o tratados con 
las dos intensidades de radiación inmediatamente luego de los tratamientos o bien al final del período de almacenamiento. Finalizada la irradiación UV-C no se observaron variaciones en el log de UFC $\mathrm{g}^{-1}$ de bacterias mesófilas frutos control o tratados. Luego de $5 \mathrm{~d}$ de almacenamiento los recuentos fueron significativamente inferiores en los frutos tratados, no observándose diferencias para las dos intensidades de UV-C. (Figura IV.13). Los resultados sugieren que en las condiciones de tratamiento aplicadas no logran ser letales para los microorganismos. El menor recuento de UFC al final del almacenamiento en los frutos tratados podría resultar como consecuencia de un efecto indirecto de los tratamientos (Pombo et al., 2010). Varios estudios han demostrado que la radiación UV-C puede inducir respuestas defensivas en los frutos y esto podría dificultar la multiplicación de los microorganismos. Otra alternativa podría tener que ver con un retraso general en la maduración que permite mantener una mayor integridad de tejidos reduciendo su susceptibilidad. Con respecto al recuento total de hongos, inmediatamente después del tratamiento no se observaron diferencias marcadas entre los frutos control y tratados. Al final del almacenamiento se observó un marcado aumento en los frutos control. Los frutos tratados mostraron en este caso menor número de UFC con un efecto más pronunciado en aquellos sometidos al tratamiento con la mayor intensidad de UV-C (Figura IV.14). 


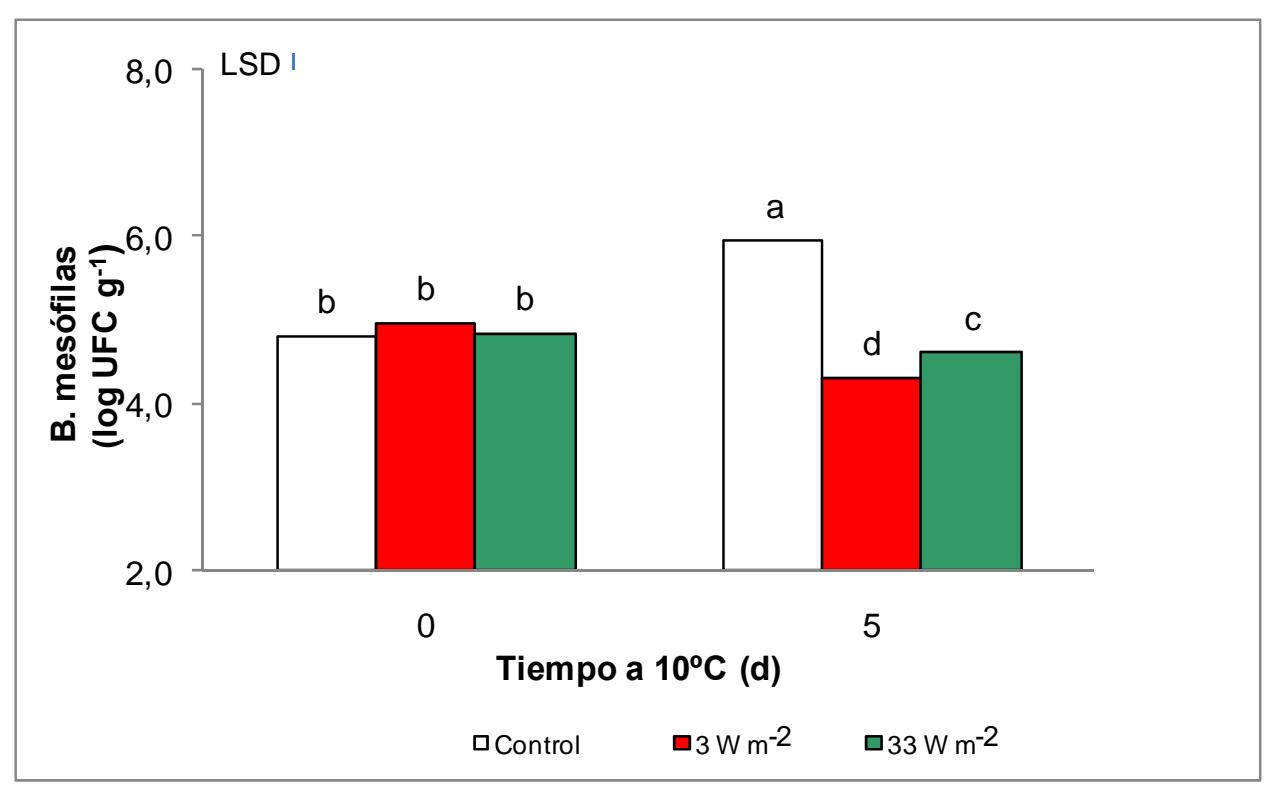

Figura IV.13: Recuento de bacterias mesófilas (log UFC $g^{-1}$ ) en frutillas control $y$ tratadas con una dosis de $4 \mathrm{~kJ} \mathrm{~m}^{-2}$ de radiación UV-C, bajo dos intensidades diferentes (3 ó $33 \mathrm{~W} \mathrm{~m}^{-2}$ ) y almacenadas por 3 ó $5 \mathrm{~d}$. Las letras distintas indican diferencias significativas en un test de Fisher con un nivel de significancia de $P \leq 0,05$.

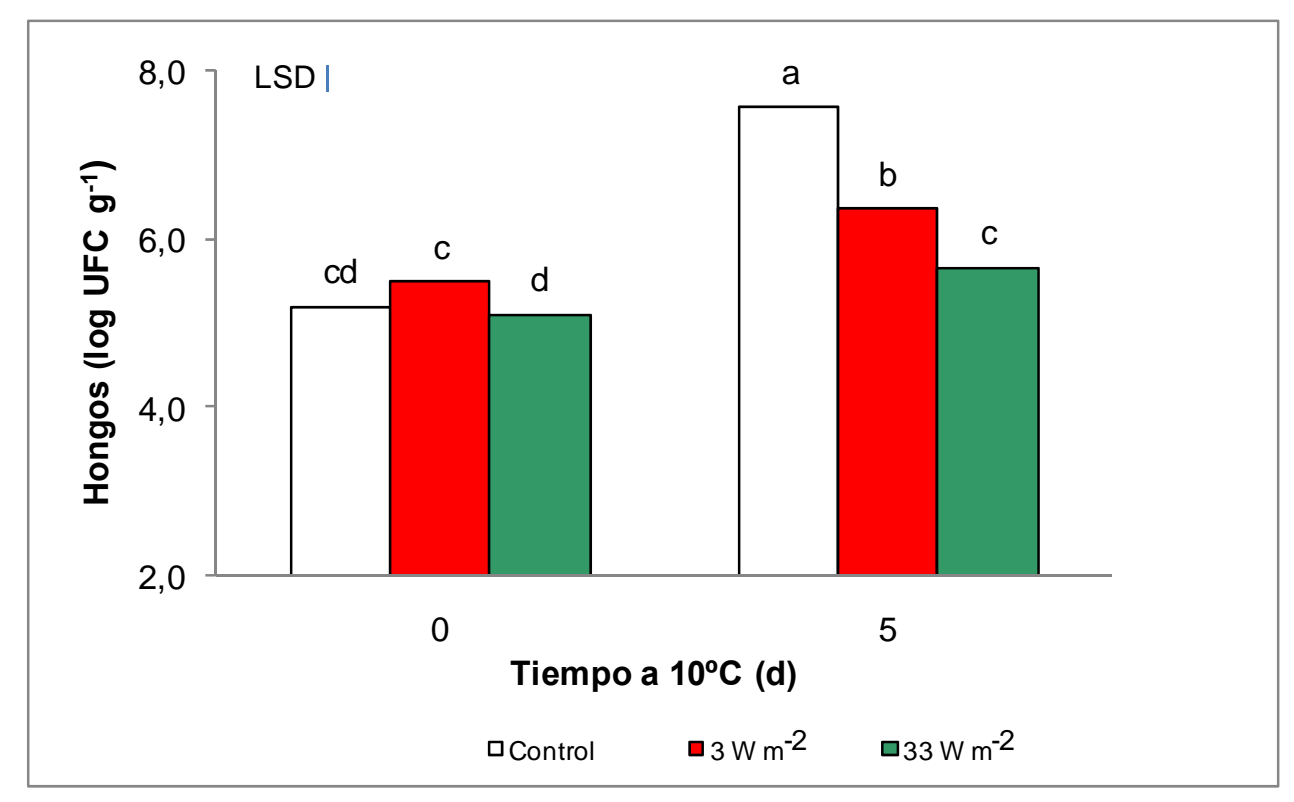

Figura IV.14: Recuento de hongos ( $\log U F C \mathrm{~g}^{-1}$ ) en frutillas control y tratadas con una dosis de $4 \mathrm{~kJ} \mathrm{~m}^{-2}$ de radiación UV-C, bajo dos intensidades diferentes (3 ó $33 \mathrm{~W} \mathrm{~m}^{-2}$ ) y almacenadas por 3 ó $5 \mathrm{~d}$. Las letras distintas indican diferencias significativas en un test de Fisher con un nivel de significancia de $P \leq 0,05$. 


\section{IV.1.8. Análisis sensorial.}

Con el objetivo de determinar la preferencia de consumidores de los frutos provenientes de los diferentes tratamientos estudiados, se diseñó un ensayo de ordenamiento de preferencia. En el mismo se solicitó detallar el principal atributo por el cual preferían las muestras presentadas. La apariencia del fruto fue la principal característica determinante de la preferencia por un grupo de frutos, siendo el color superficial la otra característica valorada para la elección. (Figura IV.15).

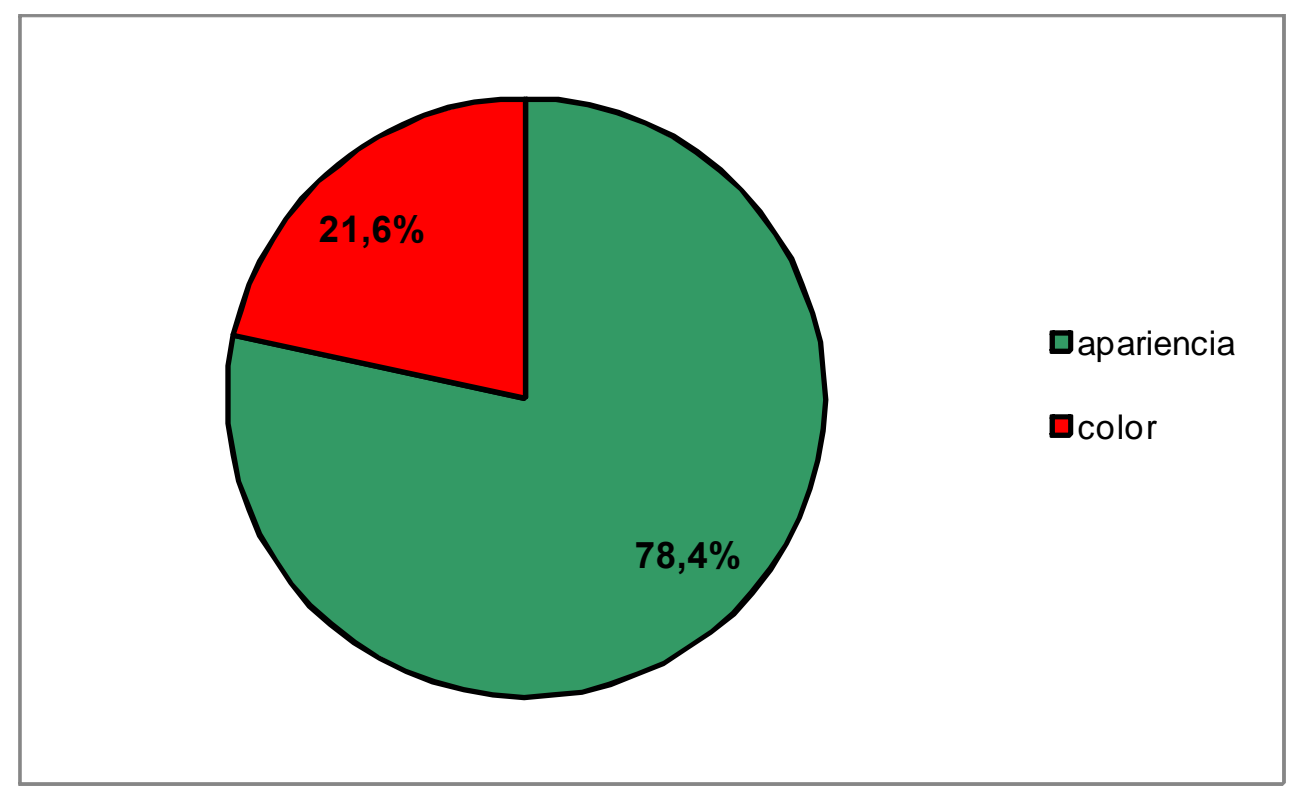

Figura IV.15: Importancia de diferentes atributos en la aceptación de frutillas identificada por el panel de consumidores no entrenados $(n=38)$.

En la Figura IV.16, se observa una preferencia de los consumidores de los frutos tratados con intensidad $33 \mathrm{~W} \mathrm{~m}^{-2}$. Luego se ubica el tratamiento con la menor intensidad de UV-C con un puntaje significativamente inferior mientras que los frutos control fueron ubicados en el último lugar. 
Estos resultados muestran claramente que los tratamientos UV-C pueden resultar valiosos para mantener la apariencia de los frutos y por otra parte confirman junto con los resultados anteriores que la intensidad de radiación utilizada es una variable de suma importancia en la eficacia de los tratamientos.

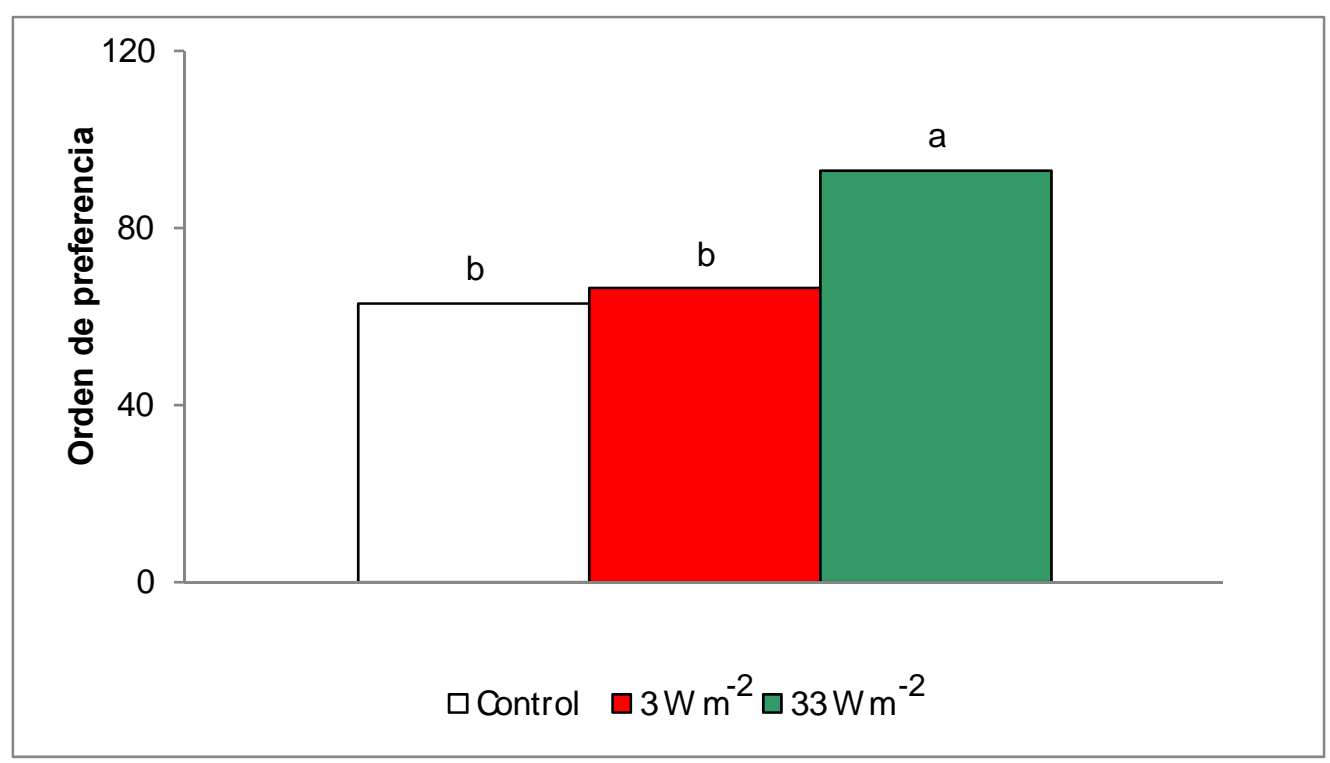

Figura IV.16: Test de ordenamiento por preferencia de frutillas control y tratadas con una dosis de $4 \mathrm{~kJ} \mathrm{~m}^{-2}$ de radiación UV-C, bajo dos intensidades diferentes (3 ó $33 \mathrm{~W}$ $\mathrm{m}^{-2}$ ) y almacenadas a $10^{\circ} \mathrm{C}$ por $3 \mathrm{~d}$, evaluadas por el panel de consumidores no entrenados $(n=38)$. 


\section{IV.2. Efecto de tratamientos UV-C de diferente intensidad sobre}

\section{la calidad y deterioro poscosecha de tomate.}

\section{IV.2.1. Ataque de hongos.}

Los frutos control presentaron un mayor deterioro evidenciado a partir de la incidencia de podredumbres y del arrugamiento de la piel (Figura IV.17).
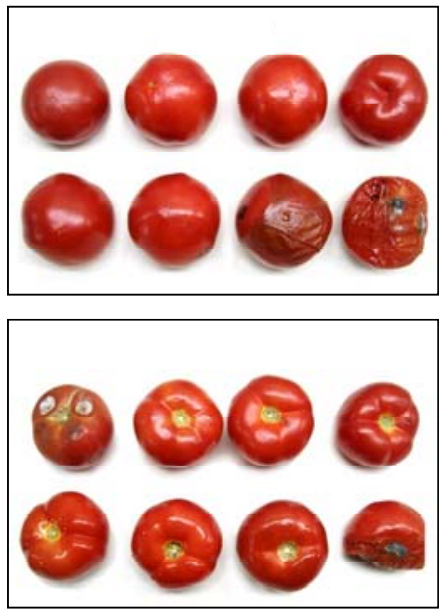

Control
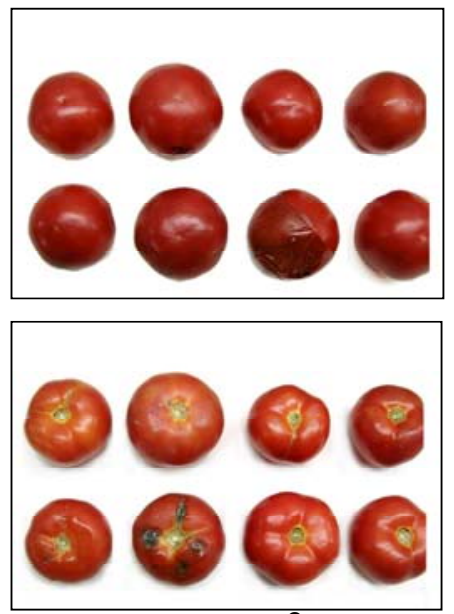

$3 \mathrm{~W} \mathrm{~m}^{-2}$
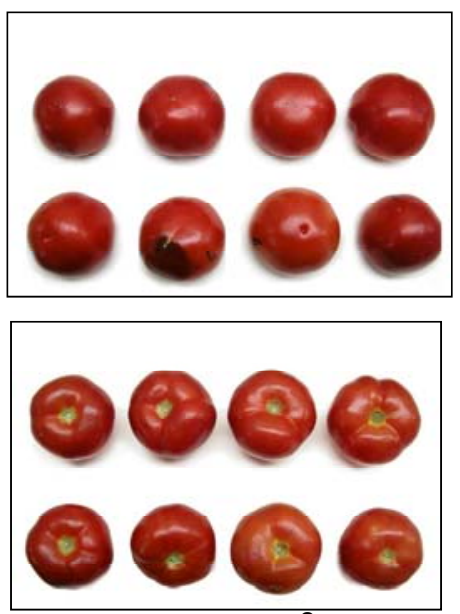

$33 \mathrm{~W} \mathrm{~m}^{-2}$

Figura IV.17: Apariencia de tomates control y tratados con una dosis de $4 \mathrm{~kJ} \mathrm{~m}^{-2}$ de radiación UV-C, bajo dos intensidades diferentes (3 ó $33 \mathrm{~W} \mathrm{~m}^{-2}$ ) y almacenados a 20 ${ }^{\circ} \mathrm{C}$ por $9 \mathrm{~d}$.

El porcentaje de frutos control atacados fue de $20 \%$ luego de 4 d de almacenamiento. Por su parte los tomates irradiados presentaron un menor ataque de hongos (4 y $2 \%$ para las intensidades de 3 y $33 \mathrm{~W} \mathrm{~m}^{-2}$ respectivamente) (Figura IV.18). Estas diferencias mantuvieron la tendencia luego $9 \mathrm{~d}$ de almacenamiento. Como se mencionó anteriormente, existe evidencia de la participación de mecanismos tanto directos como indirectos en la resistencia a las enfermedades de frutos tratados con UV-C (Shama, 2007). En tomate se ha descrito la inducción de respuestas 
defensivas contra Botrytis cinerea en frutos tratados con UV-C (Liu et al., 1993; Charles et al., 1996; Charles et al., 2008). De todos modos, Stevens et al., (1998) informaron que el tratamiento con UV-C $\left(3,6 \mathrm{~kJ} \mathrm{~m}^{-2}\right)$ retrasa la maduración de tomates, lo cual por sí sólo, sin la activación de respuestas directas, podría mantener a los frutos en un estado de menor susceptibilidad a las podredumbres. En el presente trabajo se observa nuevamente que la intensidad de radiación utilizada juega un papel importante en los efectos logrados contra patógenos. Las diferencias entre los tratamientos con las dos intensidades podría deberse a un distinto nivel de activación de estas respuestas, aspecto que resultaría de interés estudiar. En maíz, por ejemplo, se ha descrito que algunos genes de respuesta al UV-B se inducen sólo por encima de un nivel mínimo de radiación. Los autores sugieren que diferentes vías de señalización operarían a distintas fluencias (Casati y Walbot, 2004).

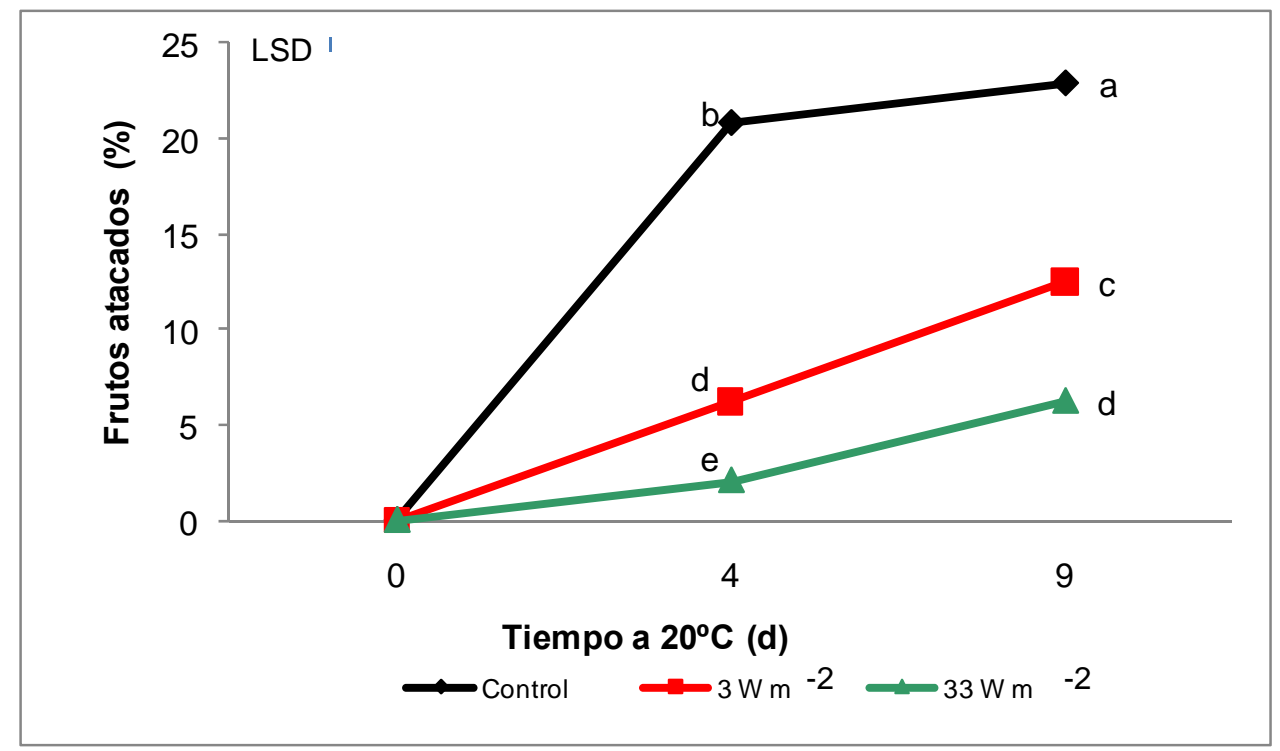

Fiqura IV.18: Ataque de hongos en tomates control y tratados con una dosis de $4 \mathrm{~kJ}$ $\mathrm{m}^{-2}$ de radiación UV-C, bajo dos intensidades diferentes (3 ó $33 \mathrm{~W} \mathrm{~m}^{-2}$ ) y almacenados a $20{ }^{\circ} \mathrm{C}$ por 4 ó $9 \mathrm{~d}$. Las letras distintas indican diferencias significativas en un test de Fisher con un nivel de significancia de $P \leq 0,05$. 


\section{IV.2.2. Pérdida de peso.}

La pérdida de peso se incrementó en forma lineal durante el almacenamiento en todos los tratamientos (Figura IV.19). Las diferencias observadas fueron menores a las descritas en frutilla. En este caso, luego del almacenamiento la pérdida de peso fue de alrededor de $1,5 \%$ para todos los tratamientos. Al final del almacenamiento los frutos tratados presentaron una pérdida de peso significativamente menor que los frutos control o tratados con la menor intensidad de UV-C. Si bien es posible que la radiación a tiempos largos favorezca procesos de cicatrización o acumulación de componentes hidrofóbicos (Charles et al., 2009), también es factible que el menor deterioro por ataque microbiano contribuya a explicar la menor pérdida de peso en los frutos tratados con alta intensidad de UV-C.

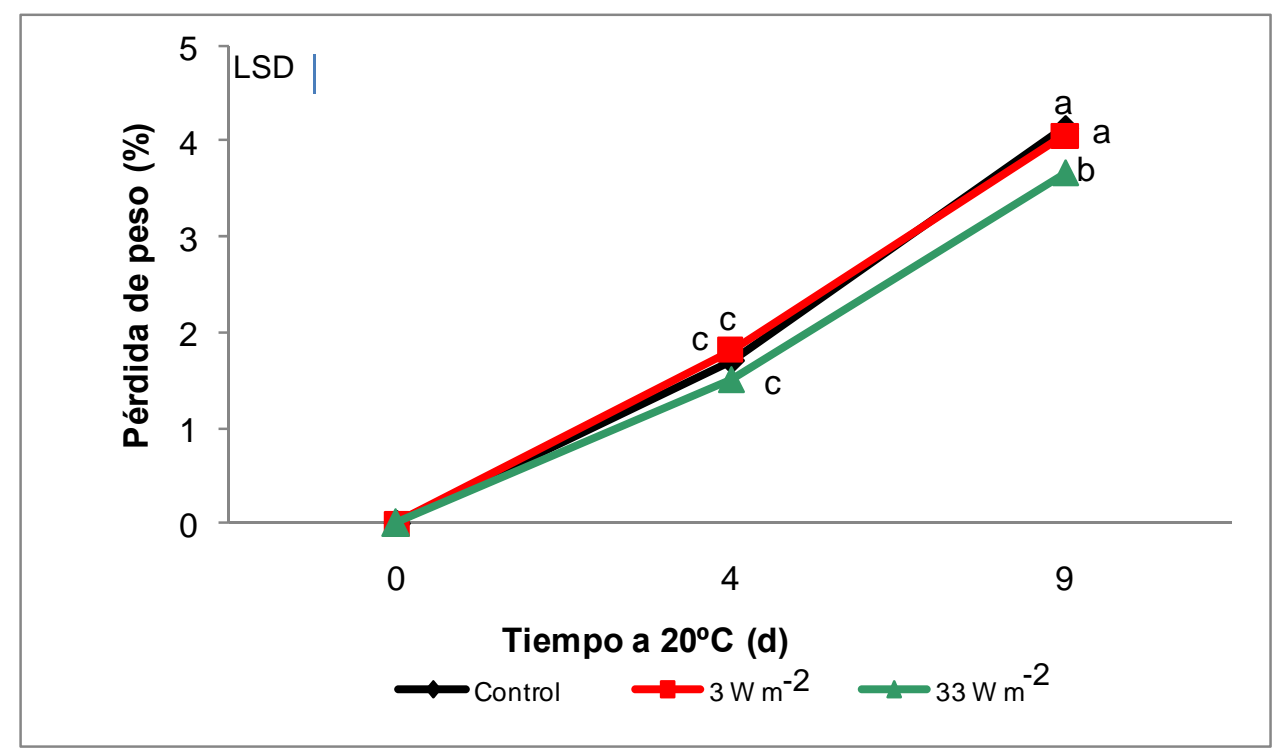

Figura IV.19: Pérdida de peso en tomates control y tratados con una dosis de $4 \mathrm{~kJ} \mathrm{~m}^{-2}$ de radiación UV-C bajo dos intensidades diferentes (3 ó $33 \mathrm{~W} \mathrm{~m}^{-2}$ ) y almacenados a 20 ${ }^{\circ} \mathrm{C}$ por 4 ó $9 \mathrm{~d}$. Las letras distintas indican diferencias significativas en un test de Fisher con un nivel de significancia de $P \leq 0,05$. 


\section{IV.2.3. Color superficial y licopeno.}

Al momento de cosecha la luminosidad $\left(L^{\star}\right)$ de los frutos fue cercana a 50 , y su valor descendió luego en todos los frutos durante el almacenamiento. Los tratamientos no provocaron modificaciones en forma inmediata (Figura IV.20), pero los frutos tratados presentaron una menor disminución de L* que los frutos controles. Durante el almacenamiento a $20^{\circ} \mathrm{C}$ el valor de hue descendió para todos los frutos. En este caso no se encontraron diferencias entre las dos intensidades de radiación UV-C. El tono y la saturación del color (hue y croma, respectivamente) continuaron su evolución normal durante el almacenamiento a medida que se incrementaba la tonalidad rojiza del fruto, no observándose modificaciones significativas entre frutos controles y tratados con ambas intensidades (Figuras IV.21 y 22). Estos resultados son similares

a los descritos por Liu et al., (2009). El contenido de licopeno se incrementó paulatinamente durante el almacenamiento, no encontrándose mayores diferencias entre frutos tratados y controles (Figura IV.23). Esto sugiere que el efecto de la exposición a la radiación UV en tomate es menor que en frutilla y que la intensidad de la misma no parece tener una influencia tan marcada sobre el avance del color. 


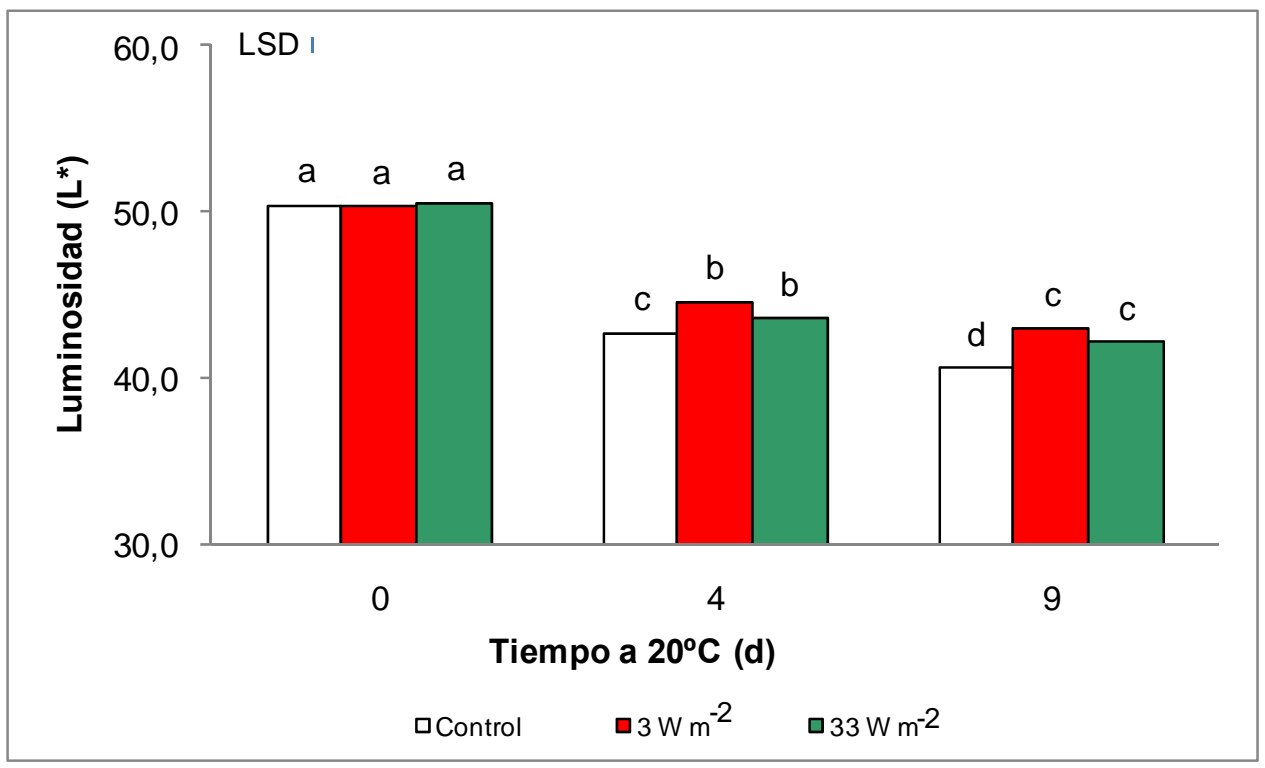

Figura IV.20: Luminosidad $\left(L^{*}\right)$ en tomates control y tratados con una dosis de $4 \mathrm{~kJ} \mathrm{~m}^{-2}$ de radiación UV-C, bajo dos intensidades diferentes (3 ó $33 \mathrm{~W} \mathrm{~m}^{-2}$ ) y almacenados a $20{ }^{\circ} \mathrm{C}$ por 4 ó $9 \mathrm{~d}$. Las letras distintas indican diferencias significativas en un test de Fisher con un nivel de significancia de $P \leq 0,05$.

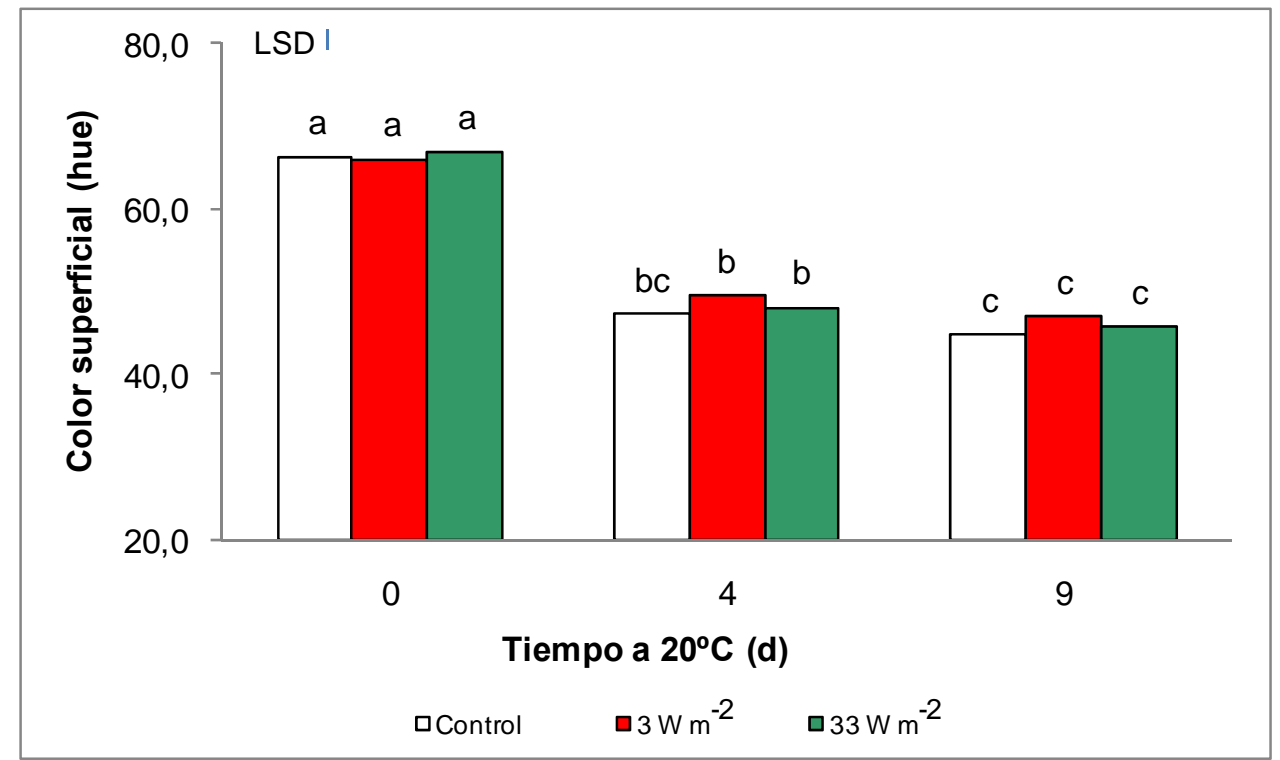

Figura IV.21: Tono de color superficial (hue) en tomates control y tratados con una dosis de $4 \mathrm{~kJ} \mathrm{~m}^{-2}$ de radiación UV-C, bajo dos intensidades diferentes (3 ó $33 \mathrm{~W} \mathrm{~m}^{-2}$ ) y almacenados a $20^{\circ} \mathrm{C}$ por 4 ó $9 \mathrm{~d}$. Las letras distintas indican diferencias significativas en un test de Fisher con un nivel de significancia de $P \leq 0,05$. 


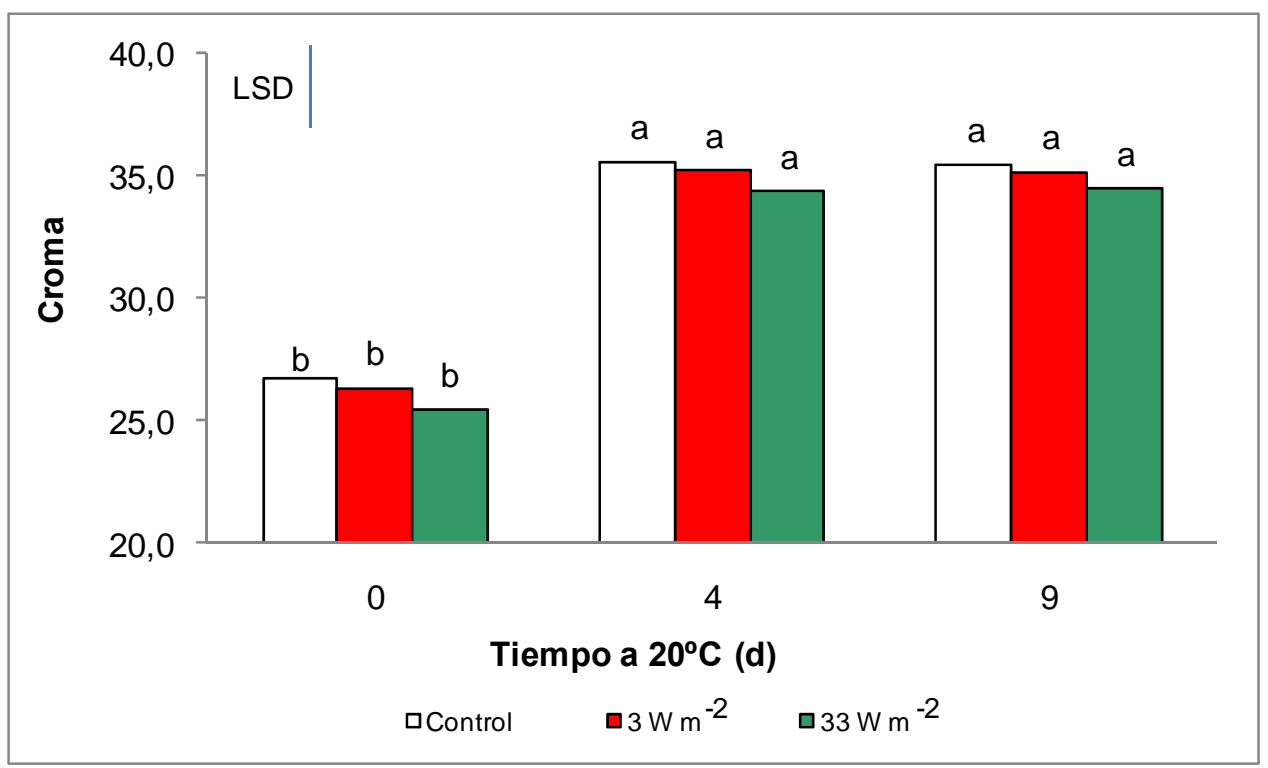

Figura IV.22: Saturación del color superficial (croma) en tomates control y tratados con una dosis de $4 \mathrm{~kJ} \mathrm{~m}^{-2}$ de radiación UV-C, bajo dos intensidades diferentes (3 ó 33 $W \mathrm{~m}^{-2}$ ) y almacenados a $20^{\circ} \mathrm{C}$ por 4 ó $9 \mathrm{~d}$. Las letras distintas indican diferencias significativas en un test de Fisher con un nivel de significancia de $P \leq 0,05$.

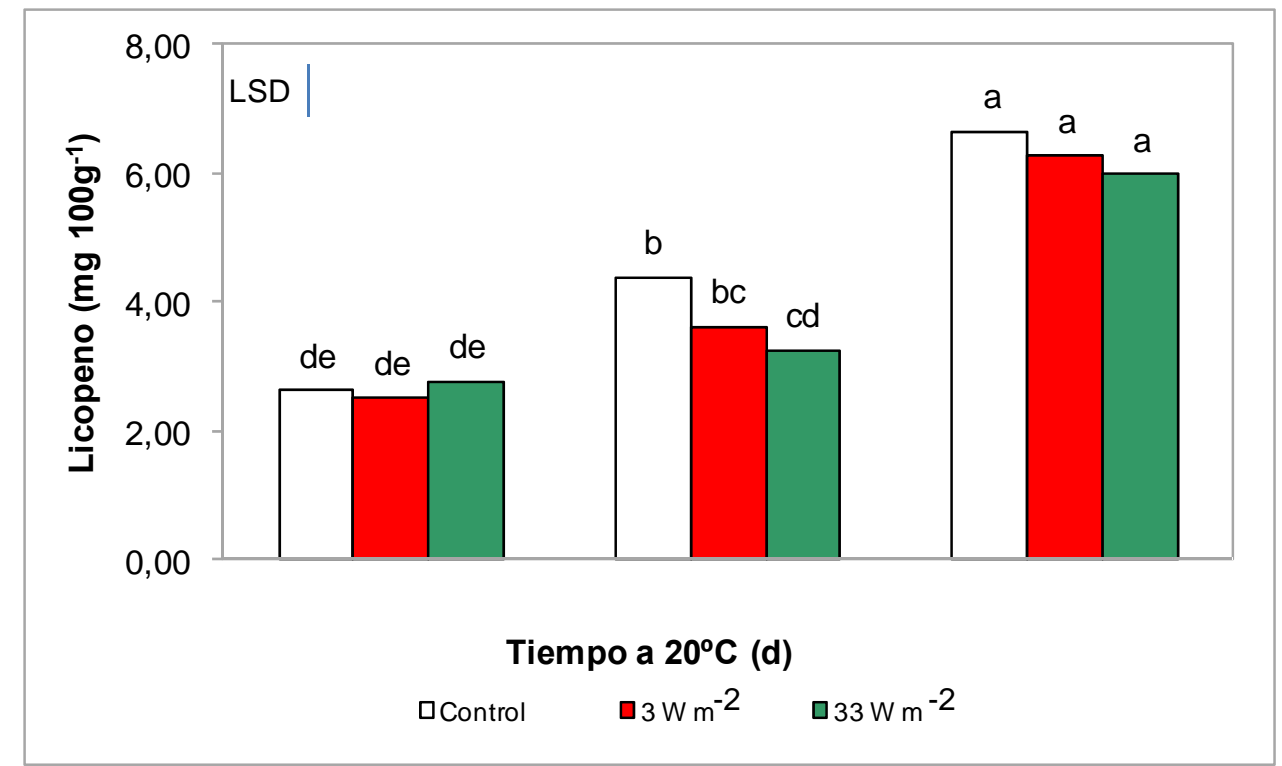

Figura IV.23: Licopeno en tomates control y tratados con una dosis de $4 \mathrm{~kJ} \mathrm{~m}^{-2}$ de radiación UV-C, bajo dos intensidades diferentes (3 ó $33 \mathrm{~W} \mathrm{~m}^{-2}$ ) y almacenados a 20 ${ }^{\circ} \mathrm{C}$ por 4 ó $9 \mathrm{~d}$. Las letras distintas indican diferencias significativas en un test de Fisher con un nivel de significancia de $P \leq 0,05$. 


\section{IV.2.4. Firmeza.}

La Figura IV.24 muestra los cambios en la firmeza de los frutos durante el almacenamiento. Se observa que la misma disminuyó conforme progresó el almacenamiento. Luego de $4 \mathrm{~d}$ los frutos tratados con ambas intensidades de radiación se mantuvieron más firmes que los controles. Nuevamente aquí no se observaron diferencias entre los dos tratamientos UV-C. Finalmente, después del almacenamiento durante $9 \mathrm{~d}$ no se encontraron diferencias de firmeza entre frutos control y tratados.

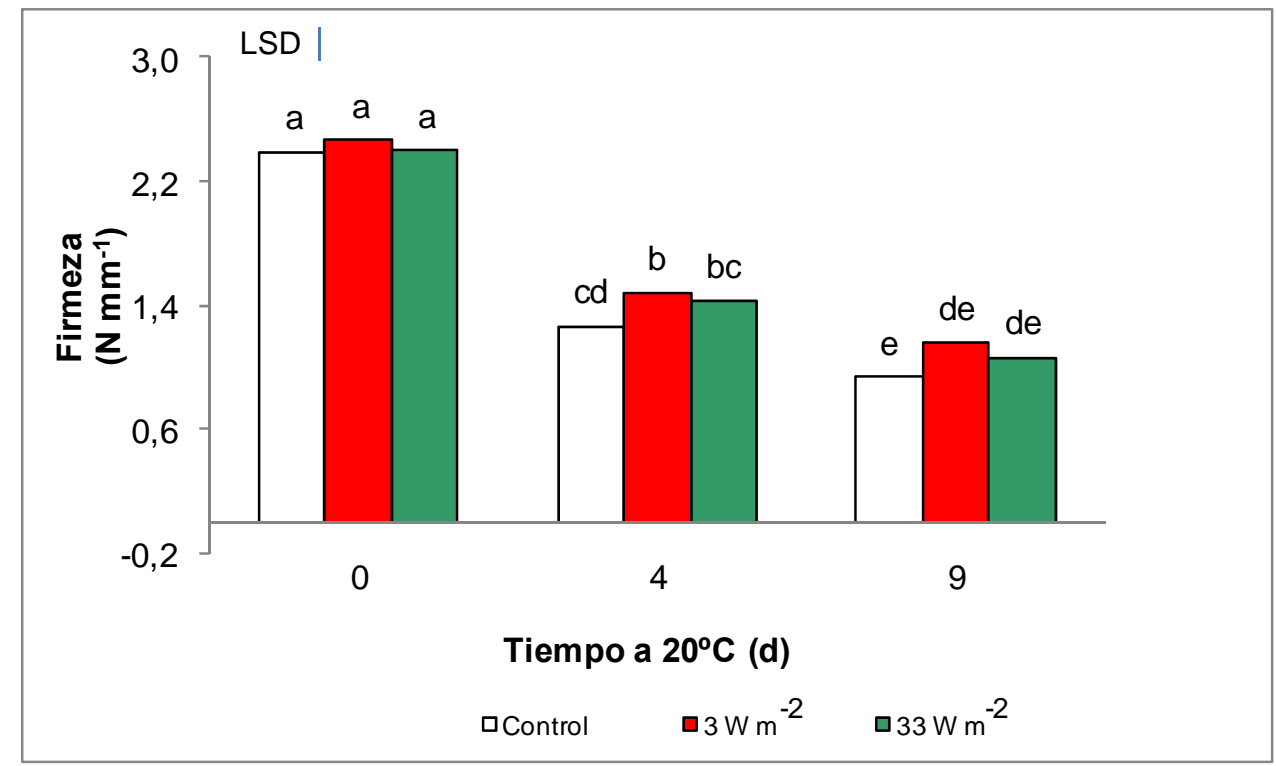

Figura IV.24: Firmeza en tomates control y tratados con una dosis de $4 \mathrm{~kJ} \mathrm{~m}^{-2}$ de radiación UV-C, bajo dos intensidades diferentes (3 ó $33 \mathrm{~W} \mathrm{~m}^{-2}$ ) y almacenados a 20 ${ }^{\circ} \mathrm{C}$ por 4 ó $9 \mathrm{~d}$. Las letras distintas indican diferencias significativas en un test de Fisher con un nivel de significancia de $P \leq 0,05$.

Los resultados obtenido en color y firmeza sugieren que, en tomate la intensidad de radiación UV-C utilizada posee menor influencia en la eficacia de los tratamientos. Para asegurar este efecto sería necesario ensayar un rango más amplio de intensidades de radiación y estudiarla a su vez para diferentes dosis. Maharaj et al., 
(1999) mostraron que la exposición de tomates a la radiación UV-C reduce la producción de etileno. La falta de diferencias de las dos intensidades de UV-C en tomate, podría deberse a que el tratamiento menos intenso ya es suficiente para frenar la producción de esta hormona generando respuestas similares a la exposición a condiciones más drásticas.

\section{IV.2.5. Sólidos solubles, acidez y capacidad antioxidante.}

El contenido de sólidos solubles no presentó variaciones entre los grupos control y tratados (Figura IV.25).

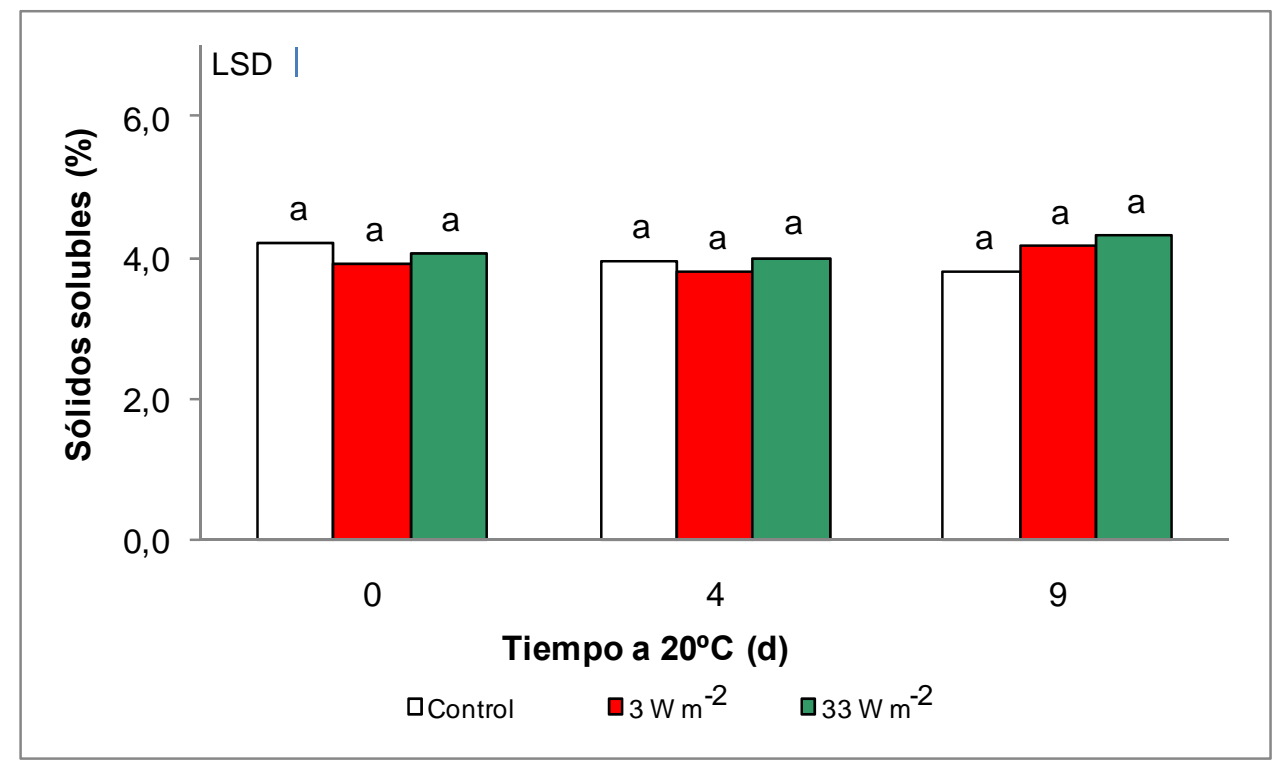

Figura IV.25: Sólidos solubles en tomates control y tratados con una dosis de $4 \mathrm{~kJ} \mathrm{~m}^{-2}$ de radiación UV-C, bajo dos intensidades diferentes (3 ó $33 \mathrm{~W} \mathrm{~m}^{-2}$ ) y almacenados a $20{ }^{\circ} \mathrm{C}$ por 4 ó $9 \mathrm{~d}$. Las letras distintas indican diferencias significativas en un test de Fisher con un nivel de significancia de $P \leq 0,05$.

Por su parte, se observó una reducción de la acidez en los frutos sometidos a la mayor intensidad de UV-C (Figura IV.26). Estas diferencias se observaron durante los días 4 y 9 de almacenamiento. Finalmente, la capacidad antioxidante no sufrió 
modificaciones significativas durante el almacenamiento ni en respuesta a los tratamientos (Figura IV.27).

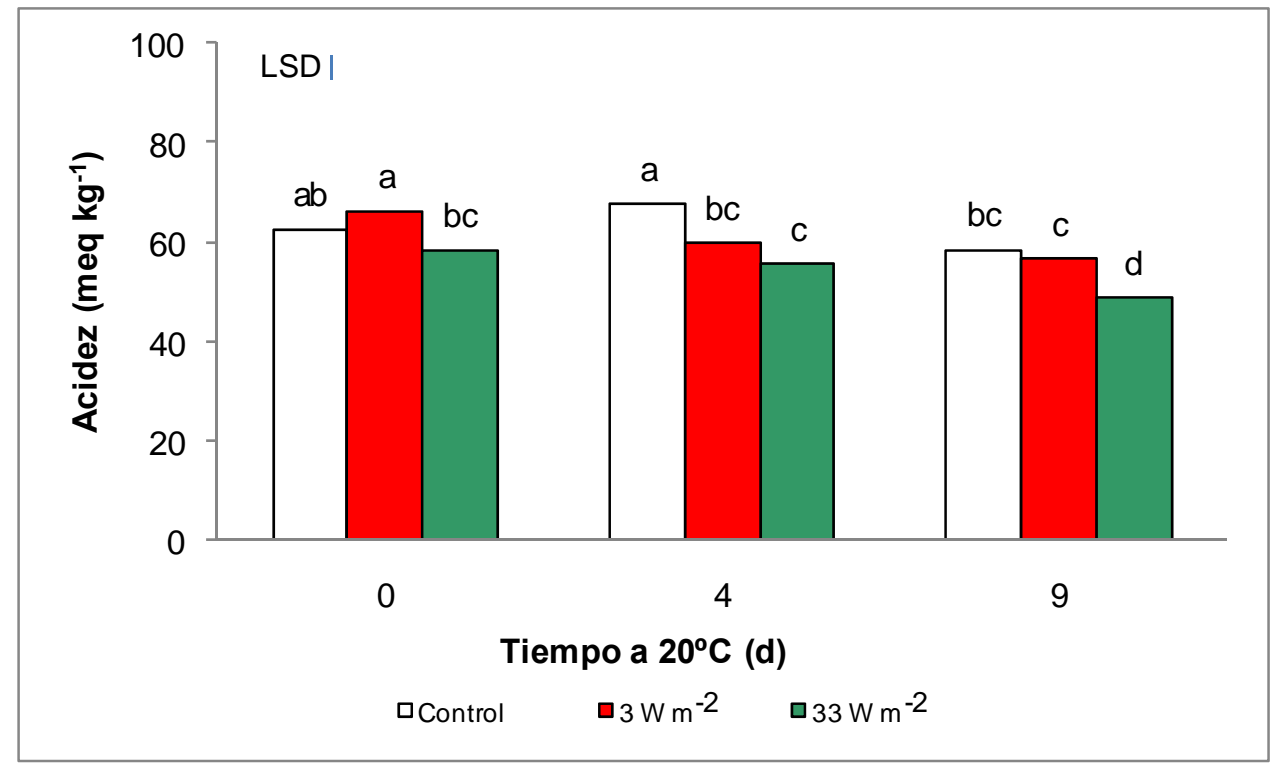

Figura IV.26: Acidez en tomates control y tratados con una dosis de $4 \mathrm{~kJ} \mathrm{~m}^{-2}$ de radiación UV-C, bajo dos intensidades diferentes (3 ó $33 \mathrm{~W} \mathrm{~m}^{-2}$ ) y almacenados a 20 ${ }^{\circ} \mathrm{C}$ por 4 ó $9 \mathrm{~d}$. Las letras distintas indican diferencias significativas en un test de Fisher con un nivel de significancia de $P \leq 0,05$.

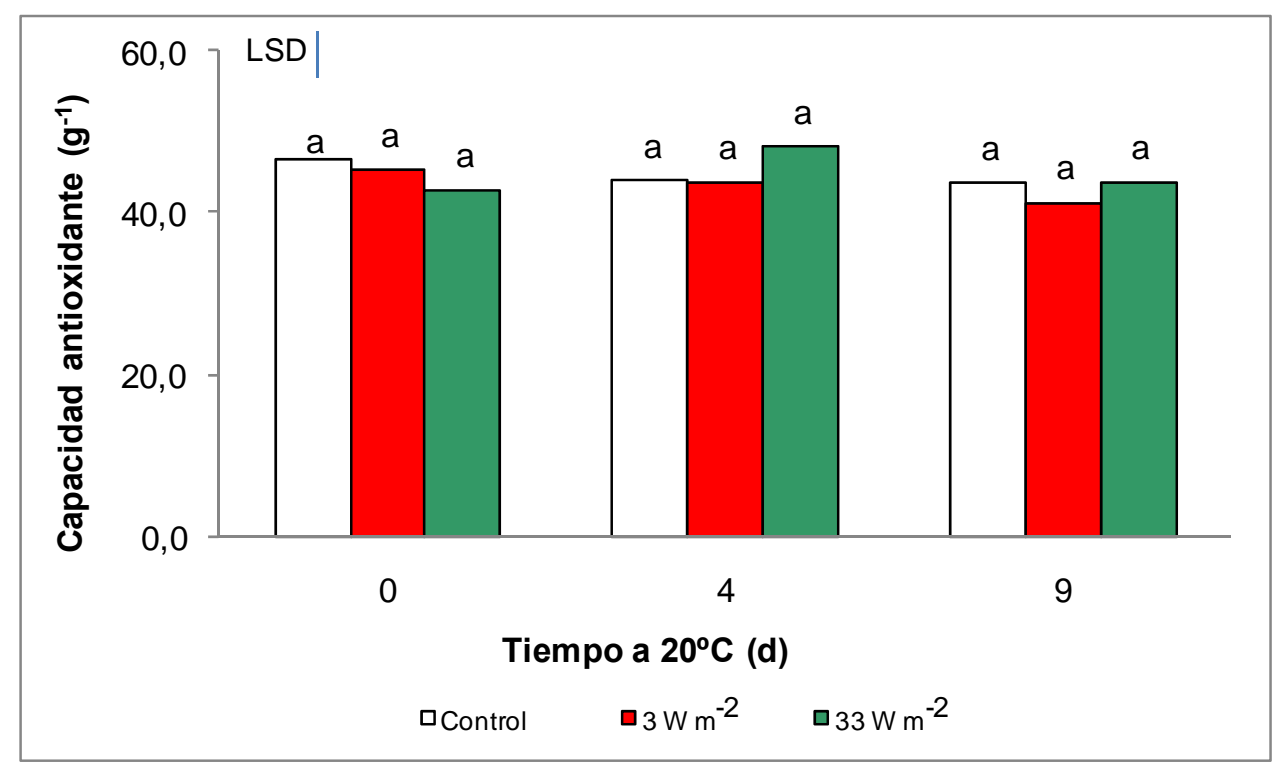

Figura IV.27: Capacidad antioxidante en tomates control y tratados con una dosis de 4

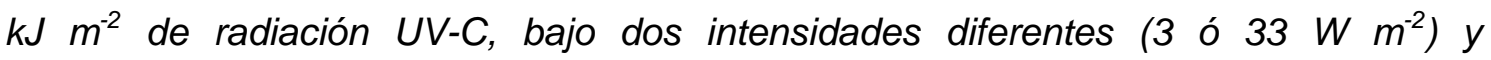


almacenados a $20^{\circ} \mathrm{C}$ por 4 ó $9 \mathrm{~d}$. Las letras distintas indican diferencias significativas en un test de Fisher con un nivel de significancia de $P \leq 0,05$.

\section{IV.2.6. Actividad respiratoria.}

La tasa respiratoria luego de 4 días de almacenamiento fue similar en todos los frutos. Al final del almacenamiento los frutos tratados con una intensidad de $33 \mathrm{~W} \mathrm{~m}^{-2}$ mostraron una mayor actividad respiratoria (Figura IV.28).

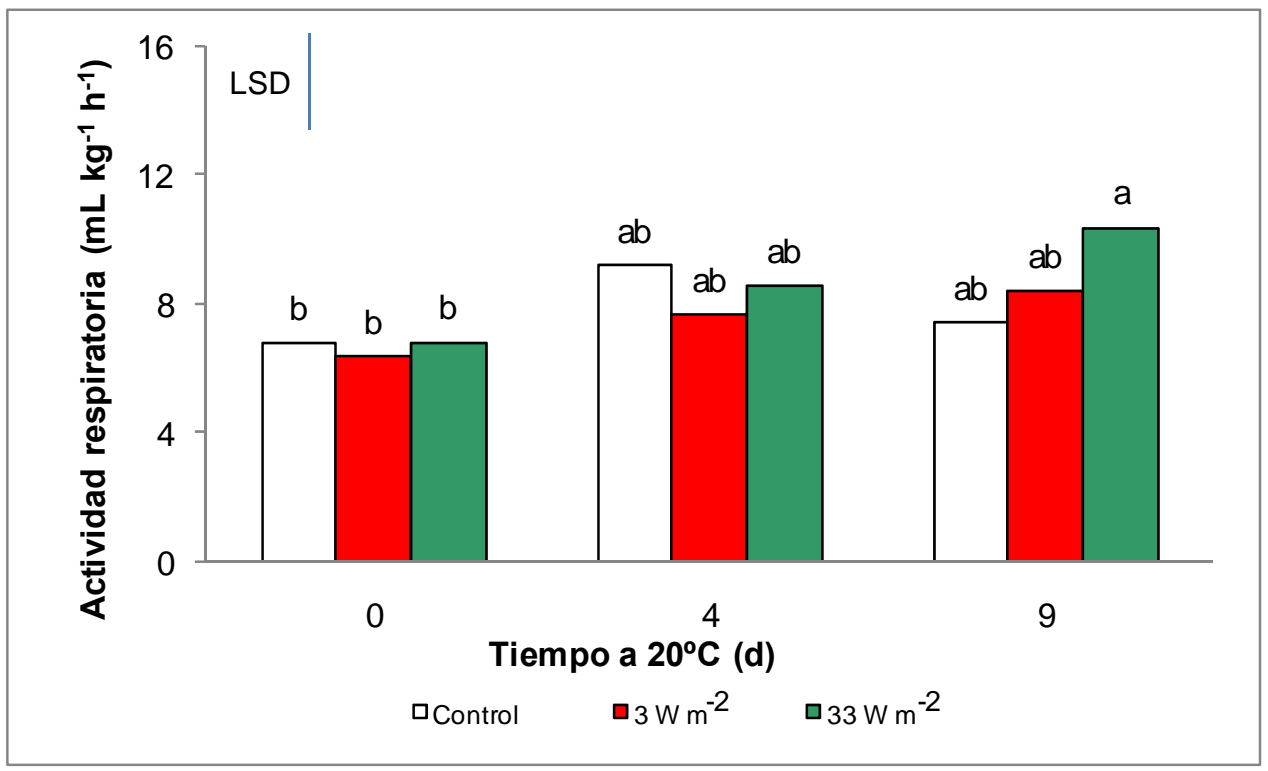

Figura IV.28: Actividad respiratoria en tomates control y tratados con una dosis de 4

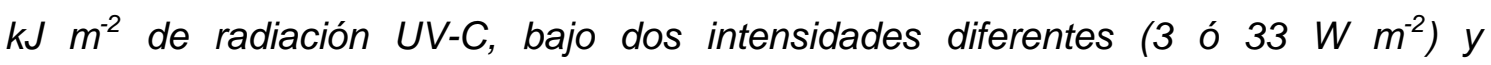
almacenados a $20^{\circ} \mathrm{C}$ por 4 ó $9 \mathrm{~d}$. Las letras distintas indican diferencias significativas en un test de Fisher con un nivel de significancia de $P \leq 0,05$.

\section{IV.2.7. Recuentos de bacterias mesófilas y hongos.}

En este caso se observó que la aplicación de los tratamientos disminuyó el contenido de bacterias mesófilas inmediatamente después de la irradiación con UV-C con respecto a los frutos control (Figura IV.29). Las diferencias con los resultados 
descritos en frutilla podría asociarse con que las poblaciones de bacterias puedan ser distintas entre frutos. De todos modos, la reducción no fue mayor a un ciclo logarítmico. Al finalizar el período de almacenamiento los frutos tratados con una menor intensidad presentaron un menor número total de recuento de bacterias mesófilas, mientras que los frutos tratados con una mayor intensidad presentaron un valor superior a los dos grupos de frutos mencionados anteriormente.

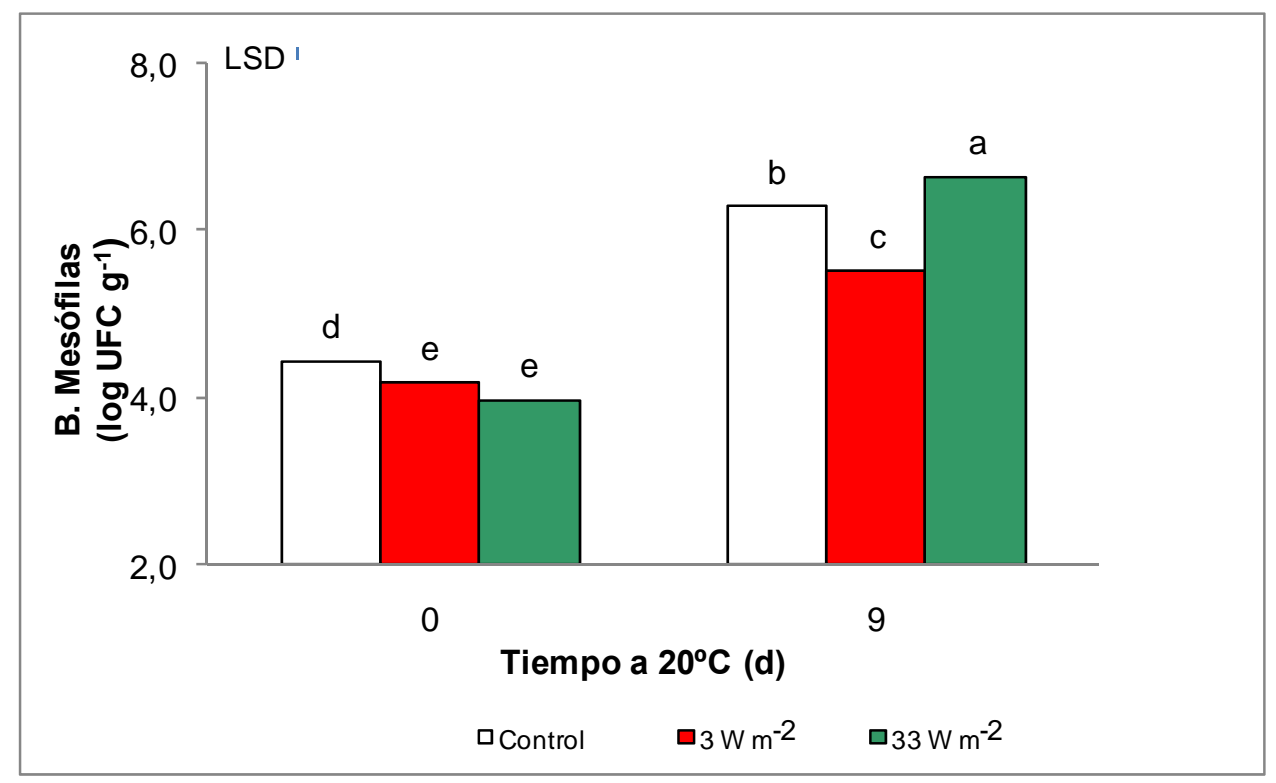

Figura IV.29: Recuento de bacterias mesófilas (log UFC $g^{-1}$ ) en tomates control y tratados con una dosis de $4 \mathrm{~kJ} \mathrm{~m}^{-2}$ de radiación UV-C, bajo dos intensidades diferentes (3 ó $33 \mathrm{~W} \mathrm{~m}^{-2}$ ). Las letras distintas indican diferencias significativas en un test de Fisher con un nivel de significancia de $P \leq 0,05$.

Con relación al recuento de hongos, inmediatamente después del tratamiento se observó un descenso en el número de UFC $\mathrm{g}^{-1}$ respecto a los frutos controles (Figura IV.30), mientras que luego de 9 días de almacenamiento el tratamiento con mayor intensidad $\left(33 \mathrm{~W} \mathrm{~m}^{-2}\right.$ ) presentó un menor recuento de colonias. Por otra parte no se evidenciaron diferencias entre los frutos control y tratados con una menor intensidad $\left(3 \mathrm{~W} \mathrm{~m}^{-2}\right)$. Las diferencias relativamente pequeñas en las poblaciones 
microbianas al final del almacenamiento y el menor ataque en los frutos tratados descrito anteriormente, sugieren que el efecto de la radiación UV en control de enfermedades se asociaría con cambios en los niveles de susceptibilidad de los frutos más que con su acción germicida. Charles et al., (2009) demostraron que el tratamiento con UV-C en tomates induce la acumulación de compuestos fenólicos y la formación de lignina y suberina, jugando un rol como barrera física que impide el ingreso de patógenos.

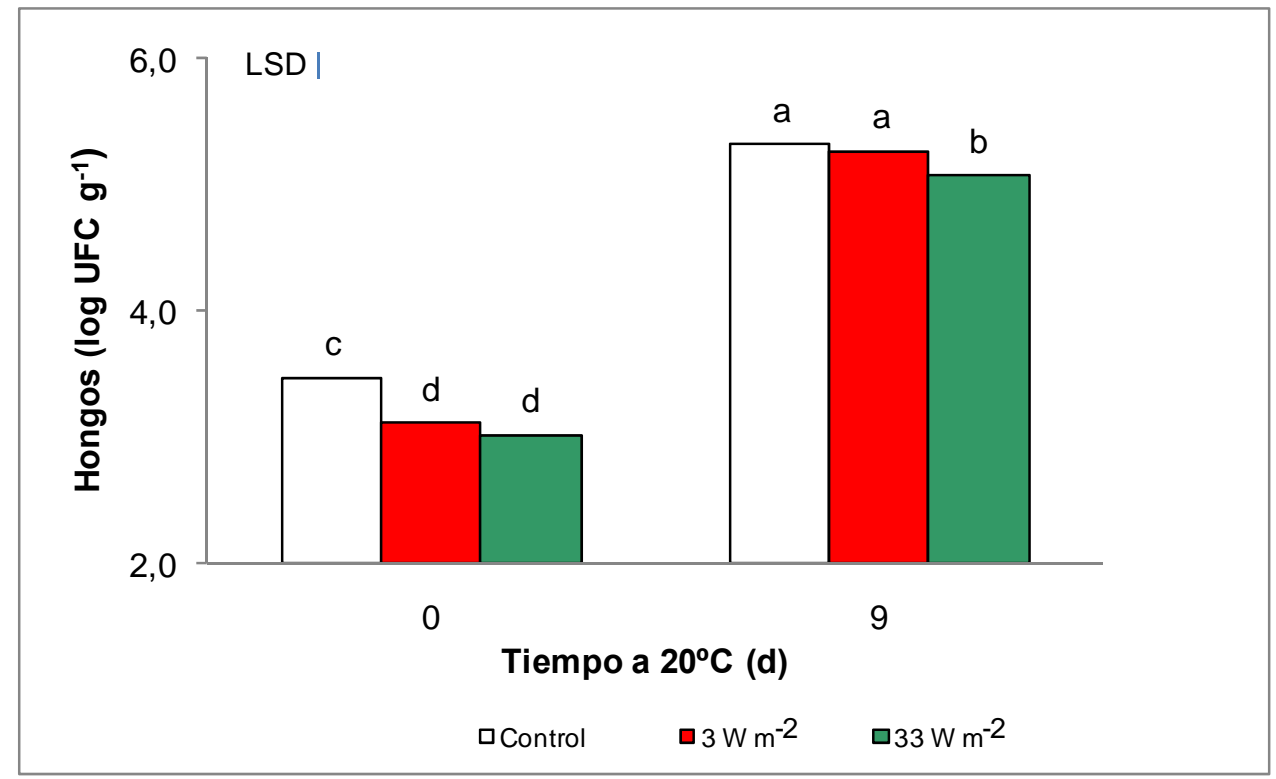

Figura IV.30: Recuento de hongos (log UFC $g^{-1}$ ) en tomates control y tratados con una dosis de $4 \mathrm{~kJ} \mathrm{~m}^{-2}$ de radiación UV-C, bajo dos intensidades diferentes (3 ó $33 \mathrm{~W} \mathrm{~m}^{-2}$ ). Las letras distintas indican diferencias significativas en un test de Fisher con un nivel de significancia de $P \leq 0,05$.

\section{IV.2.8. Análisis sensorial.}

La calidad de los vegetales determinada por los consumidores resulta de una combinación de parámetros que incluyen la apariencia, textura, sabor, aroma y el valor nutricional (Kader, 2002b). La influencia de cada atributo es dependiente del vegetal, aunque el impacto visual es el factor decisivo de la compra. Según lo indicado por los 
panelistas la apariencia de los frutos es la característica más importante en la selección, el 57\% de los consumidores basaron su preferencia en este aspecto, mientras que la textura fue indicada como el segundo atributo de influencia y por último se mencionó al color con un porcentaje mucho menor (Figura IV.31). Los resultados del presente estudio mostraron una mayor aceptación de los frutos tratados respecto a los controles. Los frutos irradiados con mayor intensidad (33 $\mathrm{W} \mathrm{m}^{-2}$ ) se ubicaron en el primer lugar de preferencia por el panel, seguidos por los frutos irradiados con menor intensidad $\left(3 \mathrm{~W} \mathrm{~m}^{-2}\right)$ y en el último lugar se ubicaron los frutos sin tratamiento (Figura IV.32). Sgroppo y Sosa (2009) encontraron una mayor aceptación de frutos irradiados con UV.

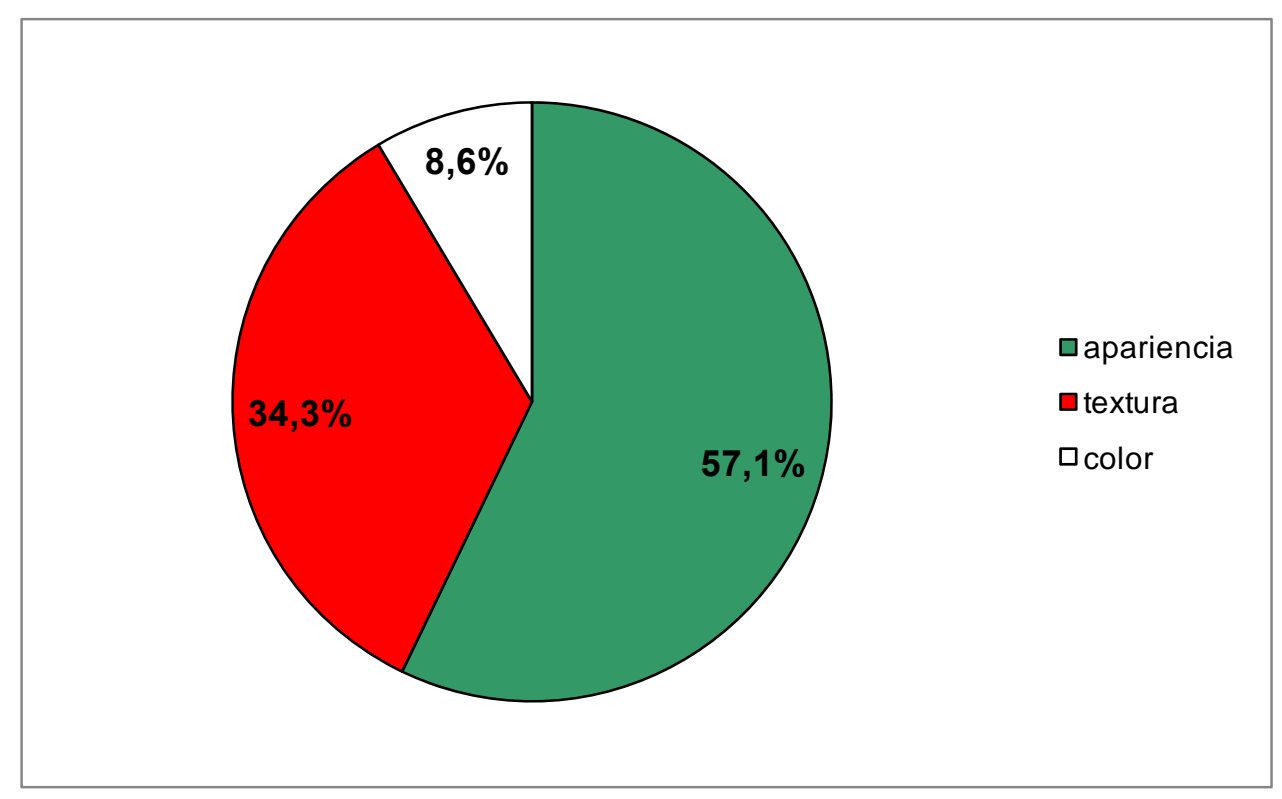

Figura IV.31: Importancia de diferentes atributos en la aceptación de tomates identificada por el panel de consumidores no entrenados $(n=35)$. 


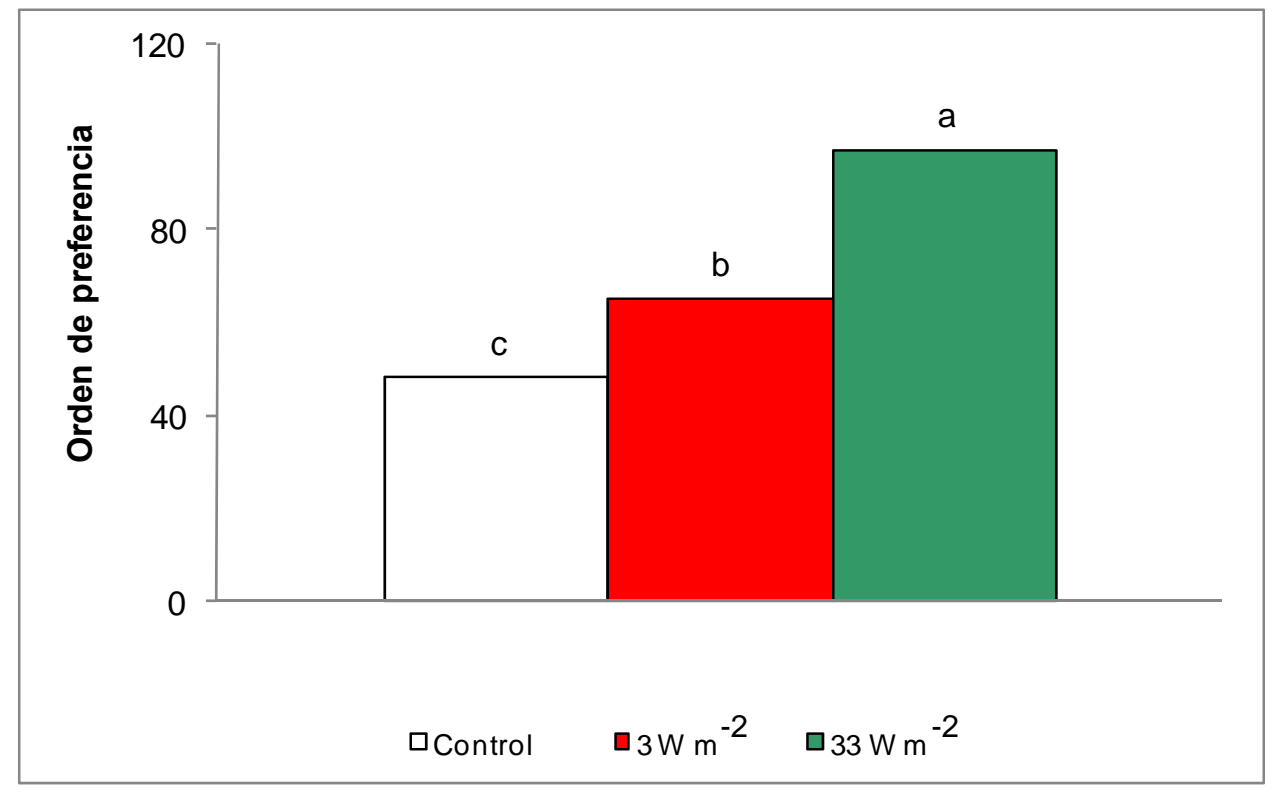

Figura IV.32: Test de ordenamiento por preferencia de tomates control y tratados con una dosis de $4 \mathrm{~kJ} \mathrm{~m}^{-2}$ de radiación UV-C, bajo dos intensidades diferentes (3 ó $33 \mathrm{~W}$ $\mathrm{m}^{-2}$ ) y almacenados a $20^{\circ} \mathrm{C}$ por $4 \mathrm{~d}$, evaluados por el panel de consumidores no entrenados $(n=35)$. 


\section{CONCLUSIONES}


Los resultados de este trabajo muestran que más allá de la dosis total, la intensidad de radiación es un factor muy importante en la determinación de la eficacia de los tratamientos UV-C en frutos. El incremento de la fluencia de 3 a $33 \mathrm{~W} \mathrm{~m}^{-2}$ en frutilla aumenta marcadamente los beneficios obtenidos con una dosis total de radiación de $4 \mathrm{~kJ} \mathrm{~m}^{-2}$. En tomate, las mejoras sobre la calidad de la fruta como consecuencia del aumento de la intensidad de radiación UV-C no son tan evidentes, aunque se observa un mayor control de enfermedades al igual que en frutilla. Dado que no se observaron síntomas de fitotoxicidad en ninguna de las intensidades evaluadas, el uso de las más elevadas podría resultar de interés desde el punto de vista tecnológico por permitir incrementar los beneficios obtenidos, reducir los tiempos de proceso y aumentar las posibilidades de aplicación a nivel industrial. 


\section{REFERENCIAS}


Abdel-Kader, M., El-Mougy, N. 2007. Applicable control measure against Orobanche ramosa in tomato plants. Aust. Plant Pathol. 36: 160-164.

Abeles, F., Morgan, P., Saltveit, M. 1992. Ethylene in plan biology. San Diego, California. 6-9, 182.

A-H-Mackerness, S., John, C., Jordan, B., Thomas, B. 2001. Early signaling components in UV-B responses: distinct roles for different reactive oxygen species and nitric oxide. FEBS Lett. 489: 237-42.

Allende, A., McEvoy, J., Luo, Y.,Artes, F., Wang, C. 2006. Effectiveness of two-sided UV-C treatments in inhibiting natural microflora and extending the shelf-life of minimally processed 'Red Oak Leaf' lettuce. Food Microbiol. 23: 241-249.

Andrade Cuvi, M.J., Vicente, A., Concellón, A., Chaves, A. 2011. Changes in red pepper antioxidants as affected by UV-C treatments and storage at chilling temperatures. LWT - Food Sci. Technol. 44: 1666-1671.

AOAC. 1980. Methods of Analysis, 13th ed., Association of Official Analytical Chemists. Washington, DC.

Apel, K., Hirt, H. 2004. Reactive oxygen species: Metabolism, oxidative stress, and signal transduction. Annu. Rev. Plant Biol. 55: 373-399.

Baka, M., Mercier, J., Corcuff, F., Castaigne., F., Arul, J., 1999. Photochemical treatment to improve storability of fresh strawberries. J. Food Sci. 64: 1068-1072.

Barka, E., Kalantari, S., Makhlouf, J., Arul, J., 2000. Impact of UV-C irradiation on the cell wall-degrading enzymes during ripening of tomato (Lycopersicon esculentum L) fruit. J Agric Food Chem. 48: 667-671.

Barka, E.A. 2001. Protective enzymes against reactive oxygen species during ripening of tomato (Lycopersicon esculentum) fruits in response to low amounts of UV-C. Funct. Plant Biol. 28: 785-791. 
Ben-Yehoshua, S., Rodov, V., Kim, J. J., Carmeli, S. 1992. Preformed and induced antifungal materials of citrus fruits in relation to the enhancement of decay resistance by heat and ultraviolet treatments. J. Agric. Food Chem. 40: 12171221.

Birt, D.F., Hendrich, S., Wang, W. 2001. Dietary agents in cancer prevention: flavonoids and isoflavonoids. Pharmacol. \& Therap. 90: 157-177.

Brand-Williams, W., Cuvelier, E., Berset, C. 1995. Use of free radical method to evaluate antioxidant activity. Lebensm. Wiss. Technol. 28: 25-30.

Branzanti, E. 1989. La fresa. Ediciones Mundi Prensa. Madrid, España. 350.

Brosché, N., Strid, A. 2003. Molecular events following perception of UV-B radiation by plants. Physiol. Plant. 117: 1-10.

Brown, B, Jenkins, G. 2008. UV-B signalling pathways with different fluence-rate response profiles are distinguished in mature Arabidopsis leaf tissue by requirement for UVR8, HY5, and HYH. Plant Physiol. 146: 576-588.

Cantos, E., Espín, J., Tomás-Barberán, F. 2002. Postharvest stilbene-enrichment of red and white table grape varieties using UV-C irradiation pulses. J. Agric. Food Chem. 50: 6322-6329.

Cantwell, M., Kasmire, R. 2007. Tecnología postcosecha de Cultivos Hortofrutícolas. $3^{a}$ edición. Universidad de California. Centro de Información e Investigación en Tecnología Postcosecha. Series de Horticultura Postcosecha. 24: 469. 570.

Casati, P., Walbot, V. 2004. Rapid transcriptome responses of maize (Zea mays) to UV-B in irradiated and shielded tissues. Genome Biol. 5:R16. En: http://www.springerlink.com/content/t03w369xw311575n/

Charles, M., Benhamoun, N., Arul, J., 1996. Induction of resistance to gray mold in tomato fruit by UV light. En: proceedings of the IFT Annual meeting, New Orleans. Charles, M.T., Goulet, A., Arul, J. 2008. Physiological basis of UV-C induced resistance 
to Botrytis cinerea in tomato fruit IV. Biochemical modification of structural barriers Postharvest Biol. Technol. 47: 41-53.

Charles, M., Tano, K., Asselin, A., Arul, J. 2009. Physiological basis of UV-C induced resistance to Botrytis cinerea in tomato fruit. V. Constitutive defence enzymes and inducible pathogenesis-related proteins. Postharvest Biol. Technol. 51, 414-424.

Chung, M.J., Lee S.H., Sung, N.J. 2002. Inhibitory effects of whole strawberries, garlic juice or kale juice on endogenous formation of $\mathrm{N}$-nitrosodimethylenamine in humans. Cancer Lett. 182: 1-10.

Civello, P., Vicente, A., Martínez, G. 2006. UV-C technology to control postharvest diseases of fruits and vegetables. Recent Advances in Alternative Postharvest Technologies to Control Fungal Diseases in Fruits \& Vegetables. Transworld Research Network, 37/661 (2), Fort P.O. Trivandrum-695 023, Kerala, India. 71102.

Corvo, D. 2002. Zonas de producción del cultivo del tomate en la Argentina. Informe. $\begin{array}{lll}\text { Dirección de } & \text { Agricultura. }\end{array}$ http://www.seedquest.com/News/releases/2005/pdf/13528.pdf

Costa, L., Vicente, A., Civello, P., Chaves, A., Martínez, G. 2006. UV-C treatment delays postharvest senescence in broccoli florets. Postharvest Biol. Technol. 39: 204-210.

D'hallewin, G., Schirra, M., Manueddu, E., Piga, A., Ben-Yehoshua, S. 1999. Scoparone and scopoletin accumulation and ultraviolet- $\mathrm{C}$ induced resistance to postharvest decay in oranges as influenced by harvest date. J. Amer. Soc. Hortic. Sci. 124: 702-707.

D'Hallewin, G., Schirra, M., Pala, M.,Ben-Yehoshua, S. 2000. Ultraviolet C irradiation at $0.5 \mathrm{~kJ} \cdot \mathrm{m}^{-2}$ reduces decay without causing damage or affecting postharvest quality of Star Ruby grapefruit (C. paradisi Macf.). J. Agric. Food Chem. 48: 4571-4575. 
Debnath, S., Teixeira, J.A. 2007. Strawberry culture in vitro: applications in genetic transformation and biotechnology. Fruit, Veg. \& Cereal Sci. Biotech. 1: 1-12.

DeEll, J. Fresh Market Quality Program Lead/OMAFRA. Ministry of agriculture food \& rural affairs. Ontario. $2011 . \quad$ En: http://www.omafra.gov.on.ca/english/crops/hort/news/ hortmatt/2006/13hrt06a4.htm.

DeEll, J., Toivonen, P., Cornut, F., Roger, C., Vigneault, C. 2006. Addition of sorbitol with $\mathrm{KMnO} 4$ improves broccoli quality retention in modified atmosphere packages. J. Food Qual. 29: 65-75.

Demchak, K., Harper J., Kime, L., Lantz, W. Strawberry production. College of Agricultural Sciences Agricultural Research and Cooperative Extension. 2011. In: http://agalternatives.aers.psu.edu/Publications/Strawberries.pdf.

Dotto, M. 2008. Participación de expansinas en el ablandamiento de frutilla: regulación hormonal, expresión en distintas variedades y efecto de la aplicación de tratamientos físicos. Tesis para optar por el título de Doctor en Biología Molecular y Biotecnología. Universidad Nacional de General San Martín, Argentina.

El Ghaouth, A.,Wilson, C., Callahan, A. 2003. Induction of chitinase, beta-1,3glucanase, and phenylalanine ammonia lyase in peach fruit by UV-C treatment. Phytopathol. 93: 349-355.

FAOSTAT base de datos. 2011. http://faostat.fao.org/site/444/DesktopDefault.aspx? PagelD=444\#ancor.

Folta, K., Davis, T. 2006. Strawberry genes and genomics. Crit. Rev. Plant Sci. 25: 399-415.

Frohnmeyer, H., Jenkins, G., Long, J., Wade, H., Shenton, M., Bibikova, T. 2001. UV and blue light signalling: pathways regulating chalcone synthase gene expression in Arabidopsis. New Phytol. 151: 121-131. 
Giovannoni, J. 2001. Molecular biology of fruit maturation and ripening. Annu. Rev. Plant Physiol. Plant Mol. Biol. 52: 725-749.

Harm, W. 1980. Biological effects of ultraviolet radiation. IUPAB Biophysics. Cambrige UP, New York. 29-30.

Helbig, J. 2002. Ability of the antagonistic yeast Cryptococcus albidus to control Botrytis cinerea in strawberry. BioControl. 47: 85-99.

Hobson, G., Grirson, D. 1993. Tomato. Biochemistry of fruit ripening. Editorial Chapman and Hall. 405-442.

Hough, G. 2010. Curso taller sensorial de alimentos. Instituto superior de tecnología de alimentos (ISETA). Buenos Aires. 10, 112 - 114.

Hough, G., Wakeling, I., Mucci, A., Cahmbers, E., Gallardo, I., Rangel, L. 2006. Number of consumers necessary for sensory acceptability test. Food Qual. Pref. 17: $522-526$.

Jenkins, G., Long, J., Wade, K., Shenton, M., Bibikov, N. 2001. UV and blue light signalling: pathways regulating chalcone synthase gene expression in Arabidopsis. New Phytol. 151: 121-31.

Kader, A., 2002a. Postharvest technology of horticultural crops,third edition. University of California, Agriculture and Natural Resources, Publication 3311, 535.

Kader, A., 2002b. Quality parameters of Fresh-cut Fruit and Vegetable Products. 1415. En: Lamikanra, O. (Ed.); Fresh-cut Fruits and Vegetables. Science Technology and Market. CRC Press. Boca Raton, Florida, USA.

Karabulut, O., Tezcani, A., Daus, A., Cohen, L., Weiss, B., Droby, S. 2004. Control of preharvest and postharvest fruit rot in strawberry by Metschnikowia fructicola. Biocont. Sci. Technol.. 14: 513-521. 
Kilian, J., Whitehead, D., Horak, J.,Wanke, D., ,Weinl, S. 2007. The AtGenExpress global stress expression data set: protocols, evaluation and model data analysis of UV-B light, drought and cold stress responses. Plant J. 50: 347-63.

Kresty, L., Morse, M., Morgan, C., Carlton, P., Lu, J., Gupta, A., Blackwood, M., Stoner, G. 2001. Chemoprevention of esophageal tumorigenesis by dietary administration of lyophilized black raspberries. Cancer Res. 61: 6112-6119.

Ku, V., Wills, R., Ben-Yehoshua, S. 1999. 1-Methylcyclopropene can differentially affect the postharvest life of strawberries exposed to ethylene. HortScience. 34: 119120.

Lemoine, M., Civello, P.,Chaves, A., Martínez, G. 2008. Effect of combined treatment with hot air and UV-C on senescence and quality parameters of minimally processed broccoli (Brassica oleracea L. var. Italica). Postharvest Biol. Technol. 48: 15-21.

Liu, J., Stevens, C., Khan, V.A., Lu, J.Y.,Wilson, C., Adeyeye, O., Kabwe, M., Pusey, P., Chalutz, E., Sultana, T., Droby, S., 1993. Application of ultraviolet-C light on storage rots and ripening of tomatoes. J. Food Prot. 56: 868-872.

Liu, W., Zhang, Y. 2006. Effects of UV intensity and water turbidity on microbial indicator inactivation. J. Env. Sci. 18: 650-653.

Liu, L., Zabaras, D., Bennett, I., Agua, P., Woonton, B. 2009. Effects of UV-C, red light and sun light on the carotenoid content and physical qualities of tomatoes during post-harvest storage. Food Chem. 115: 495-500.

López, R., Conesa, A., Allende, A., Artés, F. 2005. Shelf life and overall quality of minimally processed pomegranate arils modified atmosphere packaged and treated with UV-C. Postharvest Biol. Technol. 37: 174-185. 
Maharaj, R., Arul, J., Nadeau, P. 1999. Effect of photochemical treatment in the preservation of fresh tomato (Lycopersicon esculentum cv. Capello) by delaying senescence. Postharvest Biol. Technol. 15: 13-23.

Marquenie, D., Lammertyn, J., Geeraerd, A., Soontjens, C., Van Impe, J., Nicolai, B., Michiels, C. 2002. Inactivation of conidia of Botrytis cinerea and Monilinia frutigena using UV-C and heat treatment. Int. J. Food Microbiol. 74: 27-35.

Mercier, J., Arul, J., Julien, C., 1993b. Effect of UV-C on phytoalexin accumulation and resistance to Botrytis cinerea in stored carrots. J. Phytopathol. 139: 17-35.

Mercier, J., Arul, J., Ponnampalam, R., Boulet, M. 1993a. Induction of 6methoxymellein and resistance to storage pathogens in carrot slices by UV-C. J. Phytopathol. 137: 44-54.

Mercier, J., Baka, M., Reddy, B.,Corcuff, R.,Arul, J. 2001. Shortwave ultraviolet irradiation for control of decay caused by Botrytis cinerea in bell pepper: Induced resistance and germicidal effects. J. Amer. Soc. Hort. Sci. 126: 128-133.

Mercier, J., Roussel, D., Charles, M.-T., Arul, J. 2000. Systemic and local responses associated with UV-C and pathogen-induced resistance to Botrytis cinerea in stored carrot. Phytopathol. 90: 981-986.

Mitcham E., Crisosto C., Kader, A. Bushberry: blackberry, blueberry, cranberry, raspberry: Recommendations for maintaining postharvest quality. 2002. Department of Pomology, University of California, Davis, en: http://postharvest.ucdavis.edu/Produce/ProduceFacts/Fruit/berry.shtml.

Mitchell, F., Mitcham, E., Thompson, J., Welch, N. 1996. Handling strawberries for fresh market. Oakland, CA: Univ. Calif. Agr. Nat. Resources, Special Publ. 2442, 14.

Nigro, F., Ippolito, A., Lattanzio, V., Di Venere, D., Salerno, M. 2000. Effect of ultraviolet-C light on postharvest decay of strawberry. J. Plant Pathol. 82: 29-37. 
Nuez, F. 1995. El cultivo de tomate. Editorial Mundi Prensa. España, 793.

Pan, J., Vicente, A., Martínez, G., Chaves, A., Civello, P. 2004. Combined use of UV-C irradiation and heat treatment to improve postharvest life of strawberry fruit. J. Sci. Food Agric. 84: 1831-1838.

Peng, G., Sutton, J. 1991. Evaluation of microorganisms for biocontrol of Botrytis cinerea in strawberry. Can. J. Plant Pathol. 13: 247-257.

Perkins-Veazie, P., Collins, K., Howard, L., 2008. Blueberry fruit response to postharvest application of ultraviolet radiation. Postharvest Biol. Technol. 47: 280285.

Pombo, M., Rosli, H., Martínez, G., Civello, P. 2010. UV-C treatment affects the expression and activity of defense genes in strawberry fruit (Fragaria $\times$ ananassa, Duch.). Postharvest Biol. Technol. 59: 94-102.

Puupponen-Pimiä, R., Nohynek, L., Alakomi, H.L., Oksman-Caldentey, K.M. 2005. Bioactive berry compounds-novel tools against human pathogens Appl. Microbiol. Biotechnol. 67: 8-18.

Rhodes, M., 1980. The maturation and ripening of fruits. Senescence in plants. Ed. K. V. Thimann, Boca Raton, FL:CRC Press. 157-205.

Rick, C. 1990. Tomato. In: J Smartt and NW Simmonds (eds), Evolution of Crop Plants. Longman Scientific and Technical, Essex, England. 452-457.

Rodoni, L. 2008. Efecto y tratamiento con ozono sobre maduración y calidad de tomate Solanum lycopersicum y frutilla Fragaria x ananassa. UNLP. 66, 13.

Ryffel, S., Piccianali, U., Butikofer, U. 2008. Sensory descriptive analysis and consumer acceptability of selected Swiss goat and sheep cheeses. Small Rum. Res. 79: 80-86.

Schreiner, M., Krumbein, A., Mewis, I., Ulrichs, C., Huyskens-Keil, S. 2009. Short-term and moderate UV-B radiation effects on secondary plant metabolism in different 
organs of nasturtium (Tropaeolum majus L.). Innov. Food Sci. and Emerg. Technol. 10: 93-96.

Sgroppo, S., Sosa, C. 2009. Zapallo anco (Cucurbita moschata, D.) fresco cortado tratado con luz uv-c. Facena. 25: 7-19.

Shama, G. 2007. Process challenges in applying low doses of ultraviolet light to fresh produce for eliciting beneficial hormetic responses. Postharvest Biol. Technol. 44: $1-8$.

Shama, G., Alderson, P. 2005. UV hormesis in fruits: A concept ripe for commercialisation. Trends Food Sci. Technol. 16: 128-136.

Sommer, R., Cabaj, A., Haider, T., 1996a. Microbicidal effect of reflected UV radiation in devices for water disinfection. J. Water Sci Technol. 34: 173-177.

Sommer, R., Haider, T., Heidenreich, A. 1996b. Increased inactivation of Saccharomyces cerevisiae by protraction of UV irradiation. J. Appl Environ Microbiol. 62: 1977-1983.

Stevens, C., Khan, V., Lu, J., Wilson, C., Pusey, P., Kabwe, M., Igwegbe, E., Chalutz E., Droby, S. 1998. The germicidal and hormetic effects of UV-C light on reducing brown rot disease and yeast microflora of peaches. Crop Prot. 17: 75-84.

Stevens, C., Lui, J., Khan, V., Lu, J., Kabwe, M., Wilson, C., Igwegbe, E., Chalutz, E., Droby, S. 2004. The effects of low-dose ultraviolet light-C treatment on polygalacturonase activity, delay ripening and Rhizopus soft rot development of tomatoes. Crop Prot. 23: 551-554.

Stevens, C., Wilson, C., Lu, J., Khan, V., Chalutz, E., Droby, S., Kabwa, M., Haung, Z., Adeyeye, O., Pusey, L., Wisniewski, M., West, M. 1996. Plant hormesis induced by ultraviolet light-C for controlling postharvest diseases of tree fruits. Crop Prot. 15: 129-134. 
Stratmann, J. 2003. Ultraviolet-B radiation co-opts defense signaling pathways. Trends Plant Sci. 8: 526-533.

Suslow, T., Cantwell, M. 2006. Tomato. Recommendations for maintaining Postharvest quality.

En:

www.posharvest.ucdavis.edu/Produce/ProduceFacts/Veg/tomatos.html.

Tucker, G.A. 1993. Introduction. Biochemistry of fruit ripening. Seymour, Taylor, Tucker. Editorial Chapman and Hall. 1-43.

Ulm, R., Baumann, A., Oravecz, A., Mate, Z., Adam, E., Oakeley, E., Scahfer, E., Nagy, F. 2004. Genome wide analysis of gene expression reveals function of the bZIP transcription factor HY5 in the UV-B response of Arabidpsis. Proc. Natl. Acad. Sci. USA. 101: 1397-1402.

Ulm, R., Nagy, F. 2005. Signalling and gene regulation in response to UV light. Curr. Opin. Plant Biol. 8: 477-482.

USDA National Nutrient Database for Standard Reference. 2010. En: http://www.nal.usda.gov/fnic/foodcomp/cgi-bin/list_nut_edit.pl.

Valea, A. 1998. Radiación Infrarroja y ultravioleta. Ed. McGraw Hill, España. 240-241, 307-310.

Vicente, A. 2004. Efecto de tratamientos térmicos de alta temperatura sobre calidad y fisiología postcosecha de frutilla (Fragaria x ananassa Duch.). Trabajo de tesis doctoral. Facultad de Ciencias Exactas. Universidad Nacional de La Plata.

Vicente, A., Martínez, G., Civello, P., Chaves, A. 2002. Quality of heat-treated strawberry fruit during refrigerated storage. Postharvest Biol. Technol. 25: 59-71.

Vicente, A., Pineda, C., Lemoine, L., Civello, P., Martinez, G., Chaves, A., 2005. UV-C treatments reduce decay, retain quality and alleviate chilling injury in pepper. Postharvest Biol. Technol. 35: 69-78.

Vigliola, M. 1991. Manual de Horticultura. INTA Pro. Huerta GOT Salado Norte, 
Chascomús. Editorial hemisferio sur. Argentina. 2 ed. 224-225.

Villarreal, N.,Rosli, H.,Martínez, G.,Civello, P. 2008. Polygalacturonase activity and expression of related genes during ripening of strawberry cultivars with contrasting fruit firmness. Postharvest Biol. Technol. 47: 141-150.

Walle, T. 2004. Absorption metabolism of flavonoids. Free Rad. Biol. Med. 36: 829837.

Wang, H., Cao, G., Prior, R. 1996. Total antioxidant capacity of fruits. J. Agric. Food Chem. 44: 701-705.

Wisniewski, M., Wilson, C. 1992. Biological control of postharvest diseases of fruits and vegetables: recent advances. Hortscience. 27: 94-98.

Yaun, B., Sumner, S., Eifert, J., Marcy, J. 2003. Inhibition of pathogens on fresh produce by ultraviolet energy. Int. J. Food Microbiol. 90: 1-8. 